\title{
Atomic-Scale Structure and its Impact on Chemical Properties of Alu- minum Oxide Layers Prepared by Atomic Layer Deposition on Silica
}

\author{
Monu Kaushikł; César Leroy†’\#, Zixuan Chen §, David Gajanł, Elena Willinger§, Christoph R. Mül- \\ ler§, Franck Fayon†, Dominique Massiot $\uparrow$, Alexey Fedorov§, Christophe Copéret囚 , Anne Lesageł**, \\ Pierre Florian†,* \\ ${ }^{\dagger}$ CNRS, CEMHTI UPR3079, Univ. Orléans, F-45071 Orléans, France \\ ‡ Centre de RMN à Très Hauts Champs, Université de Lyon (CNRS/ENS Lyon/UCB Lyon 1), 69100 Villeurbanne, France \\ $\S$ Department of Mechanical and Process Engineering, ETH Zürich, CH 8092 Zürich, Switzerland \\ ${ }^{\otimes}$ Department of Chemistry and Applied Biosciences, ETH Zürich, CH 8093 Zürich, Switzerland
}

\begin{abstract}
Alumina and aluminosilicates, prepared under various synthesis conditions, play a central role in heterogeneous catalysis with a broad range of industrial applications. We report herein the atomic-scale structure of alumina layers obtained by atomic layer deposition (ALD) of trimethylaluminum onto partially dehydroxylated silica. Such a detailed insight into the atomic structure of the species formed with increasing $\mathrm{Al}$ content was gained using a variety of one- and two-dimensional solid-state nuclear magnetic resonance (NMR) experiments involving ${ }^{27} \mathrm{Al},{ }^{1} \mathrm{H}$ and ${ }^{29} \mathrm{Si}$ nuclei. Multi-component fittings of the $1 \mathrm{D}$ and $2 \mathrm{D}$ experimental datasets

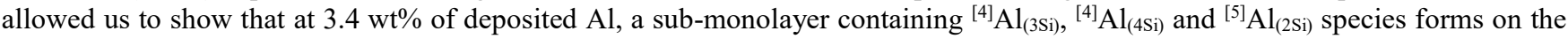
silica surface, with most of these sites carrying OH groups. The films obtained after additional ALD cycles (depositing 9.2 or 15.4 $\mathrm{wt} \% \mathrm{Al}$ ) feature characteristics of an amorphous alumina phase with a high concentration of ${ }^{[5]} \mathrm{Al}$ species and abundant $\mathrm{OH}$ groups. The most probable species at the interface between silica and alumina are ${ }^{[4]} \mathrm{Al}_{(2 \mathrm{Si})},{ }^{[4]} \mathrm{Al}_{(3 \mathrm{Si})}$ and ${ }^{[5]} \mathrm{Al}_{(2 \mathrm{Si})}{ }^{15} \mathrm{~N}$ dynamic nuclear polarization surface-enhanced NMR spectroscopy $\left({ }^{15} \mathrm{~N}\right.$ DNP SENS $)$ and infrared spectroscopy using ${ }^{15} \mathrm{~N}$-labeled pyridine as a probe molecule reveal that aluminum oxide layers on amorphous silica contain both strong Brønsted and strong Lewis acid sites, whereby the relative abundance and nature of these sites, and therefore the acidity of the surface, evolve with increasing thickness of the alumina films (controlled by the number of ALD cycles). This study provides the first in-depth atomic-scale description of (sub) nanometerscale aluminum oxide films prepared by ALD as a function of their growth on a partially dehydroxylated silica support, opening the way to molecular-level understanding of the catalytic activity of such heterogeneous catalysts with tailored acidity.
\end{abstract}

\section{Introduction}

Alumina and amorphous aluminosilicates (ASAs) are important classes of industrial catalysts and catalyst supports, with applications ranging from petroleum refining to automotive emission control or biomass conversion. ${ }^{1}$ These materials have been extensively studied in attempts to correlate their surface (Lewis and/or Brønsted) acidity with their catalytic activity. In contrast to alumina, which is known for the presence of strong Lewis sites associated with coordinatively unsaturated $\mathrm{Al}^{3+}$ ions, ASA materials contain Brønsted acid sites that drive their catalytic properties. ${ }^{1,2}$ Their Brønsted acidity, milder than that of crystalline zeolites, was originally proposed to arise from protons compensating the electronic charge of the surface. It is now more precisely described as zeolite-like acidic sites (i.e. bridging $\mathrm{Si}-\mathrm{OH}-\mathrm{Al}$ groups), ${ }^{3}$ or more recently as pseudobridging silanols,,${ }^{4,5}$ consisting of a silanol group in close vicinity to an aluminum atom so that $\mathrm{Si}-\mathrm{O}-\mathrm{Al}$ bridges are formed upon proton transfer. Several forms of Lewis acid sites were also identified in ASA materials, stemming from undercoordinated $\mathrm{Al}$ sites located at the interface of ASA and alumina-rich domains or at the silica surface. ${ }^{3}$

Understanding and controlling acidity and thereby the property of these materials require the detailed knowledge of the chemical nature of the surface sites (i.e. at the atomic scale), which is a challenging experimental task. Most of the studies performed at the gas-solid interface involve the use of molecular probes, allowing a characterization of the strength and amount of the adsorbed species. For instance, the presence of tri-coordinated Al sites on highly dehydroxylated surfaces of $\gamma$-alumina has been evidenced by their interaction with $\mathrm{N}_{2}$, their reaction with $\mathrm{H}_{2}$ and $\mathrm{CH}_{4}{ }^{6,7}$ and pyridine adsorption, which has also been helpful in studying acid sites on $\gamma$-alumina and aluminosilicate materials. ${ }^{8,9}$ Advanced spectroscopic techniques have also been implemented to obtain insight into surface acidity and among those FTIR using probe molecules has traditionally played a central role in the assessment of surface acidity. ${ }^{10}$ In addition, solid-state NMR spectroscopy has also been used to a large extent, providing atomic-scale insights into the surface structure of aluminum and mixed oxides, ${ }^{11-13}$ while being often limited by its lack of sensitivity towards surface species. ${ }^{14}$ This limitation has been alleviated in part with the emergence of hyperpolarization techniques such as dynamic nuclear polarization (DNP) solid-state $\mathrm{NMR}^{15-17}$ for $\gamma$-alumina and alumino-silicates. ${ }^{18-23}$ In parallel, the detailed structure of acid sites or the role of facets has been addressed through DFT methods, where the predicted chemical shifts and anisotropies provide insightful information that can be used to interpret experimental values. ${ }^{24,25}$ 
The surface properties of ASA materials are proposed to be linked to the distribution of the Al surface sites on the silica materials, therefore major research efforts have been directed towards the controlled deposition of $\mathrm{Al}^{26,27}$ One of the most powerful methods to control precisely the growth of oxide layers onto oxide supports is atomic layer deposition (ALD), ${ }^{28}$ in which the self-limiting reaction of a volatile reactive molecular precursor with specific sites on a substrate (such as surface hydroxyls) is followed by a post-treatment, with ozone or steam, allowing the controlled growth of oxide layers with atomic resolution. Repeated ALD cycles lead to a step-by-step deposition of layers, whose thickness can be controlled by the number of cycles. $^{26,27}$ Thus, ALD, using trimethylaluminum (TMA) as a precursor and silica as a support, allows the deposition and growth of aluminum oxide layers on silica, from grafted submonolayer species ${ }^{26}$ to nanometer-sized ultra-thin layers of $\mathrm{Al}_{2} \mathrm{O}_{3}$, with correlated changes in their catalytic activities. ${ }^{29}$ Yet the atomic-scale structure of the aluminum oxide layer, its acidity, and the detailed mechanisms of the chemical reactions involved are not fully understood. ${ }^{30,31}$
Here, we exploited ALD of the precursor TMA onto amorphous silica, dehydroxylated at $500{ }^{\circ} \mathrm{C}$ (i.e. $\mathrm{SiO}_{2-500}$ ), and ozone for oxidation of the deposited TMA (Figure 1a), in order to obtain precise control over the atomic composition of the formed layer and to minimize rehydroxylation of the support during film growth. ${ }^{26}$ Thin films with thicknesses between a sub-monolayer up to several nanometers were prepared, providing a consistent series of materials with different ratios of bulk to surface $\mathrm{Al}$ atoms, thereby allowing the detection of different NMR signatures as the thickness of the layer grows. Reinforced by complimentary information from diffuse reflectance infrared Fourier transform spectroscopy (DRIFTS), elemental analysis, highresolution transmission electron microscopy (HRTEM), energy-dispersive X-ray (EDX) spectroscopy and high-angle annular dark-field imaging (HAADF), we describe below how the structure, surface acidity, and domain interface of the silicasupported aluminum oxide layers is uncovered by high magnetic field and DNP surface-enhanced solid-state (DNP SENS) NMR spectroscopies.

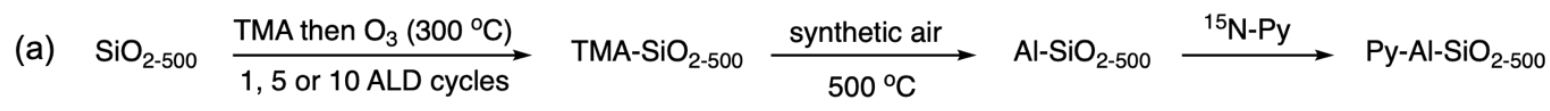

(b)
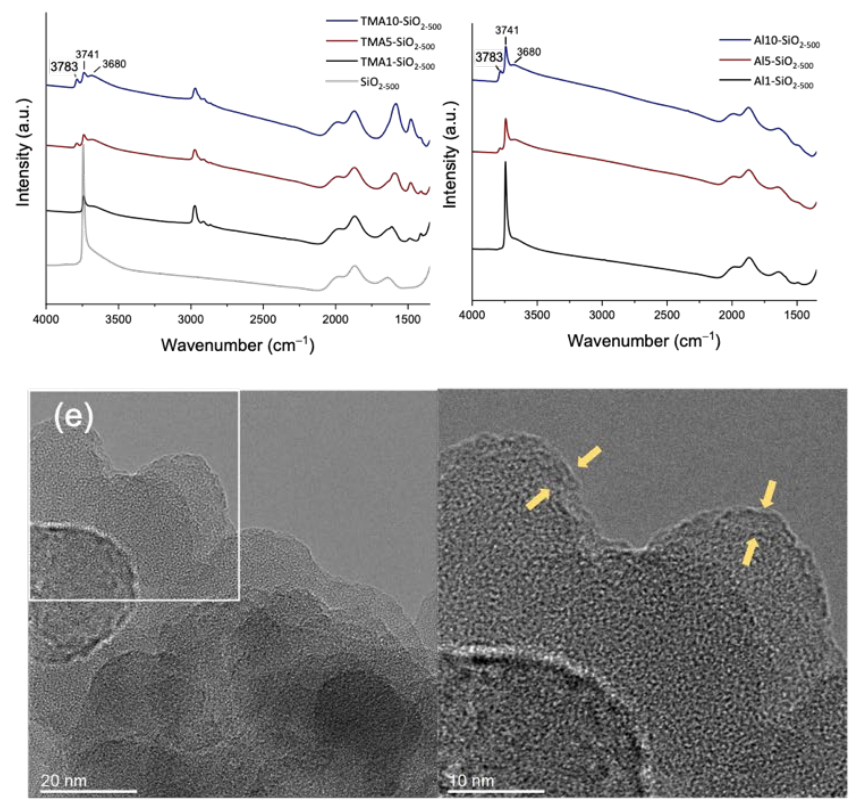

(c)

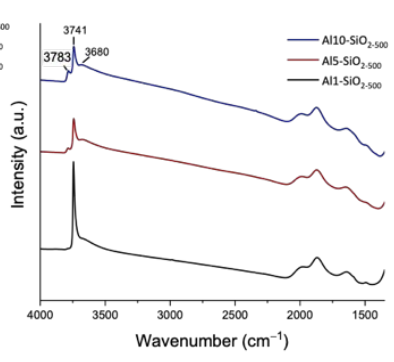

Figure 1. (a) Synthetic approach to obtain $\mathrm{Al}_{2} \mathrm{O}_{3} / \mathrm{SiO}_{2}$ materials by $\mathrm{ALD}$, as well as transmission FTIR spectra of (b) $\mathrm{SiO} 2-500$ (grey),

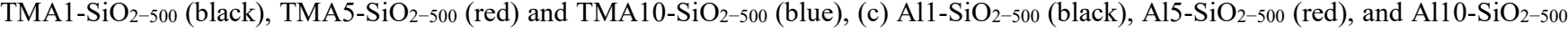
(blue), and HRTEM images of (d) $\mathrm{Al1}-\mathrm{SiO}_{2-500}$, (e) $\mathrm{Al}-\mathrm{SiO}_{2-500}$, (f) $\mathrm{Al10}-\mathrm{SiO}_{2-500}$. The yellow arrows indicate the ALD-grown film.

\section{Experimental section}

Sample preparation. Materials studied in this work were prepared by ALD using alternating pulses of trimethylaluminum and ozone, at $300^{\circ} \mathrm{C}$, onto silica dehydroxylated at $500{ }^{\circ} \mathrm{C}$. $\mathrm{SiO}_{2-500}$ contained $1.3 \mathrm{OH} \mathrm{nm}^{-2}\left(0.74 \mathrm{mmol} \mathrm{g}^{-1}\right)$ of reactive $\mathrm{OH}$ sites according to dibenzylmagnesium titration. Further details of the ALD deposition protocol are provided in the Supporting Information. The as-prepared ALD-treated materials, depending on the number of the used ALD cycles denoted as TMA1-, TMA5-, and TMA10-SiO ${ }_{2-500}$, were calcined in synthetic air $\left(500^{\circ} \mathrm{C}, 4 \mathrm{~h}\right)$. The resulting materials denoted Al1-, Al5-, and Al10-SiO ${ }_{2-500}$ contained 3.4, 9.2 and $15.4 \mathrm{wt} \% \mathrm{Al}$, respectively, according to elemental analysis. For pyridine adsorption, the calcined materials were exposed to ${ }^{15} \mathrm{~N}$ pyridine vapor at room temperature for about $1 \mathrm{~min}$, followed by the removal of ${ }^{15} \mathrm{~N}$ pyridine at $150^{\circ} \mathrm{C}$ (at ca. $10^{-5} \mathrm{mbar}, 2 \mathrm{~h}$ ). All ALD-derived materials described in this work were handled without exposure to ambient air.

High-field NMR experiments. Single resonance ${ }^{27} \mathrm{Al}$ solidstate NMR experiments were performed at $20.0 \mathrm{~T}$ and $23.5 \mathrm{~T}$ 
using a $2.5 \mathrm{~mm}$ double resonance probe with a MAS rate of 33.3 $\mathrm{kHz}$. Double resonance ${ }^{27} \mathrm{Al}\left\{{ }^{1} \mathrm{H}\right\}$ experiments were performed with the same probe at $20.0 \mathrm{~T}$ whereas ${ }^{29} \mathrm{Si}\left\{{ }^{27} \mathrm{Al}\right\}$ experiments were performed with a spinning speed of $15 \mathrm{kHz}$ and a $3.2 \mathrm{~mm}$ MAS probe at $20.0 \mathrm{~T}$. Chemical shifts are referenced to a $1 \mathrm{M}$ solution of $\mathrm{Al}\left(\mathrm{NO}_{3}\right)_{3}$ in $\mathrm{HNO}_{3}$ for ${ }^{27} \mathrm{Al}$ and to tetramethylsilane for ${ }^{1} \mathrm{H}$ and ${ }^{29} \mathrm{Si}$. All samples were packed in an argon-filled glove box and NMR experiments performed under pure nitrogen. Additional details are given in the Supporting Information.

DNP NMR experiments. DNP experiments were performed using $1.3 \mathrm{~mm}$ triple-resonance low-temperature magic angle spinning (MAS) probes at $9.4 \mathrm{~T} / 263 \mathrm{GHz}$ or $18.8 \mathrm{~T} / 526 \mathrm{GHz}$ on Bruker Avance III spectrometers. DNP samples were packed in a glove box after being impregnated by a 1,1,2,2-tetracholorethane (TCE) solution containing $16 \mathrm{mM} \mathrm{TEKPol}^{32}$ or HyTEK $2^{33}$ for experiments respectively at 9.4 and $18.8 \mathrm{~T}$. Additional experimental details are provided in the SI or in the legends of the figures.

\section{Results and discussion}

Growth of the thin film. The preparation route to ALD-derived materials, which are characterized in detail below, is presented in Figure 1a. TMA was deposited onto $\mathrm{SiO}_{2-500}$ at $300^{\circ} \mathrm{C}$. In these conditions, TMA is expected to graft onto surface silanols and open siloxane (i.e. $\mathrm{Si}-\mathrm{O}-\mathrm{Si}$ ) bridges by the interaction with Al-C bonds. ${ }^{34,35}$ TMA pulses were followed by ozonolysis at $300{ }^{\circ} \mathrm{C}$. Transmission FTIR data shows that, relative to $\mathrm{SiO}_{2-500}$, the intensity of the silanol band at $3741 \mathrm{~cm}^{-1}$ decreases in all three TMA-SiO ${ }_{2-500}$ materials (Figure 1b). This is accompanied by the appearance of a new band at $3783 \mathrm{~cm}^{-1}$, very weak in TMA1-SiO ${ }_{2-500}$, but notably stronger in TMA5- $\mathrm{SiO}_{2-500}$ and TMA10-SiO $2-500$. The position of this band is close to that of an aluminol group in $\gamma-\mathrm{Al}_{2} \mathrm{O}_{3}\left(3785 \mathrm{~cm}^{-1}\right){ }^{26}$ The broad band of vicinal and geminal silanols, centered in $\mathrm{SiO}_{2-500}$ at ca. $3680 \mathrm{~cm}^{-1}$, is also present in TMA-SiO ${ }_{2-500} \mathrm{ma}-$ terials, albeit it likely contains a contribution from $\mathrm{OH}$ sites interacting with the grafted TMA species. Alkyl groups are identified in TMA-SiO ${ }_{2-500}$ materials by $v_{\mathrm{CH}}$ stretching modes at $2890-3010 \mathrm{~cm}^{-1}$ and $\delta_{\mathrm{CH}}$ bending modes at $1510-1370 \mathrm{~cm}^{-1}$ (Figure 1b), which indicates that ozone pulses at $300^{\circ} \mathrm{C}$ oxidize the grafted TMA only partially. The band at $1610 \mathrm{~cm}^{-1}$ in the TMA-SiO ${ }_{2-500}$ materials is assigned to surface carbonates, formed owing to the interaction of the surface with $\mathrm{CO}_{2}$ (released during the oxidation of the grafted TMA by ozone)..$^{36,37}$ The complete oxidation of the alkyl groups and removal of carbonates is achieved by calcining the grafted materials at $500{ }^{\circ} \mathrm{C}$ in synthetic air (Figure 1c). Thus, the resulting $\mathrm{Al}_{-} \mathrm{SiO}_{2-500}$ materials do not feature $\mathrm{C}-\mathrm{H}$ and carbonate bands, but reveal the band at $3741 \mathrm{~cm}^{-1}$, corresponding to regenerated isolated silanols, intense in $\mathrm{All}^{-\mathrm{SiO}_{2}-500}$ and notably less intense in $\mathrm{Al} 5$ and $\mathrm{A} 110-\mathrm{SiO}_{2-500}$.

High-angle annular dark-field imaging (HAADF) as well as energy-dispersive X-ray spectroscopy (EDX) were performed to investigate the distribution of the ALD coating on $\mathrm{SiO}_{2-500}$ (Figure S1). Unless specified otherwise, materials were exposed to ambient air shortly before the TEM analysis. A homogeneous distribution of deposited layers on the silica support was observed on $\mathrm{Al10}-\mathrm{SiO}_{2-500}$, which was chosen as a representative material for EDX imaging (Figure S2). Next, HRTEM was per- formed to characterize all three $\mathrm{Al}-\mathrm{SiO}_{2-500}$ materials. Al-containing coatings can be clearly visualized in $\mathrm{All}-\mathrm{SiO}_{2-500}$, $\mathrm{Al} 5-\mathrm{SiO}_{2}-500$ and $\mathrm{Al10}-\mathrm{SiO}_{2}-500$, as indicated by yellow arrows in Figure 1d-f. With an increasing number of ALD cycles, the Alcontaining coating layer becomes thicker, which is also consistent with the Al loadings determined by elemental analysis as discussed above. We observe a few crystalline planes forming a zigzag coating on a silica surface (Figure 1f and Figure S2). Nevertheless, those areas do not appear on every silica grain, and a smooth coating (i.e. a coating following the curvature of silica grains) is the most abundant morphology. Taking into account the very few occurrences of those nanocrystals, we will not consider them further (additional TEM details can be found in the Supporting Information). Lastly, no porosity can be identified by TEM in the coatings grown, also consistent with the $\mathrm{BJH}$ analysis of $\mathrm{N}_{2}$ physisorption data that shows only intergranular porosity of the support used (Figure S4-S5, Table S1)..

While instructive, TEM results do not allow to distinguish unambiguously between alumina and aluminosilicate phases of the surface coating. In what follows, we focus on high-magnetic field solid-state NMR spectroscopy to derive at an atomic-scale description of the layer, the interface and the surface.

Aluminum environments. Figure 2 shows the ${ }^{27} \mathrm{Al}$ NMR Hahn echo spectra of the three $\mathrm{Al}-\mathrm{SiO}_{2-500}$ materials and the simulations of these spectra. At least three components can be resolved, corresponding to n-coordinated aluminum species, i.e. ${ }^{[\mathrm{n}]} \mathrm{Al}$ where $\mathrm{n}=4,5$ or 6 in highly disordered environments, as seen in aluminosilicate glasses. ${ }^{38}$ There is a clear shift toward higher chemical shifts upon increasing the number of cycles (from (a) to (c) in Figure 2). This shift indicates a progressive substitution of silicon by aluminum in ${ }^{[\mathrm{n}]} \mathrm{Al}(\mathrm{OSi})_{\mathrm{p}}(\mathrm{OAl})_{\mathrm{n}-\mathrm{p}}$ environments, consistent with a +3 ppm increase of the ${ }^{[4]} \mathrm{Al}$ isotropic chemical shift upon substitution of one Si by one Al in the aluminum second coordination sphere as determined in $\mathrm{Ca}_{2} \mathrm{Al}_{2} \mathrm{SiO}_{7}$ and $\mathrm{SrAl}_{2} \mathrm{SiO}_{8}{ }^{39,40}$

The Gaussian Isotropic Model (GIM) or Czjzek model, ${ }^{41}$ based on a statistical distribution of the local environments and implemented in DMFit, ${ }^{42}$ is suitable for simulating this type of spectra. As seen in Figure 2a1 and a2, the model indeed provides a very satisfactory simultaneous fit of the $\mathrm{Al1}-\mathrm{SiO}_{2-500}$ spectra obtained in fields of 20.0 and $23.5 \mathrm{~T}$. However, this fitting procedure was less successful for $\mathrm{Al} 5-\mathrm{SiO}_{2-500}$ and $\mathrm{A} 110-\mathrm{SiO}_{2-500}$ (see Figure S6), pointing to an additional complexity in those spectra. As seen in Figure $2 b$ and $2 c$ an excellent simulation is obtained when the experimental spectrum of $\mathrm{All}-\mathrm{SiO}_{2-500}$ is also used as one of the components of the fit, indicative that A15$\mathrm{SiO}_{2-500}$ and $\mathrm{Al10}-\mathrm{SiO}_{2-500}$ contain almost unaltered $\mathrm{Al1}-\mathrm{SiO}_{2-500}$ system. The resulting NMR parameters, reported in Table S2, may nevertheless contain errors due to the use of a non-quantitative pulse sequence.

A final set of simulations was then performed on spectra obtained with a single quantitative pulse, after baseline subtraction, ${ }^{43}$ and taking into account the spinning sidebands of the external transitions (Figure S7). The resulting parameters are reported in Tables 1 and S3, revealing a good agreement between the two approaches (calculated errors for all fits are given in Table S4). We note that the MQMAS performed either at 20.0 $\mathrm{T}$ or at $23.5 \mathrm{~T}$ (Figure S8) does not clearly resolve the $\mathrm{Al1}-\mathrm{SiO}_{2}$ 500 component in $\mathrm{Al10}-\mathrm{SiO}_{2-500}$ and that simulations could be 
performed with only three components (Table S5), which could be related to filtering effects in the MQMAS experiments.

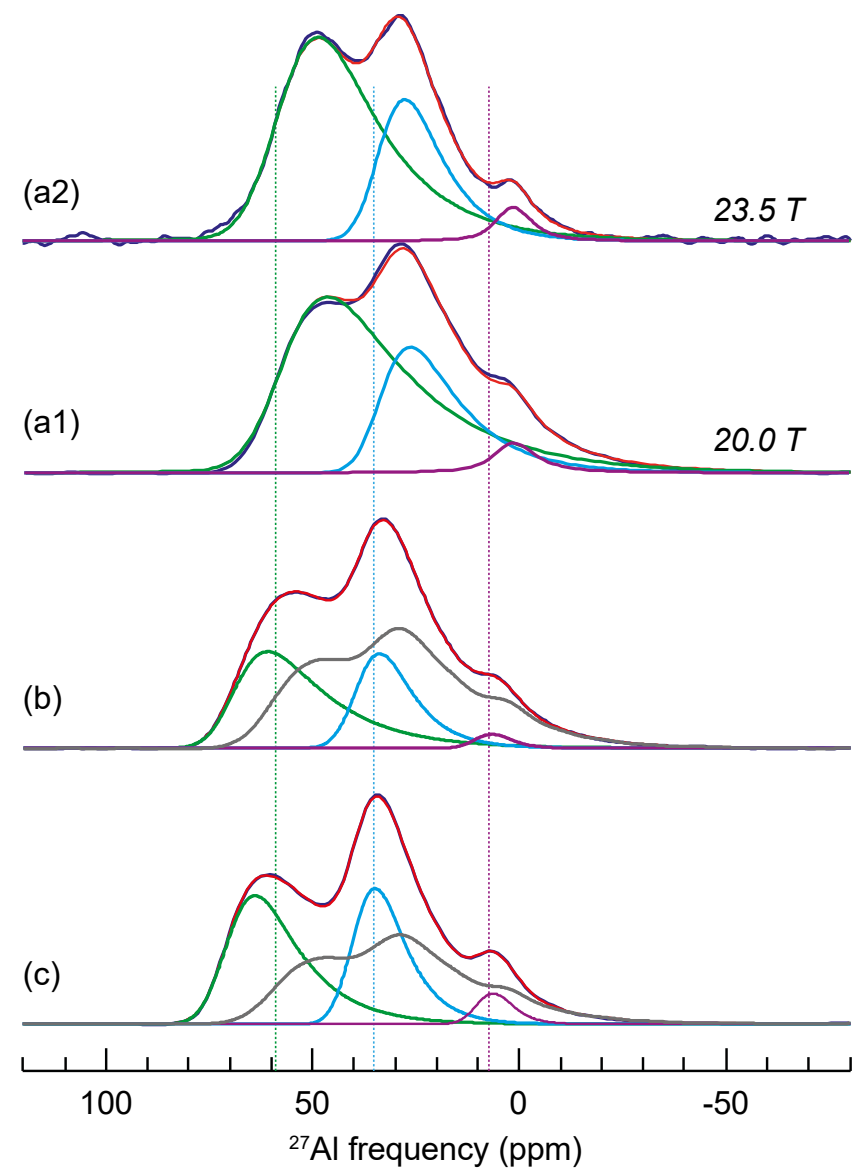

Figure 2. ${ }^{27} \mathrm{Al}$ MAS NMR experimental (dark blue) and simulated (red) spectra of (a) $\mathrm{All}-\mathrm{SiO}_{2-500}$, (b) $\mathrm{Al} 5-\mathrm{SiO}_{2-500}$ and (c) Al10$\mathrm{SiO}_{2-500}$. All spectra were recorded at 20.0 T except for (a2) which was obtained at $23.5 \mathrm{~T}$. The various components are shown in different colors: ${ }^{[4]} \mathrm{Al}$ (green) ${ }^{[5]} \mathrm{Al}$ (light blue) ${ }^{[6]} \mathrm{Al}$ (purple). The additional grey lines are the experimental spectra of $\mathrm{All}^{-\mathrm{SiO}_{2}-500}$ used as a fourth component in the simulation. Dotted lines show the $\bar{\delta}_{i s o}$ of each $\mathrm{All}-\mathrm{SiO}_{2-500}$ components.

The high and very similar $\bar{\delta}_{\text {iso }}$ obtained for $\mathrm{A} 15-\mathrm{SiO}_{2-500}$ and Al10- $\mathrm{SiO}_{2-500}$ suggests that an aluminum oxide film is formed already after five ALD cycles and the nature of the Al sites does not change significantly with additional cycles. The percentage of the "Al1-like" component decreases as expected with an increasing number of cycles, which is consistent with a description in which $\mathrm{All}-\mathrm{SiO}_{2-500}$ is, from an aluminum point of view, a good approximation of the alumina/silica interface in thicker films. The fitted Al1 content of 51\% after 5 cycles nevertheless suggests that one cycle deposits only a sub-monolayer, leaving the silica surface available for the subsequent interaction with TMA.

The NMR parameters derived for the film components (A15and $\mathrm{Al10-} \mathrm{SiO}_{2-500}$ ), and particularly the large relative amount of ${ }^{[5]} \mathrm{Al}$ sites, resemble those of amorphous alumina $\left(\mathrm{am}-\mathrm{Al}_{2} \mathrm{O}_{3}\right)$. Some of such am- $\mathrm{Al}_{2} \mathrm{O}_{3}$ materials, obtained by various chemical routes, have been probed by ${ }^{27} \mathrm{Al} \mathrm{NMR}$, viz. am- $\mathrm{Al}_{2} \mathrm{O}_{3}$ obtained by spin coating from aluminum nitrate aqueous solution, ${ }^{44}$ magnetron sputtering ${ }^{45}$ or metal organic chemical vapor deposition (MOCVD) of aluminum isopropoxide. ${ }^{46}$ Using the NMR parameters reported by those three studies (also using the GIM model for simulations) for the thinner films, the following average $\bar{\delta}_{i s o}$ and $\bar{C}_{Q}$ values and associated standard deviations are obtained: $70.0 \pm 2.2 \mathrm{ppm}$ and $8.8 \pm 2.1 \mathrm{MHz}$ for ${ }^{[4]} \mathrm{Al} ; 41.4$ $\pm 1.3 \mathrm{ppm}$ and $8.0 \pm 1.0 \mathrm{MHz}$ for ${ }^{[5]} \mathrm{Al} ; 11.0 \pm 1.4 \mathrm{ppm}$ and 6.0 $\pm 0.8 \mathrm{MHz}$ for ${ }^{[6]} \mathrm{Al}$. The span is small for $\bar{\delta}_{\text {iso }}$ and the average values are very similar to those found in this work. Thus the local structure of ALD-grown films features NMR parameters closely mimicking those of am- $\mathrm{Al}_{2} \mathrm{O}_{3}$.

Table $1 .{ }^{27} \mathrm{Al}$ NMR parameters derived from the simulation of the one-pulse quantitative spectra.

\begin{tabular}{|c|c|c|c|c|}
\hline site & $\%$ & $\bar{\delta}_{\text {iso }}(\mathrm{ppm})$ & $\Delta \delta_{i s o}(\mathrm{ppm})$ & $\bar{C}_{Q}(\mathrm{MHz})$ \\
\hline \multicolumn{5}{|c|}{$\mathrm{Al1}_{-\mathrm{SiO}}{ }_{2-500}$} \\
\hline${ }^{[4]} \mathbf{A l}_{(3-4 \mathrm{Si})}$ & 60 & 58.9 & 22.5 & 12.0 \\
\hline${ }^{[5]} \mathbf{A l}_{(2 \mathrm{Si})}$ & 35 & 35.3 & 10.9 & 10.9 \\
\hline${ }^{[6]} \mathbf{A} \mathbf{l}_{(\mathbf{1 S i})}$ & 5 & 7.3 & 9.9 & 6.21 \\
\hline \multicolumn{5}{|c|}{$\mathrm{Al5}^{-\mathrm{SiO}_{2-500}}$} \\
\hline${ }^{\left[{ }^{4}\right]} \mathbf{A l}_{(0 \mathrm{Si})}$ & 29 & 69.7 & 14.6 & 11.0 \\
\hline${ }^{[5]} \mathbf{A l}_{(0 \mathrm{OSi})}$ & 19 & 39.9 & 11.8 & 7.67 \\
\hline${ }^{\left[{ }^{6]}\right.} \mathbf{A l}_{(0 \mathrm{OSi})}$ & 1 & 10.2 & 9.5 & 4.84 \\
\hline Al1 & 51 & - & - & - \\
\hline \multicolumn{5}{|c|}{ Al10-SiO2-500 } \\
\hline${ }^{[4]} \mathbf{A l}_{(0 S i)}$ & 35 & 71.1 & 11.8 & 10.5 \\
\hline${ }^{[5]} \mathbf{A l}_{(0 \mathrm{Si})}$ & 25 & 40.6 & 10.8 & 7.39 \\
\hline${ }^{[6]} \mathbf{A l}_{(0 \mathrm{Si})}$ & 3 & 9.7 & 8.1 & 4.97 \\
\hline Al1 & 37 & - & - & - \\
\hline
\end{tabular}

Based on the above values for "pure" am- $\mathrm{Al}_{2} \mathrm{O}_{3}$ and considering that a shift of approx. -3 ppm of $\delta_{\text {iso }}\left({ }^{[4]} \mathrm{Al}\right)$ upon $\mathrm{Al}$ to Si substitution in the second coordination sphere of aluminum ${ }^{39}$ applies also for ${ }^{[5]} \mathrm{Al}$ and ${ }^{[6]} \mathrm{Al}$ sites, one can tentatively assign the observed $\mathrm{Al}$ environments in $\mathrm{All}-\mathrm{SiO}_{2-500}$ to ${ }^{[4]} \mathrm{Al}_{(3-4 \mathrm{Si})},{ }^{[5]} \mathrm{Al}_{(2 \mathrm{Si})}$ and ${ }^{\left[{ }^{6}\right.} \mathrm{Al}_{(1 \mathrm{Si})}$ sites. In other words, during the first cycle (followed by calcination), ca. $60 \%$ of the $\mathrm{Al}$ species form ${ }^{[4]} \mathrm{Al}$ environments interacting strongly with the silica interface, including possibly a migration into the silica support (vide infra). On the other hand, the remaining $35 \%{ }^{[5]} \mathrm{Al}$ and minor $5 \%{ }^{[6]} \mathrm{Al}$ species are only mono- or bis-bonded to silica, and are therefore mostly surface species. A word of caution is needed with respect to this, and further, assignments: note that they refer to the "most probable" species within the framework of a statistical distribution of environments and not "unique" environments. 


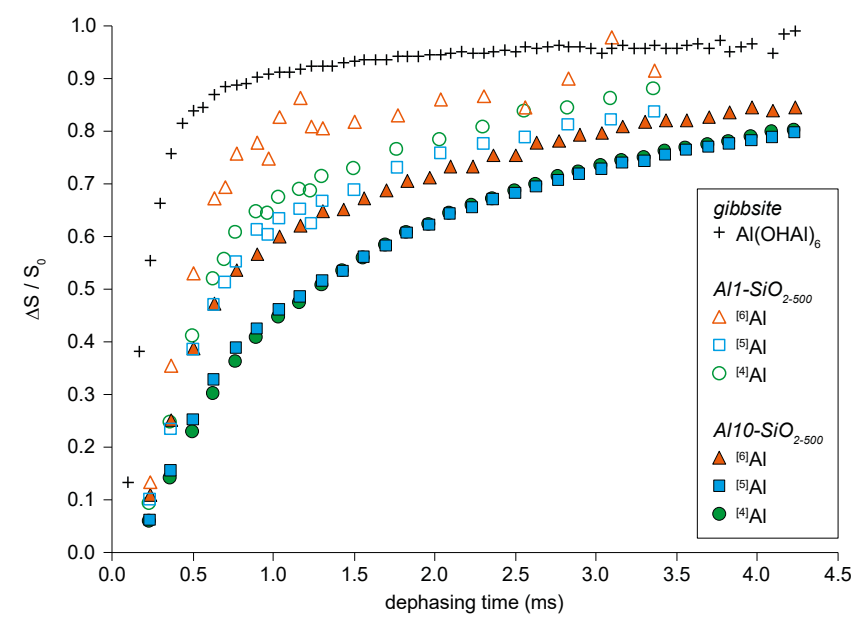

Figure 3. ${ }^{27} \mathrm{Al}\left\{{ }^{1} \mathrm{H}\right\}$ REDOR MAS NMR experiments obtained on Al1-SiO 2-500 (open symbols), $\mathrm{Al10}-\mathrm{SiO}_{2-500}$ (filled symbols) and gibbsite (crosses), simulating the spectra with components for ${ }^{[6]} \mathrm{Al}$ (triangles), ${ }^{[5]} \mathrm{Al}$ (squares) and ${ }^{[4]} \mathrm{Al}$ (circles).

Location of $\mathbf{O H}$ groups. The presence of hydroxyl groups in the investigated materials is confirmed by the appearance of characteristic $\mathrm{OH}$ bands in the FTIR spectra as discussed above (Figure 1c). While the position of $\mathrm{OH}$ bands is indicative of their nature (i.e. silanol, aluminol or bridging $\mathrm{Si}-\mathrm{OH}-\mathrm{Al}$ groups), the assignment can be ambiguous in the presence of SiOHAl species. One approach to access this information by NMR is the use of double resonance ${ }^{1} \mathrm{H} /{ }^{27} \mathrm{Al}$ methods, recalling that a very strong ${ }^{1} \mathrm{H}$ probe background prevents a reliable direct observation of diluted $\mathrm{OH}$ species.

Figure 3 plots ${ }^{27} \mathrm{Al}\left\{{ }^{1} \mathrm{H}\right\}$ REDOR dephasing curves for ${ }^{[\mathrm{n}]} \mathrm{Al}$ in All- $-\mathrm{SiO}_{2-500}$ and $\mathrm{Al10}-\mathrm{SiO}_{2-500}$. The dephasing curve obtained for natural gibbsite $\mathrm{Al}(\mathrm{OH})_{3}$ is also shown as a reference of $\mathrm{Al}(\mathrm{OHAl})_{6}$ species in a fully hydroxylated phase. Both ALD- made materials show a quick increase of the $\Delta \mathrm{S} / \mathrm{S}_{0}$ dephased fraction, evidencing the presence of protons in the vicinity of aluminum sites. The increase is nevertheless slower than in natural gibbsite, indicating a lower hydroxylation degree of the aluminum sites in the ALD-made thin films. The ${ }^{[6]} \mathrm{Al}$ environments systematically show a faster dephasing (steeper initial slope) associated with a higher degree of hydroxylation than in ${ }^{[4]} \mathrm{Al}$ and ${ }^{[5]} \mathrm{Al}$, which dephase almost at the same rate. A very similar behavior has been observed for am- $\mathrm{Al}_{2} \mathrm{O}_{3}$ films deposited onto a silicon wafer by MOCVD of aluminum isopropoxide, ${ }^{46}$ indicating a general behavior of aluminates: hexacoordinated ${ }^{[6]} \mathrm{Al}$ species are more likely to be protonated than tetraor pentacoordinated ${ }^{[4,5]} \mathrm{Al}$ species. The faster REDOR dephasing of the $\mathrm{All}-\mathrm{SiO}_{2-500}$ components points to a higher $\mathrm{OH}$ density close to aluminum centers compared to $\mathrm{A} 110-\mathrm{SiO}_{2-500}$. For long dephasing time, all $\Delta \mathrm{S} / \mathrm{S}_{0}$ fractions seem to level off at $\sim$ 0.80 which means that in both materials only $20 \%$ of the Al sites are at remote distances form protons, i.e. approximately $80 \%$ of the aluminum atoms carry $\mathrm{OH}$ groups in the form of aluminols and (pseudo)bridging silanols. This high concentration of $\mathrm{OH}$ groups allows the surface-proton magnetization to spin-diffuse through the alumina film up to the ${ }^{29} \mathrm{Si}$ nuclei of the silica support, as demonstrated by DNP SENS ${ }^{29} \mathrm{Si}\left\{{ }^{1} \mathrm{H}\right\}$ cross-polarization transfers in $\mathrm{A} 110-\mathrm{SiO}_{2-500}$ (Figure S9).

The nature of the protonated aluminum sites was also probed using ${ }^{1} \mathrm{H} /{ }^{27} \mathrm{Al} \mathrm{D}-\mathrm{HMQC}$ experiment that converts the dipolardephased ${ }^{27} \mathrm{Al}$ signal into heteronuclear MQ coherences to obtain ${ }^{1} \mathrm{H} /{ }^{27} \mathrm{Al}$ correlation maps, as recently shown for ASA. ${ }^{47}$ Figure 4 shows, for $\mathrm{All}-\mathrm{SiO}_{2-500}$ and $\mathrm{All0}-\mathrm{SiO}_{2-500}$, the ${ }^{27} \mathrm{Al}\left\{{ }^{1} \mathrm{H}\right\}$ D-HMQC spectra obtained with a short excitation time of 400 $\mu$ s to selectively probe short-range Al-H correlations within $\mathrm{Al}(\mathrm{OH}) \mathrm{X}$ species where $\mathrm{X}=\mathrm{Al}, \mathrm{Si}$ (bridging or pseudobridging silanols) or aluminols.

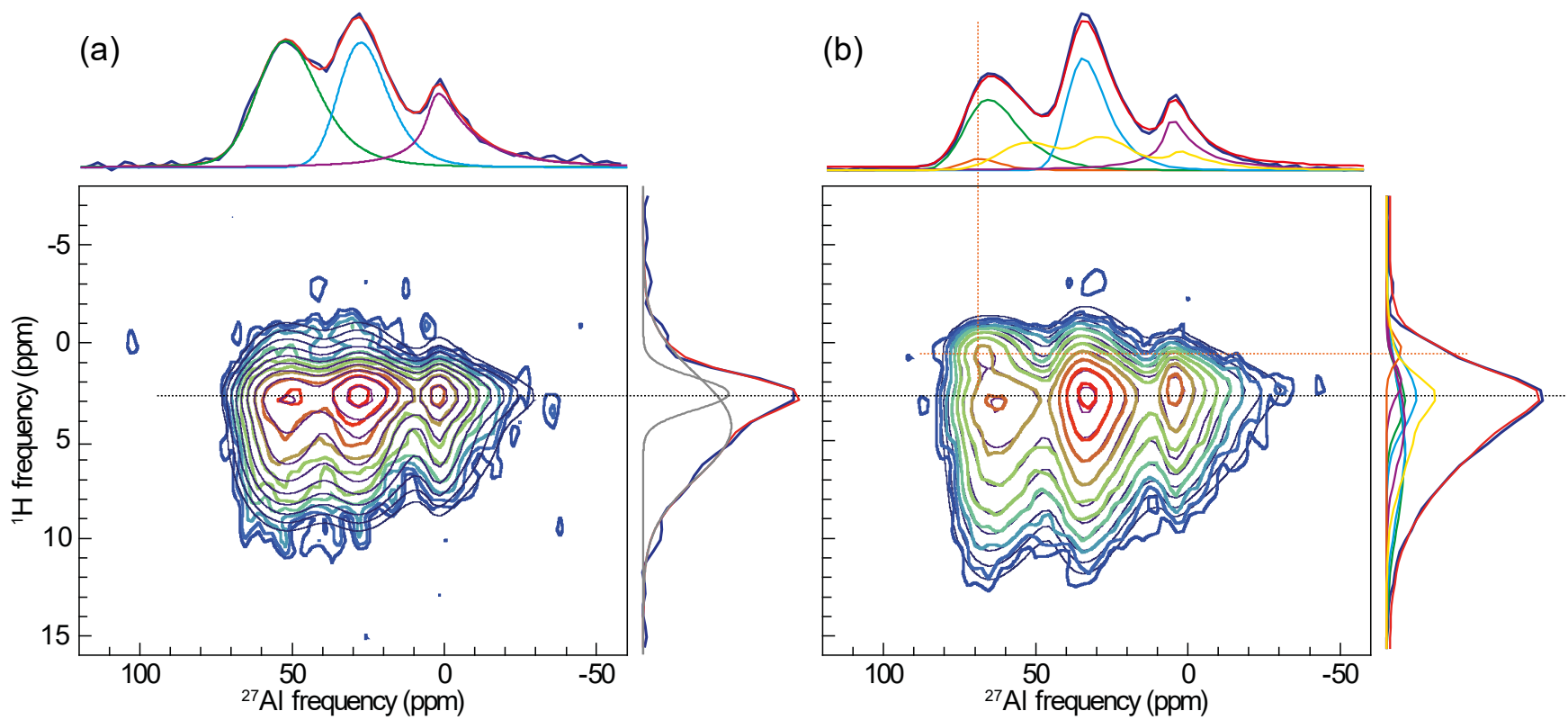

Figure 4. ${ }^{27} \mathrm{Al}\left\{{ }^{1} \mathrm{H}\right\}$ D-HMQC SR $4{ }^{2}$ MAS NMR correlation experiments for (a) $\mathrm{All}-\mathrm{SiO}_{2-500}$ and (b) Al10-SiO $2-500$ along with two-dimensional simulations and their respective projections: ${ }^{4]} \mathrm{Al}$ (green), ${ }^{[5]} \mathrm{Al}$ (light blue), ${ }^{[6]} \mathrm{Al}$ (purple). Yellow spectra and projection line correspond to the experimental spectra of $\mathrm{All}-\mathrm{SiO}_{2-500}$ used as an additional component in the simulation for $\mathrm{All}_{10}-\mathrm{SiO}_{2-500}$. 
For Al1- $\mathrm{SiO}_{2-500}$, the simulation of the two-dimensional data set is accounted for by three aluminum environments and two proton environments. The NMR parameters extracted from this data are listed in Table 2. Although we used two lines for ${ }^{1} \mathrm{H}$, it must be understood as a continuous distribution of ${ }^{1} \mathrm{H}$ environments arising from a broad range of $\mathrm{Si}(\mathrm{OH}) \mathrm{Al}$ hydrogenbonded Brønsted acid sites ${ }^{48-50}$ and possibly $\mathrm{Al}(\mathrm{OH}) \mathrm{Al}$ sites. ${ }^{51}$ This asymmetric distribution, ranging from $0 \mathrm{ppm}$ to $10 \mathrm{ppm}$ with a maximum at $2.6 \mathrm{ppm}$, is similar for all three coordination states of aluminum. In other words, the proton chemical shift of the ${ }^{[n]} \mathrm{Al}(\mathrm{OH}) \mathrm{Si}$ species is not significantly correlated to the coordination number $n$ of aluminum.

${ }^{[4]} \mathrm{Al}(\mathrm{OH}) \mathrm{X}$ and ${ }^{[5]} \mathrm{Al}(\mathrm{OH}) \mathrm{X}$ (respectively in green and light blue in Figure 5) display ${ }^{27} \mathrm{Al}$ resonances significantly narrower than those observed by direct excitation (Figure 2 and Table 1), corresponding to a decrease in $\bar{C}_{Q}$ by almost a factor of two.

Table 2. ${ }^{27} \mathrm{Al}$ NMR parameters derived from the simulation of the ${ }^{27} \mathrm{Al}\left\{{ }^{1} \mathrm{H}\right\}$ D-HMQC (Figure 4). (*) Lorentzian broadening.

\begin{tabular}{|c|c|c|c|c|}
\hline site & $\%$ & $\bar{\delta}_{i s o}(\mathrm{ppm})$ & $\Delta \delta_{i s o}(\mathrm{ppm})$ & $\bar{C}_{Q}(\mathrm{MHz})$ \\
\hline \multicolumn{5}{|l|}{$\mathrm{Al1}^{-\mathrm{SiO}_{2-500}}$} \\
\hline${ }^{[4]} \mathrm{Al}$ & 37.6 & 58.2 & 19.8 & 7.07 \\
\hline${ }^{[5]} \mathrm{Al}$ & 44.1 & 33.8 & 14.4 & 7.67 \\
\hline${ }_{[6]}^{[6]}$ & 18.3 & 3.9 & $15.5^{(*)}$ & 6.62 \\
\hline $\mathbf{H}_{(\mathbf{1})}$ & 22.5 & 4.3 & 6.03 & \\
\hline $\mathbf{H}_{(2)}$ & 77.5 & 2.6 & 1.96 & \\
\hline \multicolumn{5}{|c|}{$\mathrm{Al10-SiO}_{2-500}$} \\
\hline Al1 & 27.0 & - & - & - \\
\hline$\left.{ }^{[4]} \mathbf{A l}_{(} \mathrm{OH}\right)$ & 2.7 & 72.7 & 11.8 & 6.38 \\
\hline${ }^{[4]} \mathrm{Al}$ & 24.9 & 72.7 & 14.1 & 8.73 \\
\hline${ }^{[5]} \mathrm{Al}$ & 29.9 & 39.6 & 10.0 & 7.67 \\
\hline${ }_{[6]}^{[6]}$ & 15.5 & 6.0 & $20.3^{(*)}$ & 5.59 \\
\hline $\mathbf{H}-{ }^{[4]} \mathbf{A l}_{(\mathrm{OH})}$ & 3.7 & 0.4 & 1.6 & \\
\hline $\mathbf{H}_{(1)}{ }^{\left[{ }^{[4]}\right.} \mathbf{A l}$ & 24.7 & 5.7 & 8.0 & \\
\hline $\mathbf{H}_{(\mathbf{2})^{-}}{ }^{\left[{ }^{[4}\right.} \mathbf{A l}$ & 9.5 & 3.0 & 3.2 & \\
\hline $\mathbf{H}_{(1)^{-}}{ }^{[5]} \mathbf{A l}$ & 22.1 & 5.3 & 7.4 & \\
\hline $\mathbf{H}_{(2)^{-}}{ }^{[5]} \mathbf{A l}$ & 18.8 & 2.7 & 3.8 & \\
\hline $\mathbf{H}_{(1)^{-}}{ }^{[6]} \mathbf{A l}$ & 15.4 & 4.1 & 5.1 & \\
\hline $\mathbf{H}_{(2)^{-}}{ }^{\left[{ }^{[6]}\right.} \mathbf{A l}$ & 5.8 & 2.0 & 2.1 & \\
\hline
\end{tabular}

This structural ordering of the $\mathrm{Al}$ environments near $\mathrm{OH}$ groups mimics the one observed in $\gamma$-alumina. ${ }^{14}$ On the other hand, their average chemical shifts are identical to the non-protonated environments (obtained from the quantitative one-pulse experiments), showing that the above assignment of ${ }^{[4]} \mathrm{Al}_{(3-4 \mathrm{Si})}$ and ${ }^{[5]} \mathrm{Al}_{(2 \mathrm{Si})}$ environments holds and that both species are either bonded or close to $\mathrm{OH}$ groups. In line with its higher REDOR dephasing at short recoupling time, the ${ }^{[6]} \mathrm{Al}$ component is increased in the ${ }^{27} \mathrm{Al}\left\{{ }^{1} \mathrm{H}\right\}$ HMQC experiment $\left(\sim 20 \%\right.$ of this ${ }^{[6]} \mathrm{Al}$ component is found in the D-HMQC spectrum). It appears that a Lorentzian broadening is needed to account for the ${ }^{[6]} \mathrm{Al}$ line shape (purple component in Figure 4), rendering a comparison with the direct excitation spectra difficult.
For A110-SiO $2-500$ (Figure 4b), we performed the simulation of the $2 \mathrm{D}$ dataset with the same hypothesis used above for simulating the 1D direct excitation experiments in Figure 2, i.e. the presence of an $\mathrm{All}-\mathrm{SiO}_{2-500}$ component is accounted for by including its spectra (its simulation was used to avoid additional noise). Along the ${ }^{1} \mathrm{H}$ dimension, we found a broad and asymmetric line shape, again approximated by a pair of Gaussian lines $\left(\mathrm{H}_{(1)}, \mathrm{H}_{(2)}\right)$. The peak maxima of this $\left(\mathrm{H}_{(1)}, \mathrm{H}_{(2)}\right)$ distribution for $\mathrm{All}-\mathrm{SiO}_{2-500}$ was uncorrelated with the coordination

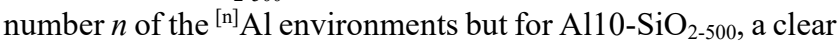
shift of the maxima is observed in Figure $4 \mathrm{~b}$. This suggests separate $\left(\mathrm{H}_{(1)}, \mathrm{H}_{(2)}\right)$ components for each ${ }^{[\mathrm{n}]} \mathrm{Al}$ environment. We therefore obtain three $\left({ }^{[\mathrm{n}]} \mathrm{Al},\left(\mathrm{H}_{(1)}, \mathrm{H}_{(2)}\right)\right)$ 2D components on top of an $\mathrm{Al1}-\mathrm{SiO}_{2-500}$ contribution; all retrieved parameters are shown in Table 2 (Table S6 contains respected calculated errors).

Similar to $\mathrm{Al1}-\mathrm{SiO}_{2-500}$, the recovered $\bar{\delta}_{\text {iso }}$ are identical to the "bulk" one derived from the quantitative experiment and $\bar{C}_{Q}$ are greatly reduced. Considering the high $\bar{\delta}_{\text {iso }}\left({ }^{27} \mathrm{Al}\right)$ obtained here, we observe mainly a wide variety of hydrogen-bonded ${ }^{[\mathrm{n}]} \mathrm{AlOH}^{[\mathrm{p}]} \mathrm{Al}$ sites such as those found in $\gamma$-alumina, ${ }^{51}$ on top of the minor $\mathrm{Al}(\mathrm{OH}) \mathrm{Si}$ ones described above and accounted for by the "Al1-SiO 2-500" component. An additional resonance which, upon simulation, corresponds to a ${ }^{1} \mathrm{H}$ chemical shift of $0.4 \mathrm{ppm}$ and a ${ }^{27} \mathrm{Al}$ line with $\bar{\delta}_{\text {iso }}=72.7 \mathrm{ppm}$ and $\bar{C}_{Q}=6.38 \mathrm{MHz}$ is also clearly seen (orange component in Figure 4b). Based on its absence in $\mathrm{Al1}-\mathrm{SiO}_{2-500}$, its low ${ }^{1} \mathrm{H}$ chemical shift and the presence of an IR band at $3783 \mathrm{~cm}^{-1}$ (Figure 1c) this latter component is assigned to terminal ${ }^{[4]} \mathrm{AlOH}$ aluminols ${ }^{12,49}$ possibly located on the surface of the am- $\mathrm{Al}_{2} \mathrm{O}_{3}$ film. We observe a $-0.5 \mathrm{ppm}$ change in the ${ }^{1} \mathrm{H}$ chemical shift for higher aluminum coordination numbers, suggesting that the proton becomes slightly less acidic with increasing aluminum coordination, a behavior not observed for $\mathrm{Al}(\mathrm{OH}) \mathrm{Si}$ environments (vide supra) but previously inferred from ${ }^{27} \mathrm{Al}\left\{{ }^{1} \mathrm{H}\right\}$ NMR experiments on $\gamma$-alumina. ${ }^{12}$ As seen from the line width of each of ${ }^{1} \mathrm{H}$ components (Table 2 ), the range of proton environments increases with decreasing aluminum coordination number and is on average broader than that for $\mathrm{Al}(\mathrm{OH}) \mathrm{Si}$ sites.

Silica-alumina interface. Accessing the signal from the $\mathrm{SiO}_{2} / \mathrm{Al}_{2} \mathrm{O}_{3}$ interface is challenging owing to the paucity of nuclei present at the interface and the low natural abundance of ${ }^{29} \mathrm{Si}$, yet we were nevertheless successful in performing ${ }^{27} \mathrm{Al}\left\{{ }^{29} \mathrm{Si}\right\}$ correlation experiments on both $\mathrm{All}-\mathrm{SiO}_{2-500}$ and Al10- $\mathrm{SiO}_{2-500}$ (Figure 5a and 5b respectively). Although both through-bond and through-space experiments are feasible at silica/alumina interfaces under DNP conditions, ${ }^{19}$ we focused here on through-space dipolar-based HMQC experiments, using a rather long $(6.4 \mathrm{~ms})$ excitation time to obtain an optimum signal-to-noise ratio and hence possibly obtain correlations between distant $\mathrm{Al} / \mathrm{Si}$ nuclei pairs.

As seen in Figure 5, both materials yield similar projections along the ${ }^{27} \mathrm{Al}$ dimension meaning that both experiments are retrieving the same type of aluminum environments. The close similarity with the direct spectra of $\mathrm{All}-\mathrm{SiO}_{2-500}$ (Figure 2a1) suggests that the ${ }^{27} \mathrm{Al}\left\{{ }^{29} \mathrm{Si}\right\}$ D-HMQC spectra indeed probe the silica-alumina interface. This feature is highlighted in Figure $6 \mathrm{a}$, which compares the ${ }^{29} \mathrm{Si}$-filtered and the ${ }^{1} \mathrm{H}$-filtered ${ }^{27} \mathrm{Al}$ spectra of $\mathrm{Al1}-\mathrm{SiO}_{2-500}$ and $\mathrm{Al10}-\mathrm{SiO}_{2-500}$ with the direct acquisition data. This similarity is not seen for the silicon projections 
in Figure 5b, which show a much broader peak tailing towards higher chemical shifts than the direct ${ }^{29} \mathrm{Si}$ spectra, suggesting the presence of either less polymerized or more Al-connected species than in $\mathrm{Al1}-\mathrm{SiO}_{2-500}$. This feature is again illustrated in
Figure $6 \mathrm{~b}$ that compares the ${ }^{27} \mathrm{Al}$-filtered (orange) and the direct acquisition (brown) ${ }^{29} \mathrm{Si}$ spectra recorded on $\mathrm{Al10}-\mathrm{SiO}_{2-500}$.
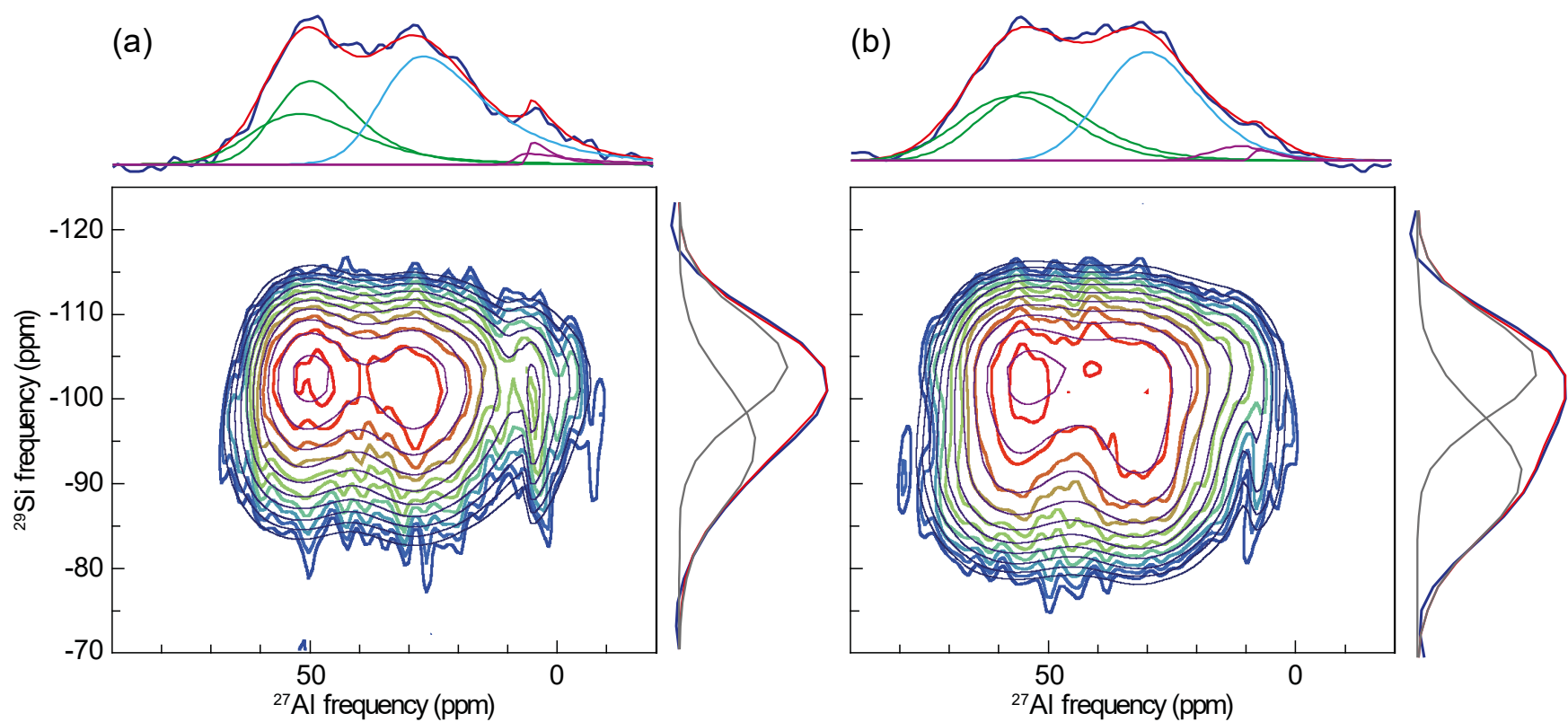

Figure 5. ${ }^{27} \mathrm{Al}\left\{{ }^{29} \mathrm{Si}\right\}$ D-HMQC SR42 ${ }_{1}$ correlation experiments for (a) $\mathrm{Al1}-\mathrm{SiO}_{2-500}$ and (b) $\mathrm{Al} 10-\mathrm{SiO}_{2-500}$ with projections (dark blue) along each dimension. Simulations of the 2D line shapes are given in grey and individual components are given in the projections in color with their sum in red.

To obtain further insights into the spectra of Figure 5, we performed a simulation of the 2D line shapes, assuming that two Gaussian lines are needed to render the ${ }^{29} \mathrm{Si}$ dimension. It appeared that two ${ }^{[4]} \mathrm{Al}$ environments (green) are required to obtain a satisfactory simulation result whereas only one ${ }^{[5]} \mathrm{Al}$ environment (blue) is sufficient to account for the observed correlations. The two ${ }^{[6]} \mathrm{Al}$ lines (purple) are very likely part of the same component, but are needed to account for the appearance of a sharp ridge on the 2D line shape. Nevertheless, the low abundance of this component (less than 5\%) does not allow its reliable simulation and it will not be discussed further. The results of the simulations are given in Table 3 and the calculated errors in Table S7.

Based on the chemical shifts reported in Table 3 and literature data, ${ }^{52}$ the silicon environments are assigned to $Q_{1 A l}^{[4]}$ sites at $-104.0 \mathrm{ppm}$ (in $\mathrm{Al1}-\mathrm{SiO}_{2-500}$ ) and $-104.6 \mathrm{ppm}$ (in $\mathrm{Al10}-\mathrm{SiO}_{2}$ 500 ), as well as to $Q_{1 \mathrm{Al}}^{[3]}$ sites at $-94.7 \mathrm{ppm}$ in $\mathrm{Al1}-\mathrm{SiO}_{2-500}$ and to $Q_{2 A l}^{[3]}$ sites at $-91.9 \mathrm{ppm}$ in $\mathrm{Al10}-\mathrm{SiO}_{2-500}$. These shifts differ from the bulk signal of the silica core (mostly $Q^{[4]}$ ) and its hydrated species (mostly $Q^{[3]}$ ), as shown in the direct (brown) and $\mathrm{CP}$ (green and blue) ${ }^{29} \mathrm{Si}$ spectra in Figure 6b. Details of the simulation are given in Figure S10 and Table S8. Clearly, increasing the thickness of the ALD-deposited alumina layer promotes the connectivity between silicon and aluminum through the $\mathrm{Q}^{[3]}$ sites, but, within error bars, the $\mathrm{Q}^{[4]}{ }_{(\mathrm{Al})} / \mathrm{Q}^{[3]}{ }_{(\mathrm{Al})}$ ratio stays constant at approx. 60/40. We also observe a shift in $\bar{\delta}_{\text {iso }}\left({ }^{[4]} \mathrm{Al}\right)$ with increased layer thickness, and the ${ }^{[4]} \mathrm{Al}$ sites are assigned to ${ }^{[4]} \mathrm{Al}_{(3-4 \mathrm{Si})}$ in $\mathrm{All}-\mathrm{SiO}_{2-500}$ and to ${ }^{[4]} \mathrm{Al}_{(2-3 \mathrm{Si})}$ in $\mathrm{Al10}-\mathrm{SiO}_{2-500}$ whereas the chemical shifts of the ${ }^{[5]} \mathrm{Al}$ sites, assigned in both cases to ${ }^{[5]} \mathrm{Al}_{(2 \mathrm{~S})}$, do not appear to vary with the thickness of the ALD layer.

It is noteworthy that ${ }^{[4]} \mathrm{Al}_{(3 \mathrm{Al}, 4 \mathrm{Al})}$ and $\mathrm{Q}^{[3]}(1 \mathrm{Al})$ are replaced by ${ }^{[4]} \mathrm{Al}_{(2 \mathrm{Al}, 3 \mathrm{Al})}$ and $\mathrm{Q}^{[3]}{ }_{(2 \mathrm{Al})}$ going from $\mathrm{All}-\mathrm{SiO}_{2-500}$ to $\mathrm{All}-\mathrm{SiO}_{2-}$ 500 . This suggests that the first cycle deposits only a sub-monolayer of aluminum on the surface of silica, possibly forming dispersed "islands" of alumina clusters, with the remaining silica surface accessible to subsequent deposition connects the clusters to form a homogeneous film. Our findings from 2D experiments here are consistent with, and refine, our observations from the analysis of Figure 2: the first ALD cycle grafts ${ }^{[4]} \mathrm{Al}_{(3 \mathrm{Si})}$ and ${ }^{[4]} \mathrm{Al}_{(4 \mathrm{Si})}$ species as well as bi-bonded ${ }^{[5]} \mathrm{Al}_{(2 \mathrm{Si})}$ onto the silica surface (Table 1). Only a very small amount of ${ }^{[6]} \mathrm{Al}$ is actually connected to the silica surface. Subsequent cycles add aluminum onto the "free" silica surface, left after the first cycle, leading to a silica/alumina interface mainly composed of ${ }^{[4]} \mathrm{Al}_{(3 \mathrm{Si})}$,

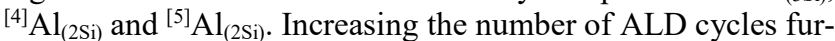
ther builds an am- $\mathrm{Al}_{2} \mathrm{O}_{3}$ film on top of this intermediate layer with additional (hydrated) ${ }^{[6]} \mathrm{Al}$ environments. For $\mathrm{Al1}-\mathrm{SiO}_{2-500}$, the slightly increased $\bar{C}_{Q}$ (Table 3 ) suggests that we observe here, on average, less of the "protonated" sites than detected with the ${ }^{27} \mathrm{Al} /{ }^{1} \mathrm{H}$ experiments (Table 2).

Table 3. ${ }^{27} \mathrm{Al}$ and ${ }^{29} \mathrm{Si}$ NMR parameters derived from the simulation of the $2 \mathrm{D}^{27} \mathrm{Al}\left\{{ }^{29} \mathrm{Si}\right\} \mathrm{D}-\mathrm{HMQC}$ experiments (Figure 5).

\begin{tabular}{lrrrr}
\hline site & $\%$ & $\bar{\delta}_{\text {iso }}(\mathrm{ppm})$ & $\Delta \delta_{\text {iso }}(\mathrm{ppm})$ & $\bar{C}_{Q}(\mathrm{MHz})$ \\
\hline $\mathrm{Al1}-\mathrm{SiO}_{2-500}$ & &
\end{tabular}




\begin{tabular}{|c|c|c|c|c|}
\hline${ }^{[4]} \mathbf{A l}_{(3 \mathrm{Si})}$ & 18.6 & 61.1 & 18.0 & 9.31 \\
\hline${ }^{[4]} \mathbf{A} \mathbf{l}_{(4 \mathbf{S i})}$ & 32.1 & 56.5 & 14.0 & 8.01 \\
\hline${ }^{[5]} \mathbf{A l}_{(2 \mathrm{Si})}$ & 44.9 & 35.9 & 14.4 & 10.0 \\
\hline${ }^{[6]} \mathbf{A l}_{(\mathbf{1})}$ & 1.8 & 9.1 & 2.4 & 8.37 \\
\hline${ }^{[6]} \mathbf{A l}_{(2)}$ & 2.6 & 6.3 & 0.9 & 5.57 \\
\hline $\mathbf{Q}^{[3]}(\mathbf{1 A l})$ & 37.8 & -94.7 & 17.0 & - \\
\hline $\mathbf{Q}^{[4]}(\mathbf{1 A l})$ & 62.2 & -104.0 & 13.8 & - \\
\hline \multicolumn{5}{|c|}{$\mathrm{Al10}^{-\mathrm{SiO}_{2-500}}$} \\
\hline${ }^{[4]} \mathbf{A} \mathbf{l}_{(2 \mathrm{Si})}$ & 22.7 & 64.2 & 23.0 & 7.59 \\
\hline${ }^{[4]} \mathbf{A} \mathbf{l}_{(3 \mathrm{Si}}$ & 33.3 & 62.2 & 19.9 & 8.69 \\
\hline${ }^{[5]} \mathbf{A} \mathbf{l}_{(2 \mathrm{Si})}$ & 39.3 & 36.9 & 19.2 & 7.60 \\
\hline${ }^{[6]} \mathbf{A l}_{(\mathbf{1})}$ & 1.3 & 12.5 & 14.5 & 2.83 \\
\hline${ }^{[6]} \mathbf{A l}_{(2)}$ & 3.4 & 9.4 & 2.0 & 6.44 \\
\hline $\mathbf{Q}^{[3]}(2 \mathrm{Al})$ & 44.2 & -91.9 & 17.3 & - \\
\hline$Q^{[4]}(1 \mathrm{Al})$ & 55.8 & -104.6 & 13.6 & - \\
\hline
\end{tabular}

The connectivity pattern derived from the $2 \mathrm{D}^{27} \mathrm{Al}\left\{{ }^{29} \mathrm{Si}\right\}$ spectra (see Table S9 for details) leads to the most probable connectivity of ${ }^{[4]} \mathrm{Al}_{(4 \mathrm{Si})}-Q_{1 A l}^{[4]}$ and ${ }^{[4]} \mathrm{Al}_{(3 \mathrm{Si})}-Q_{1 A l}^{[3]}$ for $\mathrm{All}^{\left[-\mathrm{SiO}_{2-500} \text { and }\right.}$ ${ }^{[4]} \mathrm{Al}_{(3 \mathrm{Si})}-Q_{1 A l}^{[4]}$ and ${ }^{[4]} \mathrm{Al}_{(2 \mathrm{Si})}-Q_{2 A l}^{[3]}$ for $\mathrm{Al10}-\mathrm{SiO}_{2-500}$. In other words, the proton-free fully polymerized $Q_{1 A l}^{[4]}$ species are preferably linked to the ${ }^{[4]} \mathrm{Al}$ environments with few AlOAl linkages. Apart from a slight decrease of the amount of ${ }^{[5]} \mathrm{Al}_{(2 \mathrm{Si})}$ $Q_{1 A l}^{[4]}$, the ${ }^{[n]} \mathrm{Al}-Q^{[p]}$ connectivity pattern does not seem to be strongly dependent on the number of ALD cycles, showing again that most of the alumina/silica interface is built within 1 ALD cycle. We note that the $\sim 14 \mathrm{ppm}$ and $\sim 17 \mathrm{ppm}$ widths of the, respectively, $\mathrm{Q}^{[4]}{ }_{(1 \mathrm{Al})}$ and $\mathrm{Q}^{[3]}{ }_{(\mathrm{pAl})}$, resonances (Table 3 ) are significantly broader than the $10.8 \mathrm{ppm}$ width obtained in a direct or $\mathrm{CP}$ acquisitions (Table $\mathrm{S} 8$ and Figure $6 \mathrm{~b}$ ). This suggests that those broad lines contain more environments than the single $\mathrm{Q}^{[\mathrm{n}]}{ }_{(\mathrm{pAl})}$ unit that we assigned from their maxima. Again, we emphasize that all components evidenced in this study must be seen as the "most probable" environments within the framework of a purely statistical (i.e. Gaussian) distribution of environments.

To complete the structural analysis and assess the Al-O-Al connectivity, we performed ${ }^{27} \mathrm{Al} \mathrm{DQ} / \mathrm{SQ}$ (double-quantum singlequantum) correlation experiments using a dipolar-based $\mathrm{R} 2{ }^{2}{ }_{1}$ experiment with short $(0.5 \mathrm{~ms})$ excitation times. Sheared and symmetrized spectra for $\mathrm{All}-\mathrm{SiO}_{2-500}$ and $\mathrm{Al10}-\mathrm{SiO}_{2-500}$ are given in Figure S11 along with their simulations and the parameters derived are given in Table $\mathrm{S} 10$. The $\mathrm{A} 110-\mathrm{SiO}_{2-500}$ spectrum displays strong correlations between the three ${ }^{27} \mathrm{Al}$ resonances, indicating a full connection between all of the various ${ }^{[n]} \mathrm{Al}$ species, in agreement with the am- $\mathrm{Al}_{2} \mathrm{O}_{3}$ nature of the film. For $\mathrm{Al1}-\mathrm{SiO}_{2-500}$, the $2 \mathrm{D}$ map clearly shows that ${ }^{[4]} \mathrm{Al}$ sites have no linking preferences and share bonds to all ${ }^{[\mathrm{n}]} \mathrm{Al}$ species $(n=$ 4,5 and 6) whereas ${ }^{[6]} \mathrm{Al}$ sites connect neither to themselves nor to ${ }^{[5]} \mathrm{Al}$. This reinforces the view that ${ }^{[6]} \mathrm{Al}$ species are rather isolated on the outer side of an ${ }^{[4,5]} \mathrm{Al} / \mathrm{Si}$ interface and the possible "synergy" between two ${ }^{[4,5]} \mathrm{Al}$ units forming ${ }^{[4]} \mathrm{Al}(\mathrm{SiOH})^{[5]} \mathrm{Al}$ or ${ }^{[5]} \mathrm{Al}(\mathrm{SiOH}){ }^{[5]} \mathrm{Al}$ pairs enhancing acid strength. ${ }^{53}$
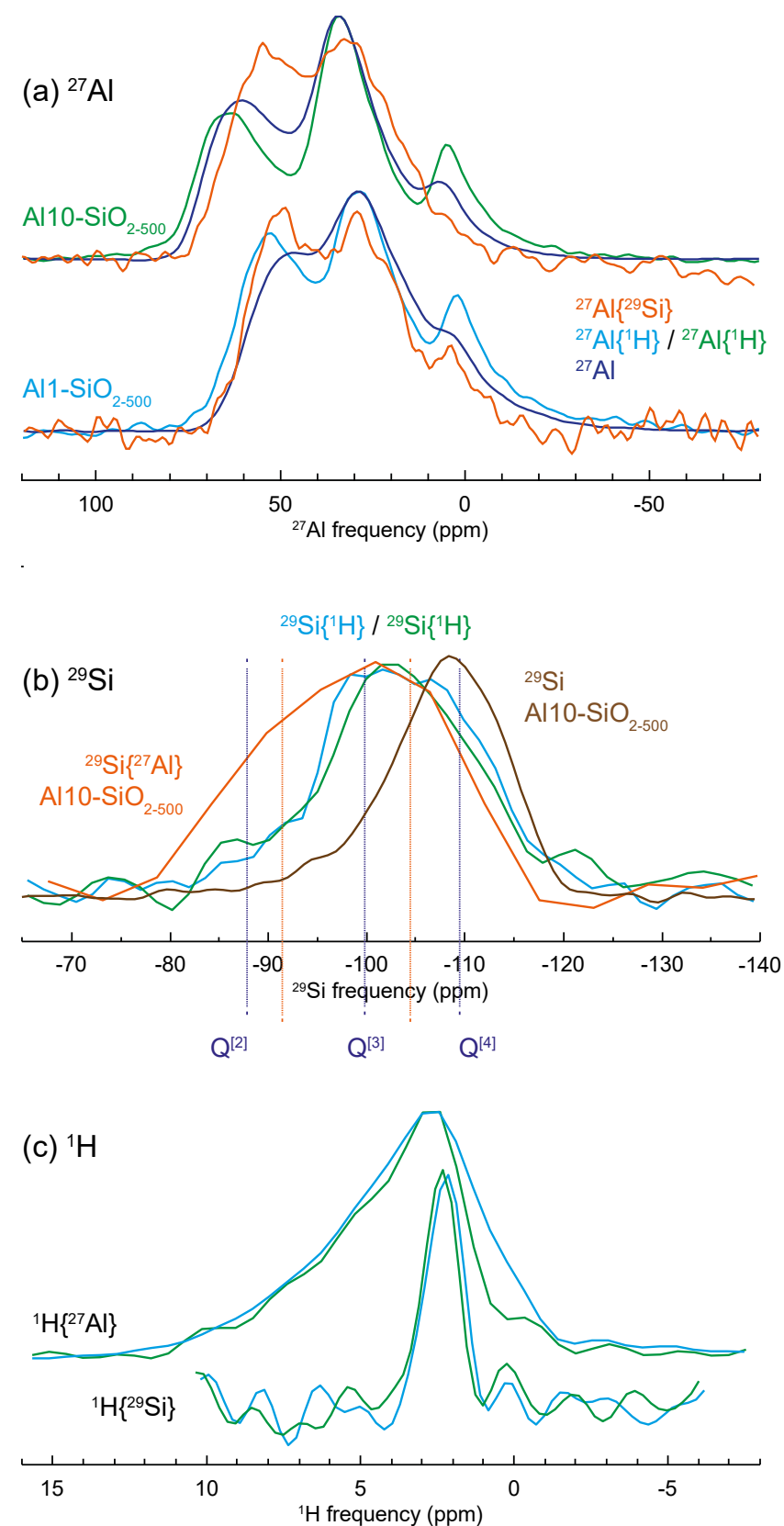

Figure 6. Various ${ }^{27} \mathrm{Al}\left\{{ }^{1} \mathrm{H}\right\}$ D-HMQC SR $4{ }^{2}{ }_{1}$ and ${ }^{29} \mathrm{Si}\left\{{ }^{1} \mathrm{H}\right\} \mathrm{CP}-$ CPMG MAS NMR experiments performed on $\mathrm{All}^{-\mathrm{SiO}_{2-500} \text { and }}$ Al10-SiO2-500 showing: (a) ${ }^{1} \mathrm{H}$ - (blue and green) and ${ }^{29} \mathrm{Si}$ - (orange) filtered ${ }^{27} \mathrm{Al}$ signals, compared with the direct spectrum (dark blue), (b) ${ }^{27} \mathrm{Al}$ - (orange) and ${ }^{1} \mathrm{H}$ - (blue and green) filtered ${ }^{29} \mathrm{Si}$ spectra compared with direct CPMG signal (brown), (c) ${ }^{27} \mathrm{Al}-$ (top) and ${ }^{29} \mathrm{Si}$ - (bottom) filtered ${ }^{1} \mathrm{H}$ spectra.

Finally, in an attempt to characterize protons located at the silica-alumina interface, two-dimensional ${ }^{29} \mathrm{Si}\left\{{ }^{1} \mathrm{H}\right\} \quad \mathrm{CP}-\mathrm{CPMG}$ experiments were recorded on $\mathrm{All}-\mathrm{SiO}_{2-500}$ and $\mathrm{Al10}-\mathrm{SiO}_{2-500}$ with a $500 \mu$ s contact time at $7.0 \mathrm{~T}$ (Figure S12). The projections in the indirect proton dimension are shown in Figure $6 \mathrm{c}$ at the bottom. There are no significant differences between Al1$\mathrm{SiO}_{2-500}$ and $\mathrm{Al10}-\mathrm{SiO}_{2-500}$, both displaying a single narrow peak at around $2.5 \mathrm{ppm}$. However, these projections are very different from those obtained from $2 \mathrm{D}{ }^{27} \mathrm{Al}\left\{{ }^{1} \mathrm{H}\right\}$ spectra of Figure 4 (shown on top in Figure 6c). This indicates that the majority of the hydroxyl groups evidenced here are of the $\mathrm{SiOH}$ type, consistent with the IR spectra (Figure 1c). ${ }^{48,54}$ 
A sketch of the various aluminum most probable environments found in $\mathrm{Al1}-\mathrm{SiO}_{2-500}$ is given in figure $\mathrm{S} 13$. A schematic representation of the possible connectives between those species is illustrated for $\mathrm{Al1}-\mathrm{SiO}_{2-500}$ in figure 7.

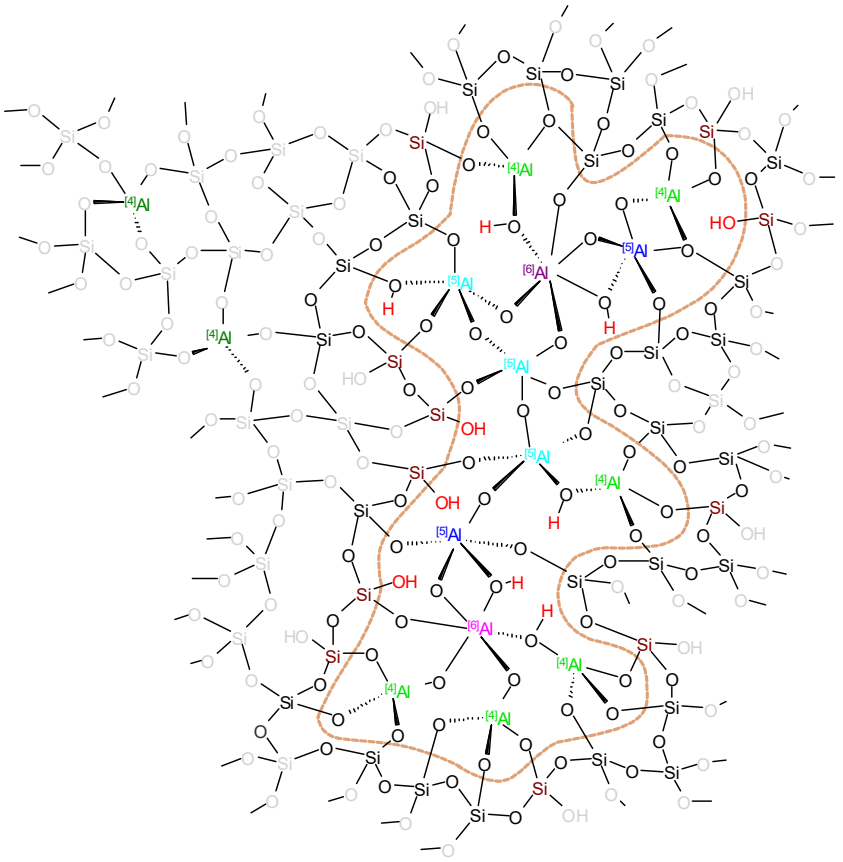

Figure 7. Sketch of the aluminum/silicon most probable connectivity for the $\mathrm{Al1}-\mathrm{SiO}_{2-500}$ surface. The aluminum environments are depicted in dark green $\left({ }^{[4]} \mathrm{Al}_{(4 \mathrm{Si})-} Q_{1 A l}^{[4]}\right)$, light green $\left({ }^{[4]} \mathrm{Al}_{(3 \mathrm{Si})}-Q_{1 A l}^{[3]}\right)$, dark blue ( $\left.{ }^{[5]} \mathrm{Al}_{(2 \mathrm{Si})}-Q_{1 A l}^{[4]}\right)$, light blue $\left({ }^{[5]} \mathrm{Al}_{(2 \mathrm{Si})}-Q_{1 A l}^{[3]}\right)$, dark purple $\left({ }^{[6]} \mathrm{Al}_{(1 \mathrm{Si})}-Q_{1 A l}^{[4]}\right)$, light purple $\left({ }^{[6]} \mathrm{Al}_{(1 \mathrm{Si})}-Q_{1 A l}^{[3]}\right)$ and silicon $Q_{1 A l}^{[3]}$ species in dark red.

Acidity of surface sites. The catalytic activity of alumina and aluminosilicates is directly linked to their surface acidity, i.e. the type, location and local environment of their acid sites. A selective characterization of those surface sites is out of reach of conventional solid-state NMR, partly due to their low concentration, which is exacerbated by the limited intrinsic sensitivity of NMR spectroscopy. Both of these obstacles can typically be overcome by implementing DNP SENS approaches. ${ }^{15}$

Figure S15 shows the DNP enhanced ${ }^{27} \mathrm{Al}$ NMR spectra of the series of $\mathrm{Py}-\mathrm{Al}-\mathrm{SiO}_{2-500}$ samples, measured at $9.4 \mathrm{~T}$ (proton enhancement $>140$ ) and $18.8 \mathrm{~T}$ (proton enhancement $>40$ ). As was demonstrated above, protons are present in the aluminum oxide thin film and are expected to relay the nuclear hyperpolarization from the surface to the inner part of the oxide layer through spin diffusion. Therefore, the DNP enhanced ${ }^{27} \mathrm{Al}$ NMR experiments are not surface-selective. We note indeed that the ${ }^{27} \mathrm{Al}$ spectra recorded at $18.8 \mathrm{~T}$ (Figure S15) are similar to those recorded at ambient temperature and at a magnetic field of $20 \mathrm{~T}$ (Figure 2). In other words, the DNP enhanced ${ }^{27} \mathrm{Al}$ spectra cannot be exploited to extract unambiguously structural information of the surface acid sites.

Therefore, we probed the acidity of the surface layer by monitoring its interaction with pyridine probe molecule. The ${ }^{15} \mathrm{~N}$ NMR pyridine chemical shifts and resonance intensities arising from various sites of adsorption has been used previously to identify the acidic nature of surface species in zeolites and amorphous aluminosilicates. ${ }^{8,55}$ The ${ }^{15} \mathrm{~N}$ chemical shift of free pyridine has been reported at 294317 ppm, whereas the chemical shift of the pyridinium ion
$\left(\mathrm{PyH}^{+}\right)$, formed upon protonation of pyridine is at 201-211 ppm. ${ }^{56} \mathrm{H}$-bonded pyridine on weak Brønsted acid sites (HPy) or pyridine bonded to Lewis acid sites (Py-L), appear as ${ }^{15} \mathrm{~N}$ resonances between these values, with $\mathrm{H}-\mathrm{Py}$ sites typically found between ca. 290-260 ppm, while Py-L sites are found between ca. 280-230 ppm. The NMR sensitivity was increased here by combining the use of isotopically-labelled ${ }^{15} \mathrm{~N}$ pyridine with DNP SENS. In addition, the cryogenic temperature $(\sim 100 \mathrm{~K})$ at which the experiments are carried out, reduces molecular motions that partly average magnetic interactions at ambient temperatures and allows for the observation of the spectral signature of all surface pyridine species that are in fast exchange at ambient temperatures. ${ }^{57}$
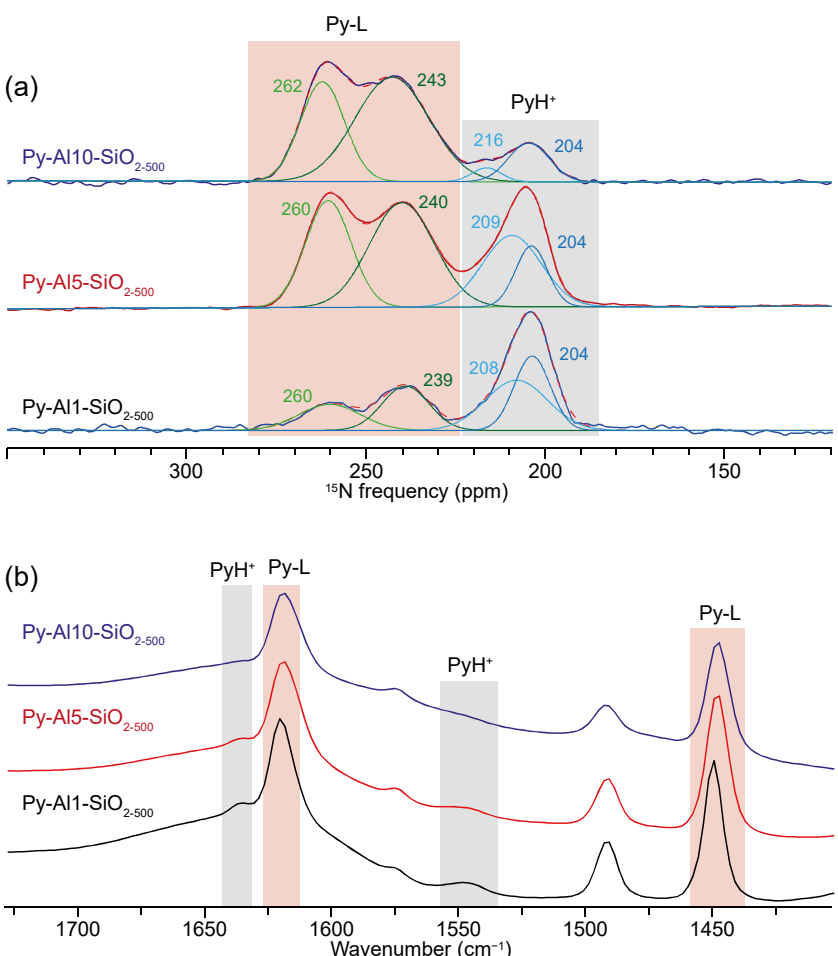

Figure 8. (a) ${ }^{15} \mathrm{~N}$ DNP enhanced NMR spectra of Py-Al1-SiO2-500 (black), Py-Al5-SiO2-500 (red), and Py-Al10-SiO2-500 (blue). (b) Corresponding FTIR spectra of each material using the same color code, and highlighting $\mathrm{PyH}^{+}$and $\mathrm{Py}-\mathrm{L}$ vibration frequencies in light grey and red respectively.

Figure 8a shows the ${ }^{15} \mathrm{~N}$ DNP SENS spectra of pyridine that remained adsorbed on the surface of the materials after a desorption step at $150{ }^{\circ} \mathrm{C}$ (see details in the SI). Three resonances are observed whose intensity varies as a function of the thickness of the aluminum oxide layer, i.e. on the number of ALD cycles. The line width of each of the three resonances reflect broad chemical shift distributions for the ${ }^{15} \mathrm{~N}$ nuclei, likely due to slight differences in local structure and environment. Notably the broad resonance at around 200-210 ppm could not be fitted by a single component but can still be assigned to pyridinium ions. Since pyridine adsorbed through hydrogen bonds on weak Brønsted acid sites is expected to be largely desorbed at $150{ }^{\circ} \mathrm{C}$ and therefore not be detected under our experimental conditions, we assign the peaks at around 240 and $260 \mathrm{ppm}$ to Py interacting with Lewis acid sites in preference to Brønsted acid sites. This assignment is confirmed by ${ }^{15} \mathrm{~N}\left\{{ }^{27} \mathrm{Al}\right\} \mathrm{J}-\mathrm{HMQC}$ experiments that detect ${ }^{15} \mathrm{~N}$ spins having a through-bond coupling to ${ }^{27} \mathrm{Al}$ sites (shown in Figure S15). The proposed assignment also agrees with a previous report on $\gamma$-alumina. ${ }^{9}$ The presence of each type of acidic site is additionally corroborated by FTIR 
spectroscopy. The IR absorption peaks at $1620 \mathrm{~cm}^{-1}$ and 1450 $\mathrm{cm}^{-1}$ are characteristic of the ring vibrational modes of pyridine bound to a Lewis site, ${ }^{8}$ and are observed for all samples (Figure 8b). $\mathrm{PyH}^{+}$vibration modes appear at $1635 \mathrm{~cm}^{-1}$ and $1545 \mathrm{~cm}^{-1}$ and are clearly visible in the IR spectra of Py-Al1-SiO $2-500$, Py$\mathrm{Al} 5-\mathrm{SiO}_{2-500}$ and to a much lesser extent in the spectrum of Py$\mathrm{Al10-} \mathrm{SiO}_{2-500}$.

While the NMR signal of the pyridinium ion is becoming less intense for thicker layers, the intensity of the peaks corresponding to the Lewis acid sites shows a reverse trend. Previous work on ASA materials showed that the formation of Brønsted acid sites is directly related to the presence of ${ }^{[4]} \mathrm{Al}$ connected to silicon atoms and that silicon connected to aluminum having a higher coordination number would not form Brønsted acid sites. ${ }^{19}$ As elaborated in the previous sections, Py-Al1- $\mathrm{SiO}_{2-500}$ contains a large fraction of ${ }^{[4]} \mathrm{Al}(\mathrm{O}) \mathrm{Si}$. Most of these sites are expected to be protonated (from REDOR data) and therefore accessible for pyridine adsorption and protonation. Strong Brønsted acid sites (providing $\mathrm{PyH}^{+}$) are thus observed in the ${ }^{15} \mathrm{~N}$ DNP SENS spectrum of $\mathrm{Py}-\mathrm{Al1}-\mathrm{SiO}_{2-500}$ as an intense resonance at 204 ppm (in black, Figure 8a). This surface Brønsted acidity is more prevalent than Lewis acidity as little $\mathrm{Al}(\mathrm{O}) \mathrm{Al}$ sites are formed at this stage.

The nature of surface acidity clearly changes with the growth of the aluminum oxide layer concomitantly with the number of ALD cycles. With the growth of the aluminum oxide layer, pyridine adsorption sites become further away from the alumina/silica interface where protonated ${ }^{[4]} \mathrm{Al}(\mathrm{OH}) \mathrm{Si}$ sites are found. As a result, the relative fraction of Brønsted acid sites decreases in $\mathrm{Py}-\mathrm{Al} 15-\mathrm{SiO}_{2-500}$ and $\mathrm{Py}-\mathrm{A} 110-\mathrm{SiO}_{2-500}$ with respect to that of Lewis acid sites, as observed in the ${ }^{15} \mathrm{~N}$ DNP SENS and FTIR spectra. The ${ }^{15} \mathrm{~N}$ DNP SENS spectrum of Py-Al10- $\mathrm{SiO}_{2-500}$ (shown in blue) is thus dominated by the resonances owing to pyridine on Lewis acid sites while the peak corresponding to the strong Brønsted acid sites, $\mathrm{PyH}^{+}$, becomes minor. This spectrum closely resembles that of pyridine adsorbed on $\gamma$-alumina (recorded after similar pyridine adsorption and desorption at $\left.150^{\circ} \mathrm{C}\right){ }^{9}$

\section{Conclusions}

We have applied a broad range of one- and two-dimensional solid-state NMR characterization approaches to understand the structural processes behind the ALD-based depositing of alumina onto a silica surface at an atom level. The first ALD cycle produces an aluminosilicate layer with aluminum environments consisting of $60 \%{ }^{[4]} \mathrm{Al}, 35 \%{ }^{[5]} \mathrm{Al}$ and $5 \%{ }^{[6]} \mathrm{Al}$. Subsequent cycles build on top of this amorphous alumina film characterized by approx. $55 \%{ }^{[4]} \mathrm{Al}, 40 \%{ }^{[5]} \mathrm{Al}$ and $5 \%{ }^{[6]} \mathrm{Al}$.

Based on the ${ }^{27} \mathrm{Al}$ average isotropic chemical shifts obtained both from one-dimensional ${ }^{27} \mathrm{Al}$ quantitative spectra and twodimensional ${ }^{27} \mathrm{Al}\left\{{ }^{29} \mathrm{Si}\right\}$ correlation experiments, we could decipher that the first aluminosilicate layer is made of ${ }^{[4]} \mathrm{Al}_{(3 \mathrm{Si})}$,

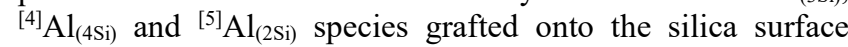
(Scheme 1). The silica surface is not fully covered after the first ALD cycle. During subsequent cycles, a film of amorphous am$\mathrm{Al}_{2} \mathrm{O}_{3}\left(42 \%\right.$ of ${ }^{[5]} \mathrm{Al}$ and less than $5 \%$ of $\left.{ }^{[6]} \mathrm{Al}\right)$ is formed and the interface between the deposited alumina and the surface of the silica support is mainly built up of ${ }^{[4]} \mathrm{Al}_{(3 \mathrm{Si})},{ }^{[4]} \mathrm{Al}_{(2 \mathrm{Si})}$ and ${ }^{[5]} \mathrm{Al}_{(2 \mathrm{Si})}$ species.

Two-dimensional ${ }^{27} \mathrm{Al}\left\{{ }^{1} \mathrm{H}\right\}$ correlation and REDOR experiments show that approximately $80 \%$ of the aluminum environments are hydroxylated. The hydroxylation level of the various ${ }^{[\mathrm{n}]} \mathrm{Al}$ species vary with $n$ as well as with the number of ALD cycles. Six-fold coordinated species show a high level of hydroxylation with more than one $\mathrm{OH}$ group attached, whereas ${ }^{[4]} \mathrm{Al}$ and ${ }^{[5]} \mathrm{Al}$ show a lower hydroxylation level. Overall, hydroxylation is higher for ${ }^{[\mathrm{n}]} \mathrm{AlOSi}$ environments (one ALD cycle) than for ${ }^{[\mathrm{n}]} \mathrm{AlOAl}$ ones ( $>5$ ALD cycles). Clear evidence of the presence of aluminols ${ }^{[4]} \mathrm{AlOH}$ is seen in the alumina film but not at the silica/alumina interface, consistent also with FTIR data.

It follows from the above description that as the number of cycles increases, the surface evolves from an ASA-like surface towards a pure alumina one, i.e. from ${ }^{[4,5]} \mathrm{AlOSi}$ environments towards ${ }^{[4,5]} \mathrm{AlO}^{[4,5]} \mathrm{Al}$ environments. Both types of species can carry $\mathrm{OH}$ groups, forming thereby weak Brønsted acid sites. Strong Brønsted acid sites, formed by an ${ }^{[\mathrm{n}]} \mathrm{Al}$ species nearby a silanol $\mathrm{SiOH}$ group, are expected only for small numbers of ALD deposition cycles. On the other hand, Lewis acid sites ${ }^{[n]} \mathrm{Al}$ are expected after several ALD cycles. To obtain a direct insight into the presence, type and strength of those surface acid sites we used ${ }^{15} \mathrm{~N}$ DNP SENS after ${ }^{15} \mathrm{~N}$-labeled pyridine adsorption. Those experiments show the presence of both pyridinium $\mathrm{PyH}^{+}$ ions (formed upon the transfer of a proton from strong Brønsted acid sites) and pyridine molecules coordinated to Al Lewis acid sites. As expected, the amount of the former, requiring silanol groups, is decreasing with increasing alumina film thickness, in agreement with the fact that the surface acidity changes from that of an ASA-like to that of an am- $\mathrm{Al}_{2} \mathrm{O}_{3}$ surface.

The extensive structural characterization performed here describes with an unprecedented level of details, the mechanisms at play during atomic layer deposition of trimethylaluminum onto partially dehydroxylated silica. It also dwells on the evolution of the surface acid sites as the thickness of the deposited alumina layer grows. Such in-depth characterization and molecular level understanding of the surface structure is crucial for the design of improved heterogeneous catalysts whose catalytic activity, selectivity and stability are often directly influenced by the surface and interfacial properties, in particular the type and the strength of the acidity.

\section{Supporting Information}

Experimental procedures and additional experimental data.

\section{Corresponding Authors}

* P.F.: pierre.florian@cnrs-orleans.fr

* A.L.: anne.lesage@ens-lyon.fr

\section{Author Contributions}

\#M.K. and C.L. contributed equally.

\section{Notes}

The authors declare no competing financial interest.

\section{Acknowledgements}

ETH Zürich (ETH-40 17-2) and the European Research Council (ERC) under the European Union's Horizon 2020 research and innovation program under grant agreement No. 819573 are acknowledge for partial funding.

Financial support from Equipex contracts ANR-10-EQPX-47-01, ANR-15-CE29- 0022-01, and ANR-17-CE29-0006-01 are gratefully acknowledged.

M.K. acknowledges financial support from the Deutsche Forschungsgemeinschaft (KA 5221/1-1).

\section{References}


(1) Busca, G. Chem. Rev. 2007, 107, 5366.

(2) Olah, G. A. Angew. Chem. Int. Ed. 1995, 34, 1393.

(3) Hensen, E. J. M.; Poduval, D. G.; Ligthart, D.; van Veen, J. A. R.; Rigutto, M. S. J. Phys. Chem. C 2010, 114, 8363.

(4) Larmier, K.; Chizallet, C.; Maury, S.; Cadran, N.; Abboud, J.; Lamic-Humblot, A.-F.; Marceau, E.; Lauron-Pernot, H. Angew. Chem. Int. Ed. 2017, 56, 230.

(5) Caillot, M.; Chaumonnot, A.; Digne, M.; van Bokhoven, J. A. J. Catal. 2014, 316, 47.

(6) Wischert, R.; Coperet, C.; Delbecq, F.; Sautet, P. Angew. Chem. Int. Ed. 2011, 50, 3202.

(7) Wischert, R.; Laurent, P.; Coperet, C.; Delbecq, F.; Sautet, P. J. Am. Chem. Soc. 2012, 134, 14430.

(8) Escribano, V. S.; Garbarino, G.; Finocchio, E.; Busca, G. Top. Catal. 2017, 60, 1554.

(9) Moroz, I. B.; Larmier, K.; Liao, W.-C.; Copéret, C. J. Phys. Chem. C 2018, 122, 10871.

(10) Jystad, A.; Leblanc, H.; Caricato, M. J. Phys. Chem. C 2020, $124,15231$.

(11) Blumenfeld, A. L.; Fripiat, J. J. Top. Catal. 1997, 4, 119.

(12) Taoufik, M.; Szeto, K. C.; Merle, N.; Rosal, I. D.; Maron, L.; Trébosc, J.; Tricot, G.; Gauvin, R. M.; Delevoye, L. Chem. Eur. J. 2014, 20, 4038.

(13) Nagashima, H.; Trébosc, J.; Kon, Y.; Sato, K.; Lafon, O.; Amoureux, J.-P. J. Am. Chem. Soc. 2020, 142, 10659.

(14) Wischert, R.; Florian, P.; Copéret, C.; Massiot, D.; Sautet, P. J. Phys. Chem. C 2014, 118, 15292.

(15) Berruyer, P.; Emsley, L.; Lesage, A. eMagRes 2018, 7, 93.

(16) Hooper, R. W.; Klein, B. A.; Michaelis, V. K. Chem. Mat. 2020, 32, 4425 .

(17) Corzilius, B. In Annu. Rev. Phys. Chem.; Johnson, M. A., Martinez, T. J., Eds.; Annual Reviews: Palo Alto, 2020; Vol. 71, p 143.

(18) Lee, D.; Duong, N. T.; Lafon, O.; De Paepe, G. J. Phys. Chem. C 2014, 118, 25065.

(19) Valla, M.; Rossini, A. J.; Caillot, M.; Chizallet, C.; Raybaud, P.; Digne, M.; Chaumonnot, A.; Lesage, A.; Emsley, L.; van Bokhoven, J. A.; Coperet, C. J. Am. Chem. Soc. 2015, 137, 10710.

(20) Rankin, A. G. M.; Webb, P. B.; Dawson, D. M.; VigerGravel, J.; Walder, B. J.; Emsley, L.; Ashbrook, S. E. J. Phys. Chem. C 2017, 121, 22977.

(21) Perras, F. A.; Wang, Z. C.; Kobayashi, T.; Baiker, A.; Huang, J.; Pruski, M. Phys. Chem. Chem. Phys. 2019, 21, 19529.

(22) Mouat, A. R.; George, C.; Kobayashi, T.; Pruski, M.; van Duyne, R. P.; Marks, T. J.; Stair, P. C. Angew. Chem. Int. Ed. 2015, 54,13346 .

(23) Mouat, A. R.; Kobayashi, T.; Pruski, M.; Marks, T. J.; Stair, P. C. J. Phys. Chem. C 2017, 121, 6060.

(24) Chizallet, C. ACS Catal. 2020, 10, 5579.

(25) Lam, E.; Comas-Vives, A.; Copéret, C. J. Phys. Chem. C 2017, 121, 19946.

(26) Copéret, C.; Comas-Vives, A.; Conley, M. P.; Estes, D. P.; Fedorov, A.; Mougel, V.; Nagae, H.; Núñez-Zarur, F.; Zhizhko, P. A. Chem. Rev. 2016, 116, 323.

(27) Caillot, M.; Chaumonnot, A.; Digne, M.; Poleunis, C.; Debecker, D. P.; van Bokhoven, J. A. Micropor. Mesopor. Mat. 2014, $185,179$.

(28) George, S. M. Chem. Rev. 2010, 110, 111.

(29) O’Neill, B. J.; Jackson, D. H. K.; Lee, J.; Canlas, C.; Stair, P. C.; Marshall, C. L.; Elam, J. W.; Kuech, T. F.; Dumesic, J. A.; Huber, G. W. ACS Catal. 2015, 5, 1804.

(30) Zaera, F. Coord. Chem. Rev. 2013, 257, 3177.

(31) Puurunen, R. L. J. Appl. Phys. 2005, 97, 121301.

(32) Zagdoun, A.; Casano, G.; Ouari, O.; Schwarzwälder, M.; Rossini, A. J.; Aussenac, F.; Yulikov, M.; Jeschke, G.; Copéret, C.; Lesage, A.; Tordo, P.; Emsley, L. J. Am. Chem. Soc. 2013, 135, 12790 .
(33) Wisser, D.; Karthikeyan, G.; Lund, A.; Casano, G.; Karoui, H.; Yulikov, M.; Menzildjian, G.; Pinon, A. C.; Purea, A.; Engelke, F.; Chaudhari, S. R.; Kubicki, D.; Rossini, A. J.; Moroz, I. B.; Gajan, D.; Copéret, C.; Jeschke, G.; Lelli, M.; Emsley, L.; Lesage, A.; Ouari, O. J. Am. Chem. Soc. 2018, 140, 13340.

(34) Bartram, M. E.; Michalske, T. A.; Rogers, J. W. J. Phys. Chem. 1991, 95, 4453.

(35) Anwander, R.; Palm, C.; Groeger, O.; Engelhardt, G. Organometallics 1998, 17, 2027.

(36) Rai, V. R.; Vandalon, V.; Agarwal, S. Langmuir 2010, 26, 13732 .

(37) Rose, M.; Niinistö, J.; Endler, I.; Bartha, J. W.; Kücher, P.; Ritala, M. ACS Appl. Mater. Interfaces 2010, 2, 347.

(38) Massiot, D.; Messinger, R. J.; Cadars, S.; Deschamps, M.; Montouillout, V.; Pellerin, N.; Veron, E.; Allix, M.; Florian, P.; Fayon, F. Acc. Chem. Res. 2013, 46, 1975.

(39) Florian, P.; Veron, E.; Green, T. F. G.; Yates, J. R.; Massiot, D. Chem. Mat. 2012, 24, 4068.

(40) Al Saghir, K.; Chenu, S.; Veron, E.; Fayon, F.; Suchomel, M.; Genevois, C.; Porcher, F.; Matzen, G.; Massiot, D.; Allix, M. Chem. Mat. 2015, 27, 508 .

(41) Le Caer, G.; Brand, R. A. J. Phys.-Condens. Matter 1998, 10,10715 .

(42) Massiot, D.; Fayon, F.; Capron, M.; King, I.; Le Calve, S.; Alonso, B.; Durand, J. O.; Bujoli, B.; Gan, Z. H.; Hoatson, G. Magn. Reson. Chem. 2002, 40, 70.

(43) Yon, M.; Fayon, F.; Massiot, D.; Sarou-Kanian, V. Solid State Nucl. Magn. Reson. 2020, 110, 101699.

(44) Cui, J.; Kast, M. G.; Hammann, B. A.; Afriyie, Y.; Woods, K. N.; Plassmeyer, P. N.; Perkins, C. K.; Ma, Z. L.; Keszler, D. A.; Page, C. J.; Boettcher, S. W.; Hayes, S. E. Chem. Mat. 2018, 30, 7456.

(45) Lee, S. K.; Ahn, C. W. Sci. Rep. 2014, 4.

(46) Sarou-Kanian, V.; Gleizes, A. N.; Florian, P.; Samélor, D.; Massiot, D.; Vahlas, C. J. Phys. Chem. C 2013, 117, 21965.

(47) Wang, Z.; Jiang, Y.; Lafon, O.; Trébosc, J.; Duk Kim, K.; Stampfl, C.; Baiker, A.; Amoureux, J.-P.; Huang, J. Nat. Commun. 2016, 7, 13820 .

(48) Hunger, M. Solid State Nucl. Magn. Reson. 1996, 6, 1.

(49) Jiang, Y.; Huang, J.; Dai, W.; Hunger, M. Solid State Nucl. Magn. Reson. 2011, 39, 116.

(50) Schroeder, C.; Siozios, V.; Mück-Lichtenfeld, C.; Hunger, M.; Hansen, M. R.; Koller, H. Chem. Mat. 2020, 32, 1564.

(51) Batista, A. T. F.; Wisser, D.; Pigeon, T.; Gajan, D.; Diehl, F.; Rivallan, M.; Catita, L.; Gay, A. S.; Lesage, A.; Chizallet, C.; Raybaud, P. J. Catal. 2019, 378, 140.

(52) Lippmaa, E.; Magi, M.; Samoson, A.; Tarmak, M.; Engelhardt, G. J. Am. Chem. Soc. 1981, 103, 4992.

(53) Wang, Z. C.; Li, T.; Jiang, Y. J.; Lafon, O.; Liu, Z. W.; Trebosc, J.; Baiker, A.; Amoureux, J. P.; Huang, J. Nat. Commun. 2020, 11, 225.

(54) Zeng, Q.; Nekvasil, H.; Grey, C. P. J. Phys. Chem. B 1999, 103,7406 .

(55) Gunther, W. R.; Michaelis, V. K.; Griffin, R. G.; RománLeshkov, Y. J. Phys. Chem. C 2016, 120, 28533.

(56) Jiang, W.; Lumata, L.; Chen, W.; Zhang, S.; Kovacs, Z.; Sherry, A. D.; Khemtong, C. Sci. Rep. 2015, 5, 9104.

(57) Maciel, G. E.; Haw, J. F.; Chuang, I. S.; Hawkins, B. L.; Early, T. A.; McKay, D. R.; Petrakis, L. J. Am. Chem. Soc. 1983, $105,5529$.

TOC 


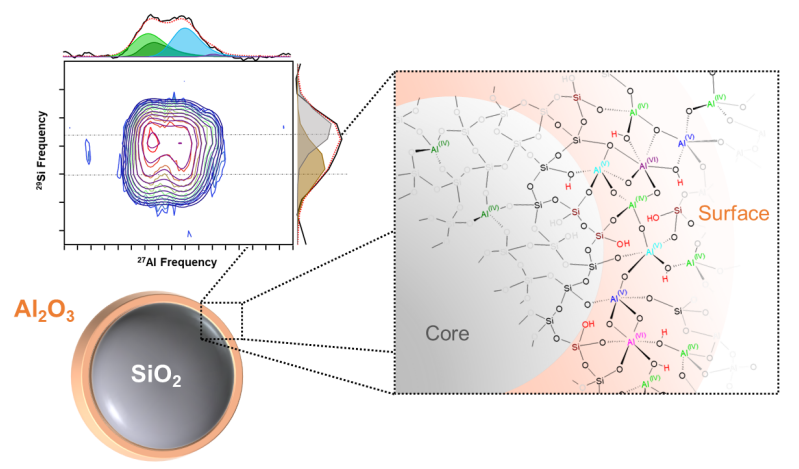


Supplementary Information

\section{Atomic-Scale Structure and its Impact on Chemical Properties of Aluminum Oxide Layers Prepared by Atomic Layer Deposition on Silica}

Monu Kaushikł*, César Leroył*, Zixuan Chen §, David Gajanł, Elena Willinger§, Christoph R. Müller§, Franck Fayon†, Dominique Massiot†, Alexey Fedorov§, Christophe Copéret II, Anne Lesage $\downarrow$, Pierre Florian $\dagger$

† CNRS, CEMHTI UPR3079, Univ. Orléans, F-45071 Orléans, France

‡ Centre de RMN à Très Hauts Champs, Université de Lyon (CNRS/ENS Lyon/UCB Lyon 1), 69100 Villeurbanne, France

$\S$ Department of Mechanical and Process Engineering, ETH Zürich, CH 8092 Zürich, Switzerland

"Department of Chemistry and Applied Biosciences, ETH Zürich, CH 8093 Zürich, Switzerland

* These authors contributed equally

\section{Characterization techniques}

Diffuse reflectance infrared Fourier transform spectroscopy (DRIFTS) was performed on an Alpha II spectrometer (Bruker) operated inside an MBraun glovebox $\left(\mathrm{O}_{2}, \mathrm{H}_{2} \mathrm{O}<1 \mathrm{ppm}\right)$. Atomic layer deposition of trimethylaluminum (TMA, Pegasus Chemicals) onto $\mathrm{SiO}_{2-500}$ using ozone as an oxidant was performed on a Picosun R-200 system enclosed within an MBraun glovebox $\left(\mathrm{O}_{2}, \mathrm{H}_{2} \mathrm{O}<1 \mathrm{ppm}\right)$. $\mathrm{N}_{2}$ (99.999\%) was used as the carrier and purge gas in the ALD experiments. Elemental analysis was performed by the Mikroanalytisches Labor Pascher, Remagen, Germany. Transmission electron microscopy (TEM), scanning transmission electron microscopy (STEM) with high-angle annular dark-field (HAADF) detection, and energy-dispersive X-ray (EDX) spectroscopy were carried out on an FEI Talos F200X transmission electron microscope. A JEOL JEM-ARM300F Grand ARM scanning transmission electron microscope that was operated at $300 \mathrm{kV}$ was also used. The microscope is equipped with a Dual EDS system (two large area SDD EDX detectors with $100 \mathrm{~mm}^{2}$ active area; total solid angle: $1.6 \mathrm{sr}$ ). The specimen for electron microscopy were prepared by dry deposition onto a copper grid with a holey carbon support film. Where indicated, the vacuum-transfer holder (Mel-Build) has been used. The surface area and pore volume of the materials were determined by $\mathrm{N}_{2}$ adsorption/desorption (Quantachrome NOVA 4000e) using the Brunauer-Emmet-Teller (BET) and Barrett-Joyner-Halenda (BJH) models, respectively. ${ }^{1}$ Prior to the measurement, the materials were outgassed at $250{ }^{\circ} \mathrm{C}$ for 2.5 hours. Powder X-ray diffraction (XRD) data were collected on a PANalytical Empyrean X-ray diffractometer equipped with a Bragg-Brentano HD 
mirror and operated at $45 \mathrm{kV}$ and $40 \mathrm{~mA}$ using Cu K $\alpha$ radiation $(\lambda=1.5418 \AA$ ). The materials were examined within the $2 \vartheta$ range of $5-100^{\circ}$ using a step size of $0.0167^{\circ}$. The scan time per step was $5 \mathrm{~s}$.

\section{Materials}

Silica powder (AdValue Technology, 99.9\%) was agglomerated into larger particles by wetting with water that was then evaporated slowly at $120^{\circ} \mathrm{C}$ ( 2 days). Silica agglomerates were sieved to collect a $180-$ $300 \mu \mathrm{m}$ fraction. The sieved support was heated $\left(5^{\circ} \mathrm{C} \mathrm{min}^{-1}\right)$ to and held overnight at $500{ }^{\circ} \mathrm{C}$ in static air, and then dehydroxylated at $500^{\circ} \mathrm{C}$ (ca. $10^{-5} \mathrm{mbar}, 20 \mathrm{~h}$ ). The resulting material, denoted $\mathrm{SiO}_{2-500}$, had a surface area of $374 \mathrm{~m}^{2} \mathrm{~g}^{-1}$ and a pore volume of $2.0 \mathrm{ml} \mathrm{g}^{-1}$ according to $\mathrm{N}_{2}$ physisorption measurements.

1, 5 or 10 ALD cycles were performed at $300{ }^{\circ} \mathrm{C}$ to deposit TMA onto $\mathrm{SiO}_{2-500}(300 \mathrm{mg}$ ). One ALD cycle includes, consecutively, 30 TMA pulses ( $0.4 \mathrm{~s}$ duration) and 20 ozone pulses ( $0.4 \mathrm{~s}$ duration). Each TMA or ozone pulse was followed by a $\mathrm{N}_{2}$ purge ( $15 \mathrm{~s}$ duration). The temperature of the TMA source was $20^{\circ} \mathrm{C}$. As-prepared materials (TMA1-SiO $2-500, \mathrm{TMA}^{-} \mathrm{SiO}_{2-500}$ and $\mathrm{TMA}^{-} \mathrm{T}-\mathrm{SiO}_{2-500}$ ) were calcined in synthetic air $\left(500{ }^{\circ} \mathrm{C}, 5^{\circ} \mathrm{C} \mathrm{min}^{-1}, 50 \mathrm{ml} \mathrm{min}{ }^{-1}, 4 \mathrm{~h}\right)$, which gave $\mathrm{Al1}-\mathrm{SiO}_{2-500}, \mathrm{Al}^{-}-\mathrm{SiO}_{2-500}, \mathrm{Al} 10-\mathrm{SiO}_{2-500}$.

${ }^{15} \mathrm{~N}$-Pyridine (99\% isotopic enrichment) was purchased from CortecNet Corp., dried over $\mathrm{CaH}_{2}$ at $60{ }^{\circ} \mathrm{C}$ overnight and degassed prior to use. Adsorption of pyridine on the calcined materials (ca. $100 \mathrm{mg}$ ) was performed in a glass reactor by exposing $\mathrm{Al}_{-} \mathrm{SiO}_{2-500}$ to ${ }^{15} \mathrm{~N}$-pyridine vapor at room temperature for ca. $1 \mathrm{~min}$. The excess of ${ }^{15} \mathrm{~N}$-pyridine was then removed at high vacuum at $150{ }^{\circ} \mathrm{C}$ (ca. $10^{-5} \mathrm{mbar}, 2 \mathrm{~h}$ ). All materials were prepared, stored, handled and characterized without exposure to air, using $\mathrm{N}_{2}$-filled gloveboxes (MBraun, $\mathrm{O}_{2}, \mathrm{H}_{2} \mathrm{O}<1 \mathrm{ppm}$ ).
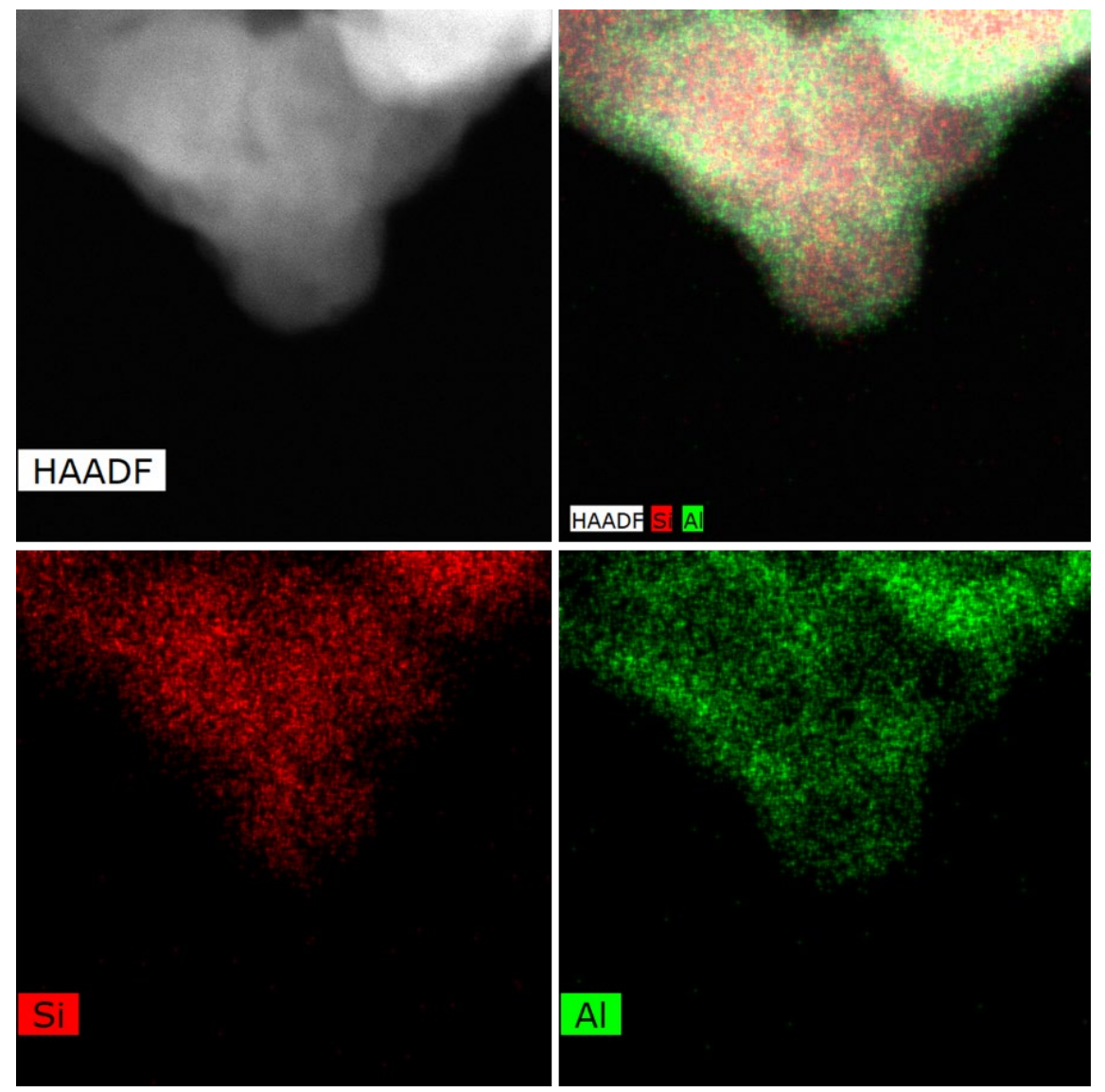


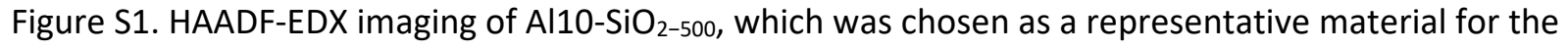
Al-SiO $2-500$ series.
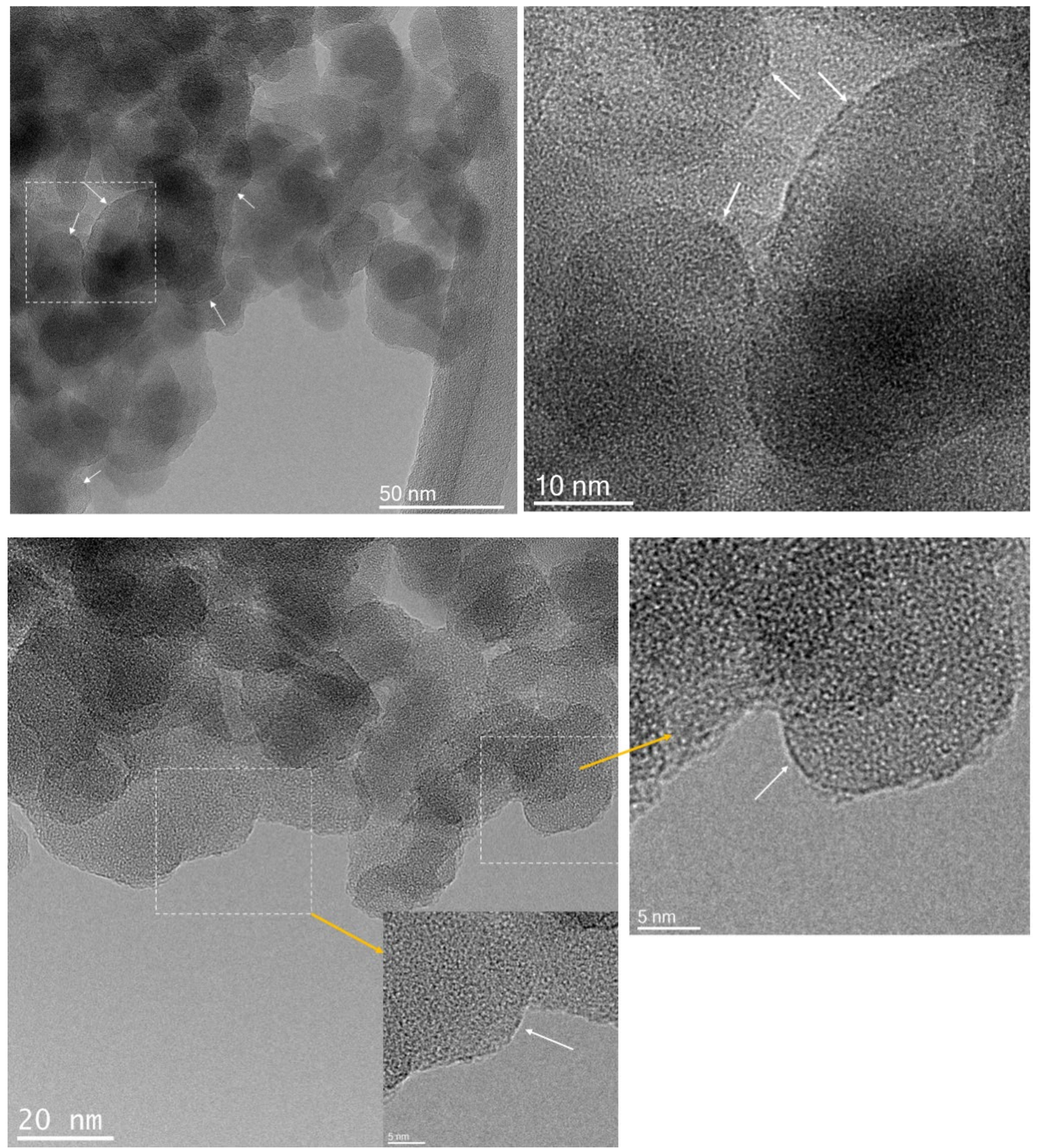

Figure S2. Representative images of a control HRTEM experiment in which Al5-SiO $2-500$ was handled using an air-tight TEM sample transfer holder. White arrows indicate ALD-grown coatings. 

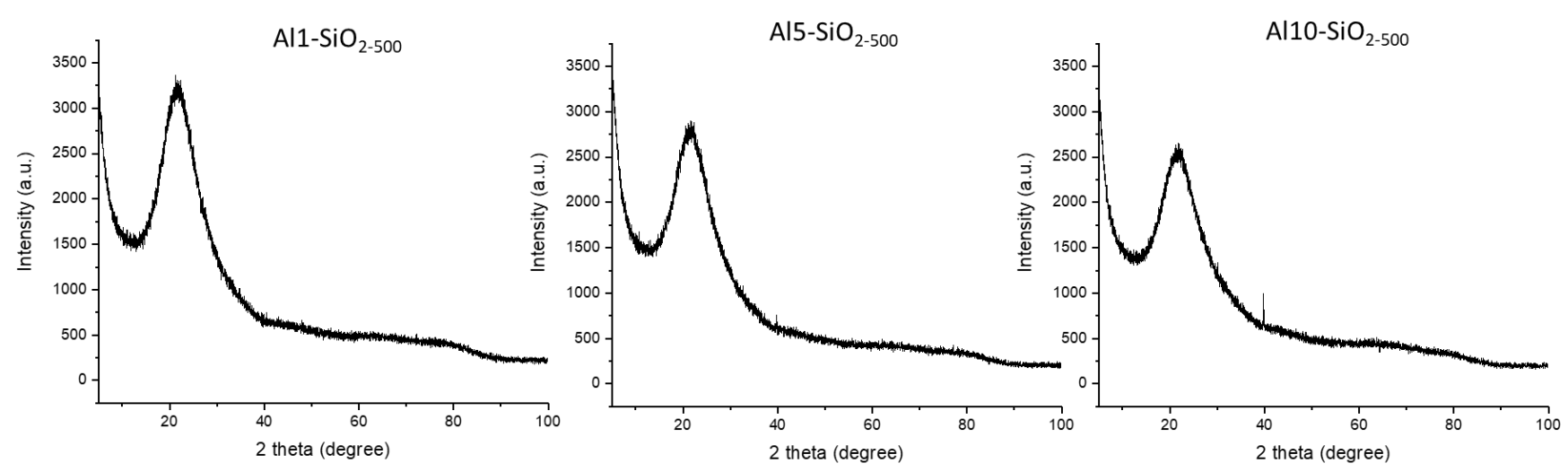

Figure S3. XRD patterns of Al1, 5, 10-SiO $2-500$ materials.
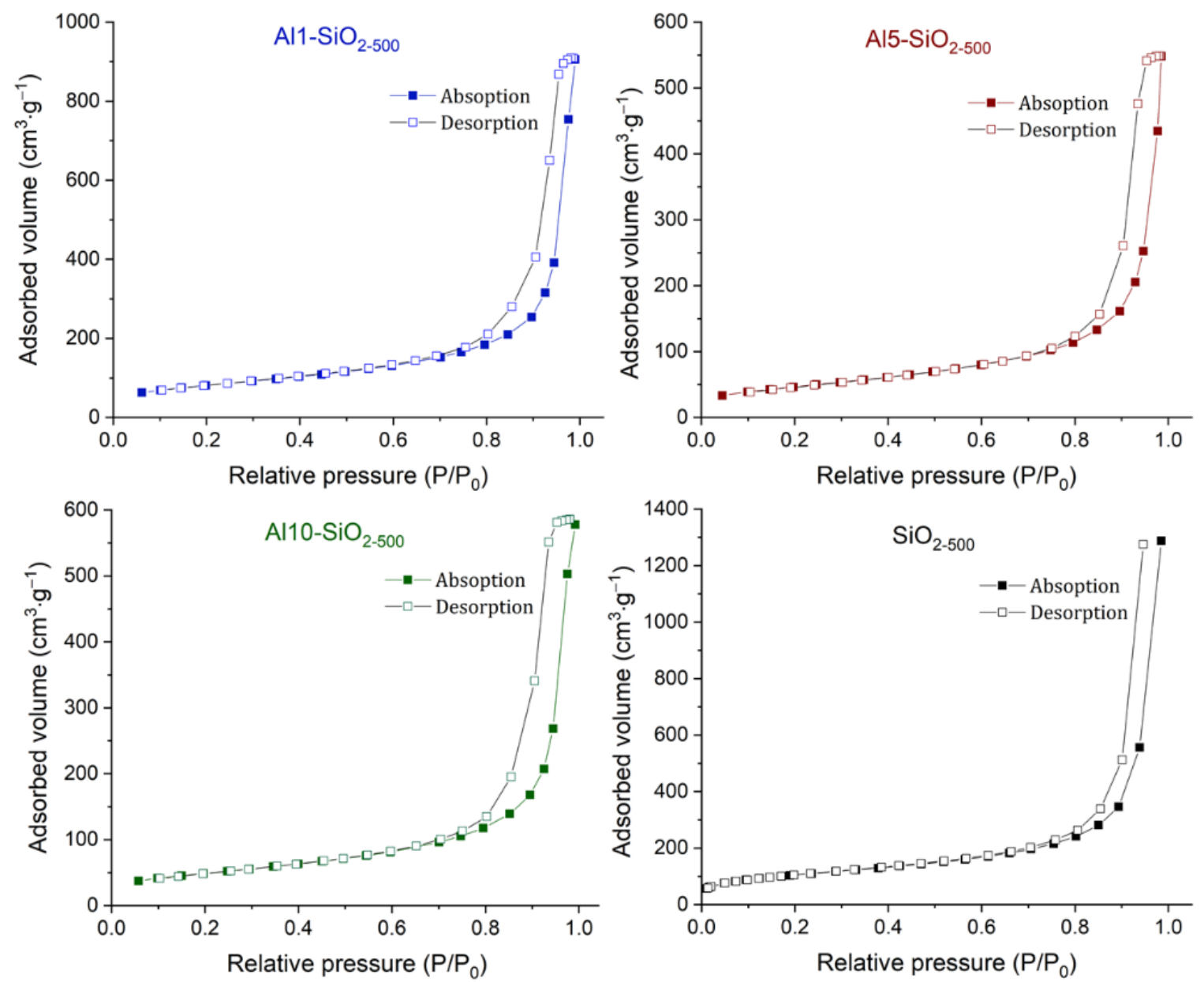

Figure S4. $\mathrm{N}_{2}$ adsorption and desorption isotherms of $\mathrm{Al} 1,5,10-\mathrm{SiO}_{2-500}$ and $\mathrm{SiO}_{2-500}$ materials. 

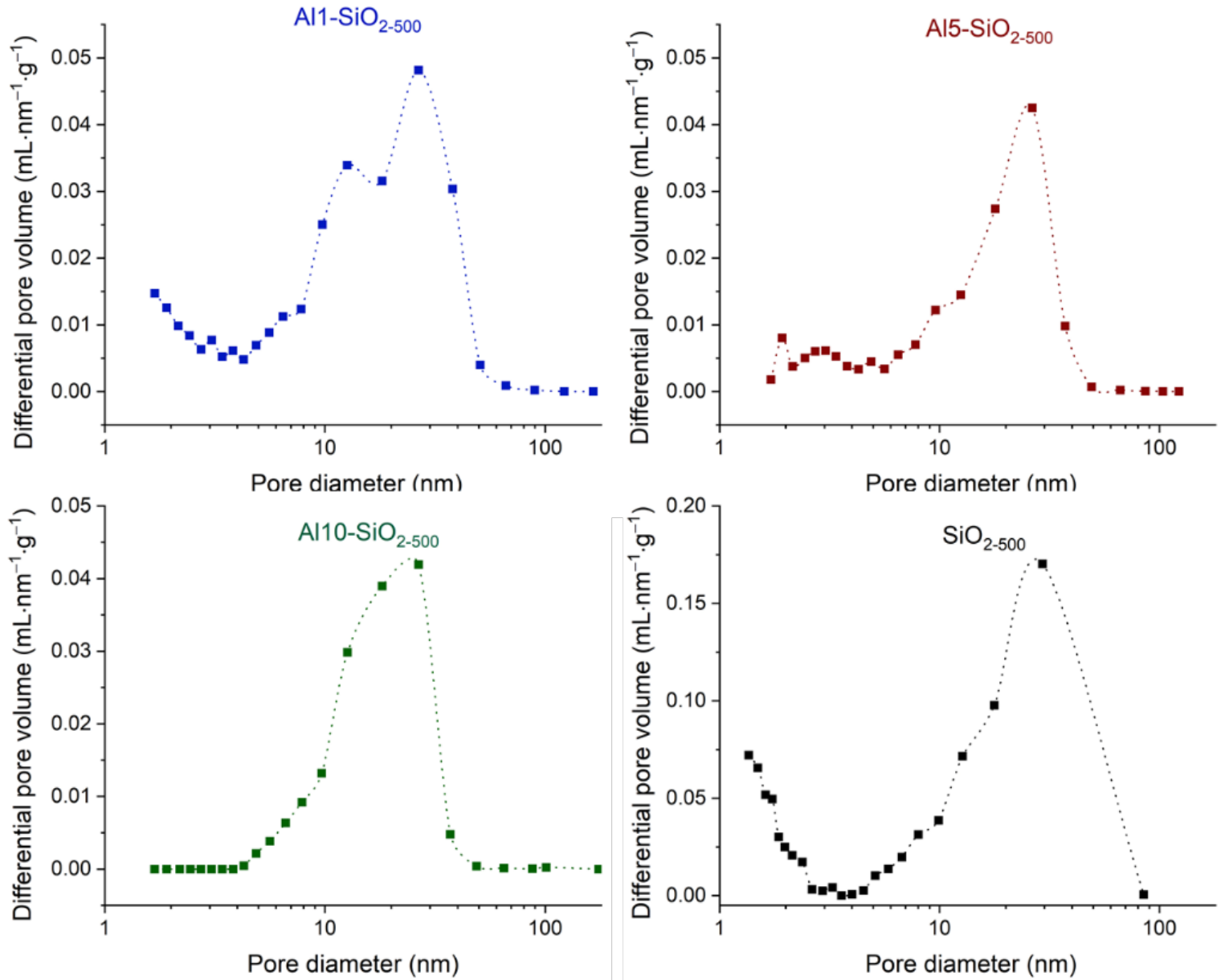

Figure S5. BJH pore size distribution of $\mathrm{Al} 1,5,10-\mathrm{SiO}_{2-500}$, and $\mathrm{SiO}_{2-500}$ materials obtained from $\mathrm{N}_{2}$ isotherms (Figure S4).

Table S1. BET surface area, pore volume and pore diameter for $\mathrm{SiO}_{2-500}$ and $\mathrm{Al} 1,5,10-\mathrm{SiO}_{2-500}$ materials.

\begin{tabular}{cccc}
\hline Materials & $\begin{array}{c}\text { BET surface area } \\
\left(\mathrm{m}^{2} \mathrm{~g}^{-1}\right)\end{array}$ & $\begin{array}{c}\text { Pore volume } \\
\left(\mathrm{cm}^{3} \mathrm{~g}^{-1}\right)\end{array}$ & $\begin{array}{c}\text { Pore diameter } \\
(\mathrm{nm})\end{array}$ \\
\hline $\mathrm{SiO}_{2-500}$ & 374 & 2.0 & 29.4 \\
$\mathrm{~A} 11-\mathrm{SiO}_{2-500}$ & 287 & 1.4 & 26.6 \\
$\mathrm{~A} 15-\mathrm{SiO}_{2-500}$ & 168 & 0.9 & 26.4 \\
$\mathrm{~A} 110-\mathrm{SiO}_{2-500}$ & 173 & 0.9 & 26.6 \\
\hline
\end{tabular}

Appearance of crystalline areas. On Al5 and $\mathrm{Al} 10-\mathrm{SiO}_{2-500}$, areas can be found where few crystalline planes form a zigzag coating on a silica surface (Figure $1 \mathrm{f}$ and Figure S2). That being said, the zigzag coating does not appear on every silica grain, and a smooth coating (i.e. a coating following the curvature of silica grains) is a more abundant morphology of the ALD-deposited coatings. Consistent with the TEM analysis, the 
observed nanocrystalline zigzag pattern does not provide XRD peaks, as all three prepared $\mathrm{Al}-\mathrm{SiO}_{2-500}$ materials are amorphous by XRD (Figure S3). However, a careful survey of selected area electron diffraction (SAED) data of Al10-SiO $2-500$ material reveals that, although rarely, this local method can resolve one set of planes corresponding to a d-spacing of ca. $1.96 \AA \pm 0.05 \AA$ (inset, Figure $1 \mathrm{f}$ ). This value of $d_{h k l}$ corresponds to the most intense reflection expected for corundum $\alpha-\mathrm{Al}_{2} \mathrm{O}_{3}\left(\mathrm{~d}_{-2,2,2}=1.9641 \AA\right.$ ) but also to a significant reflection of transition alumina $\gamma-\mathrm{Al}_{2} \mathrm{O}_{3}\left(\mathrm{~d}_{0,0,4}=1.9677 \AA\right)$ and kyanite $\mathrm{Al}_{2} \mathrm{Si}_{2} \mathrm{O}_{5}\left(\mathrm{~d}_{-1,4,0}=1.9630\right.$, but this compound is expect to form at high pressure). It can also be found in gibbsite $\mathrm{Al}(\mathrm{OH})_{3}$ and other $\mathrm{Al}_{2} \mathrm{Si}_{2} \mathrm{O}_{5}$ polymorphs (andalusite and sillimanite) but with very small intensities. Although a form of alumina seems to be a good candidate, with only one measured $d_{h k l}$ value (other observed crystalline zones were too small to diffract) this cannot be confirmed.

In a control HRTEM experiment, $\mathrm{Al5}-\mathrm{SiO}_{2-500}$ was evaluated using an air-tight TEM sample transfer holder, i.e. without exposing this material to air (Figure S2). Images of the surface layer obtained were not distinguishable from that in Figure 1e. This result confirms that the Al-containing coating layer does not restructure or crystallize during the time scale of a TEM experiment upon exposure to ambient air during specimen handling. Interestingly, the post-deposition crystallization of $\mathrm{Al}_{2} \mathrm{O}_{3}$ films with thicknesses comparable to that found in $\mathrm{Al} 5$ - and $\mathrm{Al} 10-\mathrm{SiO}_{2-500}$ materials requires high temperatures $\left(\mathrm{ca} .900{ }^{\circ} \mathrm{C}\right.$ ), which exceed significantly the calcination temperature used in this work $\left(500{ }^{\circ} \mathrm{C}\right) .{ }^{2}$ This suggests that the nanocrystalline zigzag structures likely have formed already in the as-deposited $\mathrm{TMA}^{-} \mathrm{SiO}_{2-500}$ and TMA10-SiO $2-500$. Yet the deposition of crystalline $\mathrm{Al}_{2} \mathrm{O}_{3}$ coatings is typical for high temperature ALD recipes (above $600{ }^{\circ} \mathrm{C}$ ) that use $\mathrm{AlCl}_{3}$ precursor. ${ }^{2}$ Thus, formation of nanocrystalline zigzag structures observed in this work in Al5- and $\mathrm{Al} 10-\mathrm{SiO}_{2-500}$ materials, prepared at relatively low temperatures, is unexpected and likely due to the use of dehydroxylated silica. 
NMR Room Temperature Spectroscopy. Direct excitation Hahn echo ${ }^{27} \mathrm{Al}$ NMR spectra were acquired using an Avance III standard bore 23.5 T Bruker spectrometer. All samples were packed in a $2.5 \mathrm{~mm}$ zirconia rotor inside an argon-filled glovebox. The rotor was spun at $33.3 \mathrm{kHz}$ under pure nitrogen gas. ${ }^{27} \mathrm{Al}$ chemical shift is referenced to a nitric $1 \mathrm{M}$ solution of $\mathrm{Al}\left(\mathrm{NO}_{3}\right)_{3}$ while ${ }^{1} \mathrm{H}$ and ${ }^{29} \mathrm{Si}$ positions are referenced to tetramethylsilane. Double-frequency sweep (DFS) has been used in all experiments with ${ }^{27} \mathrm{Al}$ detection, except for the quantitative 1 pulse, with a $1 \mathrm{~ms}$ double sweep ranging from $1 \mathrm{MHz}$ down to $200 \mathrm{kHz}$ and a radio-frequency amplitude of $40 \mathrm{kHz}$.

Table S2. Details of the experimental parameters used for room-temperature NMR studies in this work.

\begin{tabular}{|c|c|c|c|c|c|c|c|c|c|c|c|}
\hline $\operatorname{Exp}^{t}$ & nuclei & $\begin{array}{c}\text { Field } \\
(T)\end{array}$ & $\begin{array}{l}\emptyset_{\text {rotor }} \\
(\mathrm{mm})\end{array}$ & $\begin{array}{c}v_{r} \\
(\mathrm{kHz})\end{array}$ & $\begin{array}{l}\text { rcycl } \\
\text { (s) }\end{array}$ & $\begin{array}{c}\text { \# scans } \\
(\times 1000)\end{array}$ & $\begin{array}{l}\text { \# echos } \\
/ \tau(\mathrm{ms})\end{array}$ & $\begin{array}{c}v_{\mathrm{rf}} \\
(\mathrm{kHz})\end{array}$ & $\begin{array}{c}\text { pulses } \\
(\mu \mathrm{s})\end{array}$ & $\begin{array}{l}\Delta \mathrm{t}_{1} \\
(\mu \mathrm{s})\end{array}$ & $\# t_{1}$ \\
\hline \multirow{6}{*}{$\begin{array}{l}1 \text { pulse } \\
\text { Hahn echo } \\
\text { MQMAS } \\
\text { CPMG } \\
\text { CP-CPMG }\end{array}$} & ${ }^{27} \mathrm{Al}$ & 20.0 & 2.5 & 33.3 & 0.05 & $65-430$ & & 50 & 0.5 & & \\
\hline & ${ }^{27} \mathrm{Al}$ & 20.0 & 2.5 & 33.3 & 0.5 & 8 & & 50 & 1.67 & & \\
\hline & ${ }^{27} \mathrm{Al}$ & 20.0 & 2.5 & 33.3 & 0.5 & $2-8$ & & $140 / 25$ & $3.5,1.25 / 4.17$ & 30.0 & 24 \\
\hline & ${ }^{29} \mathrm{Si}$ & 9.4 & 4.0 & 10.0 & 900 & 0.1 & $512 / 8.0$ & 28.6 & $8.75,17.5$ & & \\
\hline & ${ }^{29} \mathrm{Si}$ & 9.4 & 4.0 & 10.0 & 1.0 & 2 & $512 / 8.0$ & 28.6 & $8.75,17.5 / 500$ & & \\
\hline & ${ }^{1} \mathrm{H}$ & & & & & & & 50.0 & 5.0 & 200 & 24 \\
\hline \multirow[t]{2}{*}{$D-H M Q C$} & ${ }^{27} \mathrm{Al}$ & 20.0 & 2.5 & 30.0 & 1.0 & $2-6$ & & 50 & 1.67 & & \\
\hline & ${ }^{1} \mathrm{H}$ & & & & & & & $130 / 60$ & $1.95 / 400$ & 33.3 & 32 \\
\hline \multirow[t]{2}{*}{$D-H M Q C$} & ${ }^{27} \mathrm{Al}$ & 20.0 & 3.2 & 15.0 & 0.5 & $10-15$ & & 20 & 4.17 & & \\
\hline & ${ }^{29} \mathrm{Si}$ & & & & & & & $26 / 30$ & $9.5 / 6400$ & 33.3 & 22 \\
\hline$D Q / S Q$ & ${ }^{27} \mathrm{Al}$ & 20.0 & 2.5 & 33.3 & 0.3 & $11-70$ & & $20 / 16.7$ & $4.2 / 480$ & 30.0 & 20 \\
\hline
\end{tabular}

DNP NMR at 9.4 T and 18.8 T. DNP experiments were performed at CRMN Lyon on Bruker Avance III wide bore spectrometers, operating at $9.4 \mathrm{~T}$ and $18.8 \mathrm{~T}$, and equipped with triple resonance $1.3 \mathrm{~mm}$ and 3.2 $\mathrm{mm}$ low-temperature MAS probes in either $\mathrm{H} / \mathrm{C} / \mathrm{N}$ or $\mathrm{H} / \mathrm{Al} / \mathrm{Si}$ configuration. Cross-effect DNP was achieved by irradiation with high-power microwaves at frequencies of $263 \mathrm{GHz}$ (for $9.4 \mathrm{~T}$ ) and $527 \mathrm{GHz}$ (for $18.8 \mathrm{~T}$ ) generated by gyrotrons operating continuously during the DNP experiments (stability higher than $\pm 1 \%$ ). A microwave power of $40 \mathrm{~W}$ was used at $9.4 \mathrm{~T}$, and $22 \mathrm{~W}$ at $18.8 \mathrm{~T}$, both measured at the bottom of the probe. A triple-resonance probe in $\mathrm{H} / \mathrm{C} / \mathrm{N}$ configuration was used. The ${ }^{27} \mathrm{Al}$ chemical shifts are referenced to $0 \mathrm{ppm}$ for a solution of $\mathrm{Al}\left(\mathrm{NO}_{3}\right)_{3}$ in $\mathrm{HNO}_{3},{ }^{29} \mathrm{Si}$ chemical shifts are referenced to tetramethylsilane, while ${ }^{15} \mathrm{~N}$ chemical shifts are referenced externally by calibrating the chemical shift of $\mathrm{NH}_{4} \mathrm{Cl}$ to $59.3 \mathrm{ppm}$ with respect to $\mathrm{NH}_{3}$.

Py-Al-SiO $2-500$ series. The materials were packed in an argon-filled glove box, with tetrachlororethane (TCE) as the impregnating solvent with either $16 \mathrm{mM}$ TEKPol (for 9.4 T) or $16 \mathrm{mM}$ HyTEK2 (for $18.8 \mathrm{~T}$ ) radical. Once removed from the glove box, the packed rotor was immediately inserted into a low-temperature DNP probe pre-cooled to $105 \mathrm{~K}$. For the ${ }^{27} \mathrm{Al}$ experiments, the $1.3 \mathrm{~mm}$ rotor was spun at the maximum spinning rate of 39 or $40 \mathrm{kHz}$. DR-INEPT (with SRS4 ${ }_{1}{ }_{1}$ recoupling) and CP experiments were optimized on impregnated $\gamma-\mathrm{Al}_{2} \mathrm{O}_{3}$ under the same conditions. Enhancements and DNP buildup times were recorded for each sample. ${ }^{1} \mathrm{H}-{ }^{15} \mathrm{~N} \mathrm{CP}$ experiments were performed with a spinning rate of $12 \mathrm{kHz}$ and a contact time of $4 \mathrm{~ms}$.

${ }^{29} \mathrm{Si}$ DNP NMR. Al-SiO $2-500$ samples were impregnated with a $16 \mathrm{mM}$ TEKPol solution in TCE. Under DNP conditions, i.e., when the samples are exposed to microwave irradiation at $100 \mathrm{~K}$, polarization transfer takes place. First, hyperpolarized unpaired electrons in the radical spread polarization to adjacent nuclei 
such as abundant protons. This enhanced polarization is transferred to ${ }^{29} \mathrm{Si}$ by $\mathrm{CP}$, which is possible by direct ${ }^{1} \mathrm{H}$ to ${ }^{29} \mathrm{Si}$ transfer if the solvent and silica core are in contact. This is probably true for $\mathrm{Al} 1-\mathrm{SiO}_{2-500}$. After 5 and 10 ALD cycles, a layer of aluminum oxide is present between the polarizing solvent and the silica core. The fact that enhanced polarization is still transferred to ${ }^{29} \mathrm{Si}$ in $\mathrm{Al} 10-\mathrm{SiO}_{2-500}$ suggests that the polarization is relayed through the aluminum oxide layer by the proton network assisted spin-diffusion. A signal enhancement of $>20$ is observed for all samples via ${ }^{1} \mathrm{H}-{ }^{29} \mathrm{Si} \mathrm{CP}$. If protons were localized in the vicinity of ${ }^{29} \mathrm{Si}$, the intensity of the $\mathrm{CP}$ signal would remain unchanged upon microwave irradiation.

${ }^{27} \mathrm{Al}$ DNP NMR. The surfaces of materials onto which pyridine adsorbed contain ${ }^{27} \mathrm{Al}$ sites as well as the ${ }^{15} \mathrm{~N}$ probe nuclei from the adsorbed ${ }^{15} \mathrm{~N}$-labelled pyridine. Both of these species can be detected by using appropriate proton to $X$ nuclei polarization transfer pulse sequences. DNP samples were prepared by incipient wetness impregnation with the best performing radicals at each field, i.e., $16 \mathrm{mM}$ TEKPol for 9.4 T, and HyTEK2 for $18.8 \mathrm{~T}$ in TCE. DNP enhanced ${ }^{27} \mathrm{Al}$ NMR spectra were also recorded at a high magnetic field. An INEPT-based transfer was implemented, as it has been recently shown to provide an enhanced sensitivity over CP transfer without causing lineshape distortions. ${ }^{3}$ Moreover, ${ }^{27} \mathrm{Al}$ spectra were recorded at a higher magnetic field using both pulse sequences to obtain a better resolution. However, due to broad quadrupolar interaction and its anisotropic nature, it is not possible to resolve each ${ }^{27} \mathrm{Al}$ site even at 18.8 T. 

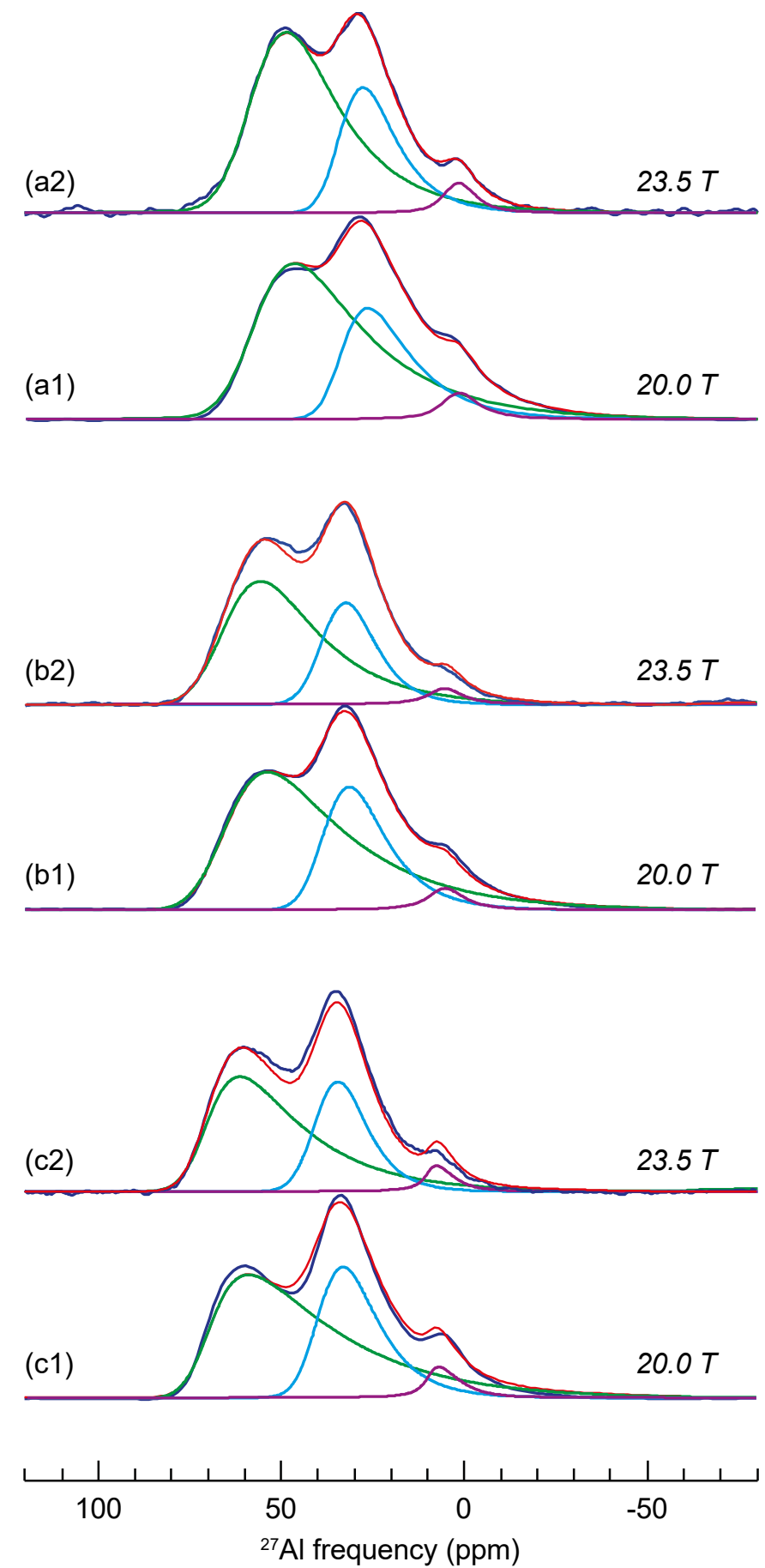

Figure S6. 1D ${ }^{27} \mathrm{Al}$ full Hahn-Echo experiments performed at 20.0 T and 23.5 T on (a) Al10-SiO $2-500$, (b) Al5$\mathrm{SiO}_{2-500}$ and (c) Al1-SiO $2-500$. Experiments are displayed in blue, simulation in red and the individual components for ${ }^{[4]} \mathrm{Al},{ }^{[5]} \mathrm{A}$, and ${ }^{[6]} \mathrm{Al}$ sites are in green, blue and purple, respectively. Simulations are performed simultaneously on both fields assuming three GIM components. 


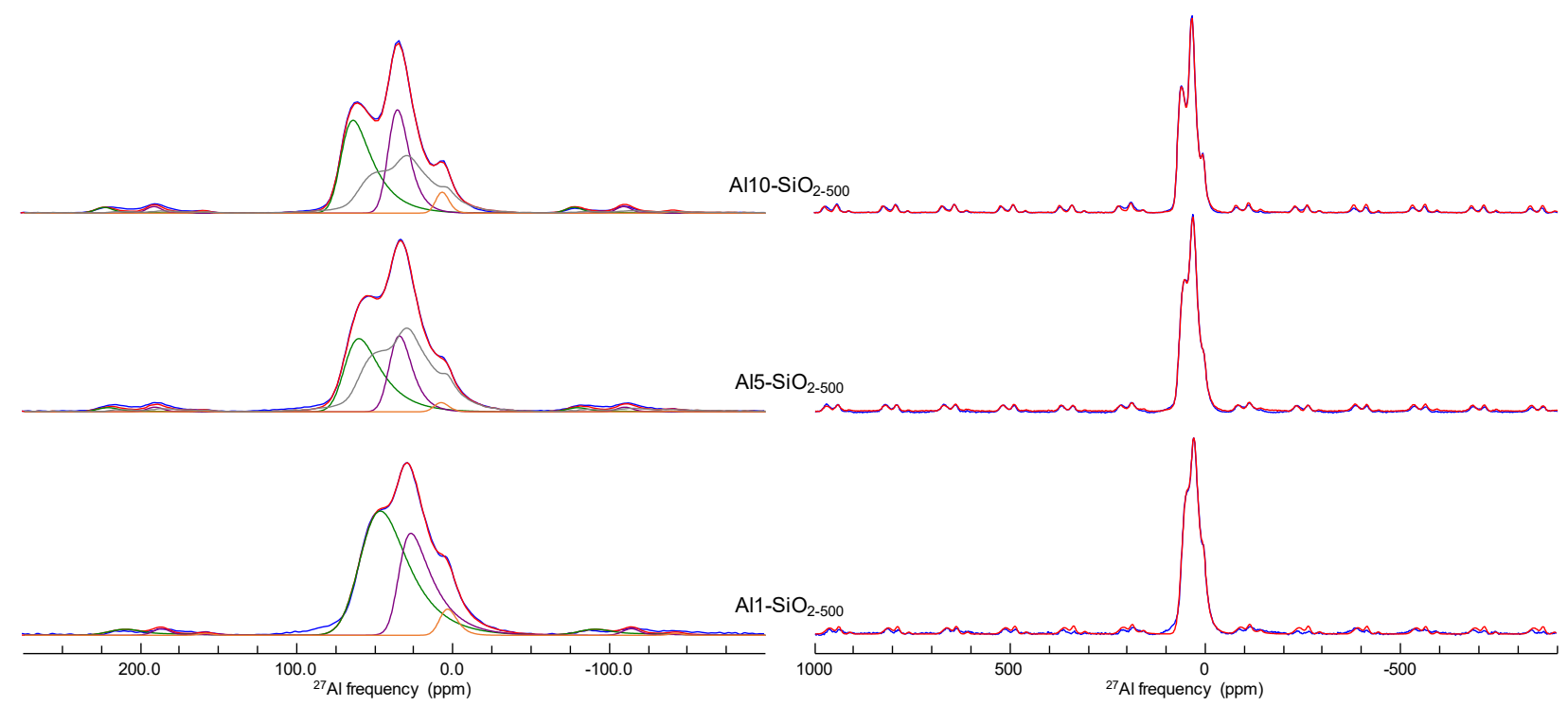

Figure S7. 1D ${ }^{27} \mathrm{Al}$ quantitative one-pulse MAS experiments performed at $20.0 \mathrm{~T}$ on $\mathrm{Al} 10-\mathrm{SiO}_{2-500}$ (top), Al5$\mathrm{SiO}_{2-500}$ (middle) and Al1-SiO 2-500 (bottom). Experiments are displayed in blue, simulation in red and the individual components for ${ }^{[4]} \mathrm{Al},{ }^{[5]} \mathrm{Al}$ and ${ }^{[6]} \mathrm{Al}$ (orange) sites are in green, purple and orange respectively. The additional grey line is the experimental spectra of Al1-SiO2-500 used as a fourth component in the simulation.

Table S3. NMR parameters derived from the simulation of the quantitative one-pulse and Hahn echo experiments at $20.0 \mathrm{~T}$. For $\mathrm{Al} 1-\mathrm{SiO}_{2-500}$, the Hahn Echo spectrum simulation is performed simultaneously at 20.0 T and $23.5 \mathrm{~T}$.

\begin{tabular}{|c|c|c|c|c|c|c|c|c|c|c|}
\hline & \multicolumn{5}{|c|}{ Quantitative 1 pulse } & \multicolumn{5}{|c|}{ Hahn Echo } \\
\hline site & $\%$ & $\begin{array}{c}\bar{\delta}_{i s o} \\
\text { (ppm) }\end{array}$ & $\begin{array}{c}\Delta \delta_{i s o} \\
(\mathrm{ppm})\end{array}$ & $\begin{array}{l}\Delta v_{1 / 2} \\
(\mathrm{kHz})\end{array}$ & $\begin{array}{c}\bar{C}_{Q} \\
(\mathrm{MHz})\end{array}$ & $\%$ & $\begin{array}{c}\bar{\delta}_{i s o} \\
\text { (ppm) }\end{array}$ & $\begin{array}{l}\Delta \delta_{i s o} \\
(\mathrm{ppm})\end{array}$ & $\begin{array}{l}\Delta v_{1 / 2} \\
(\mathrm{kHz})\end{array}$ & $\begin{array}{c}\bar{C}_{Q} \\
(\mathrm{MHz})\end{array}$ \\
\hline \multicolumn{11}{|c|}{$\mathrm{Al}_{1-\mathrm{SiO}_{2-500}}$} \\
\hline${ }^{[4]} \mathrm{Al}$ & 60 & 58.9 & 22.5 & & 12.0 & 67 & 58.7 & 16.3 & & 12.7 \\
\hline${ }^{[5]} \mathrm{Al}$ & 35 & 35.3 & 10.9 & & 10.9 & 29 & 34.1 & 11.2 & & 10.0 \\
\hline${ }^{[6]} \mathrm{Al}$ & 5 & 7.3 & 9.9 & & 6.21 & 4 & 2.5 & 6.50 & 5.37 & 4.08 \\
\hline \multicolumn{11}{|c|}{ Al5-SiO $2-500$} \\
\hline${ }^{[4]} \mathrm{Al}$ & 29 & 69.7 & 14.6 & & 11.0 & 27 & 69.4 & 12.0 & & 10.9 \\
\hline${ }^{[5]} \mathrm{Al}$ & 19 & 39.9 & 11.8 & & 7.67 & 17 & 39.1 & 10.2 & & 7.85 \\
\hline${ }^{[6]} \mathrm{Al}$ & 1 & 10.2 & 9.4 & & 4.84 & 2 & 9.5 & 8.2 & & 5.34 \\
\hline Al1 & 51 & & & & & 54 & & & & \\
\hline \multicolumn{11}{|c|}{ Al10-SiO $2-500$} \\
\hline${ }^{[4]} \mathrm{Al}$ & 35 & 72.1 & 11.8 & & 10.5 & 31 & 71.2 & 11.5 & & 9.38 \\
\hline${ }^{[5]} \mathrm{Al}$ & 25 & 40.6 & 10.8 & & 7.39 & 23 & 40.0 & 9.8 & & 7.47 \\
\hline${ }^{[6]} \mathrm{Al}$ & 3 & 9.7 & 8.12 & & 4.97 & 4 & 9.6 & 8.0 & & 5.57 \\
\hline Al1 & 37 & & & & & 43 & & & & \\
\hline
\end{tabular}


Table S4. Calculated errors of the NMR parameters, derived by DMFit during the fitting procedure.

\begin{tabular}{|c|c|c|c|c|c|c|c|c|c|c|}
\hline & \multicolumn{5}{|c|}{ Quantitative 1 pulse } & \multicolumn{5}{|c|}{ Hahn Echo } \\
\hline site & $\%$ & $\begin{array}{c}\bar{\delta}_{\text {iso }} \\
(\mathrm{ppm})\end{array}$ & $\begin{array}{l}\Delta \delta_{\text {iso }} \\
(\mathrm{ppm})\end{array}$ & $\begin{array}{l}\Delta v_{1 / 2} \\
(\mathrm{kHz})\end{array}$ & $\begin{array}{c}\bar{C}_{Q} \\
(\mathrm{MHz})\end{array}$ & $\%$ & $\begin{array}{c}\bar{\delta}_{\text {iso }} \\
(\mathrm{ppm})\end{array}$ & $\begin{array}{l}\Delta \delta_{\text {iso }} \\
(\mathrm{ppm})\end{array}$ & $\begin{array}{l}\Delta v_{1 / 2} \\
(\mathrm{kHz})\end{array}$ & $\begin{array}{c}\bar{C}_{Q} \\
(\mathrm{MHz})\end{array}$ \\
\hline \multicolumn{11}{|c|}{ Al1-SiO $2-500$} \\
\hline${ }^{[4]} \mathrm{Al}$ & & 0.4 & 0.11 & & 0.40 & 1.0 & 0.13 & 0.23 & & 0.13 \\
\hline${ }^{[5]} \mathrm{Al}$ & & 0.2 & 0.09 & & 0.24 & 5.1 & 0.06 & 0.23 & & 0.07 \\
\hline${ }^{[6]} \mathrm{Al}$ & & 0.5 & 0.20 & & 0.48 & 1.8 & 0.22 & 0.88 & 17.0 & 0.28 \\
\hline \multicolumn{11}{|c|}{ Al5-SiO $2-500$} \\
\hline${ }^{[4]} \mathrm{Al}$ & & 0.2 & 0.07 & & 0.33 & 0.6 & 0.09 & & 0.18 & 0.10 \\
\hline${ }^{[5]} \mathrm{Al}$ & & 0.1 & 0.06 & & 0.16 & 0.4 & 0.11 & & 0.21 & 0.10 \\
\hline${ }^{[6]} \mathrm{Al}$ & & 0.9 & 0.29 & & 0.95 & 0.2 & 0.39 & & 0.58 & 0.37 \\
\hline \multicolumn{11}{|l|}{ Al1 } \\
\hline \multicolumn{11}{|c|}{ Al10-SiO $2-500$} \\
\hline${ }^{[4]} \mathrm{Al}$ & & 0.2 & 0.07 & & 0.26 & 1.4 & 0.18 & & 0.42 & 0.22 \\
\hline${ }^{[5]} \mathrm{Al}$ & & 0.1 & 0.05 & & 0.17 & 0.7 & 0.22 & & 0.39 & 0.19 \\
\hline${ }^{[6]} \mathrm{Al}$ & & 0.5 & 0.17 & & 0.58 & 0.6 & 0.53 & & 1.31 & 0.48 \\
\hline Al1 & & & & & & & & & & \\
\hline
\end{tabular}

Table S5. NMR parameters derived from the simulation of the two-dimensional ${ }^{27} \mathrm{Al} 3 \mathrm{QMAS}$ experiments performed on Al10-SiO $2-500$ (at 20.0 T and 23.5 T), Al5-SiO 2-500 and Al1-SiO 2-500.

\begin{tabular}{|c|c|c|c|c|c|c|c|c|}
\hline \multirow[t]{2}{*}{ site } & $\%$ & $\begin{array}{c}\bar{\delta}_{i s o} \\
(\mathrm{ppm})\end{array}$ & $\begin{array}{c}\Delta \delta_{\text {iso }} \\
(\mathrm{ppm})\end{array}$ & $\begin{array}{c}\bar{C}_{Q} \\
(\mathrm{MHz})\end{array}$ & $\%$ & $\begin{array}{c}\bar{\delta}_{\text {iso }} \\
(\mathrm{ppm})\end{array}$ & $\begin{array}{c}\Delta \delta_{\text {iso }} \\
(\mathrm{ppm})\end{array}$ & $\begin{array}{c}\bar{C}_{Q} \\
(\mathrm{MHz})\end{array}$ \\
\hline & \multicolumn{4}{|c|}{$20.0 \mathrm{~T}$} & \multicolumn{4}{|c|}{$23.5 \mathrm{~T}$} \\
\hline \multicolumn{9}{|c|}{ Al1-SiO $2-500$} \\
\hline${ }^{[4]} \mathrm{Al}$ & 56 & 61.8 & 11.1 & 11.65 & & & & \\
\hline${ }^{[5]} \mathrm{Al}$ & 36 & 33.5 & 10.7 & 7.07 & & & & \\
\hline${ }^{[6]} \mathrm{Al}$ & 8 & 4.8 & 5.6 & 5.59 & & & & \\
\hline \multicolumn{9}{|c|}{ Al5-SiO ${ }_{2-500}$} \\
\hline${ }^{[4]} \mathrm{Al}$ & 47 & 67.2 & 11.9 & 9.4 & & & & \\
\hline${ }^{[5]} \mathrm{Al}$ & 46 & 37.2 & 9.6 & 7.3 & & & & \\
\hline${ }^{[6]} \mathrm{Al}$ & 8 & 6.5 & 8.6 & 4.5 & & & & \\
\hline \multicolumn{9}{|c|}{ Al10-SiO $2-500$} \\
\hline${ }^{[4]} \mathrm{Al}$ & 42 & 70.7 & 13.7 & 8.4 & 45 & 69.4 & 12.6 & 8.2 \\
\hline${ }^{[5]} \mathrm{Al}$ & 48 & 39.6 & 10.7 & 7.2 & 48 & 39.8 & 11.9 & 7.5 \\
\hline${ }^{[6]} \mathrm{Al}$ & 10 & 8.0 & 9.6 & 4.6 & 7 & 9.0 & 9.9 & 5.7 \\
\hline
\end{tabular}



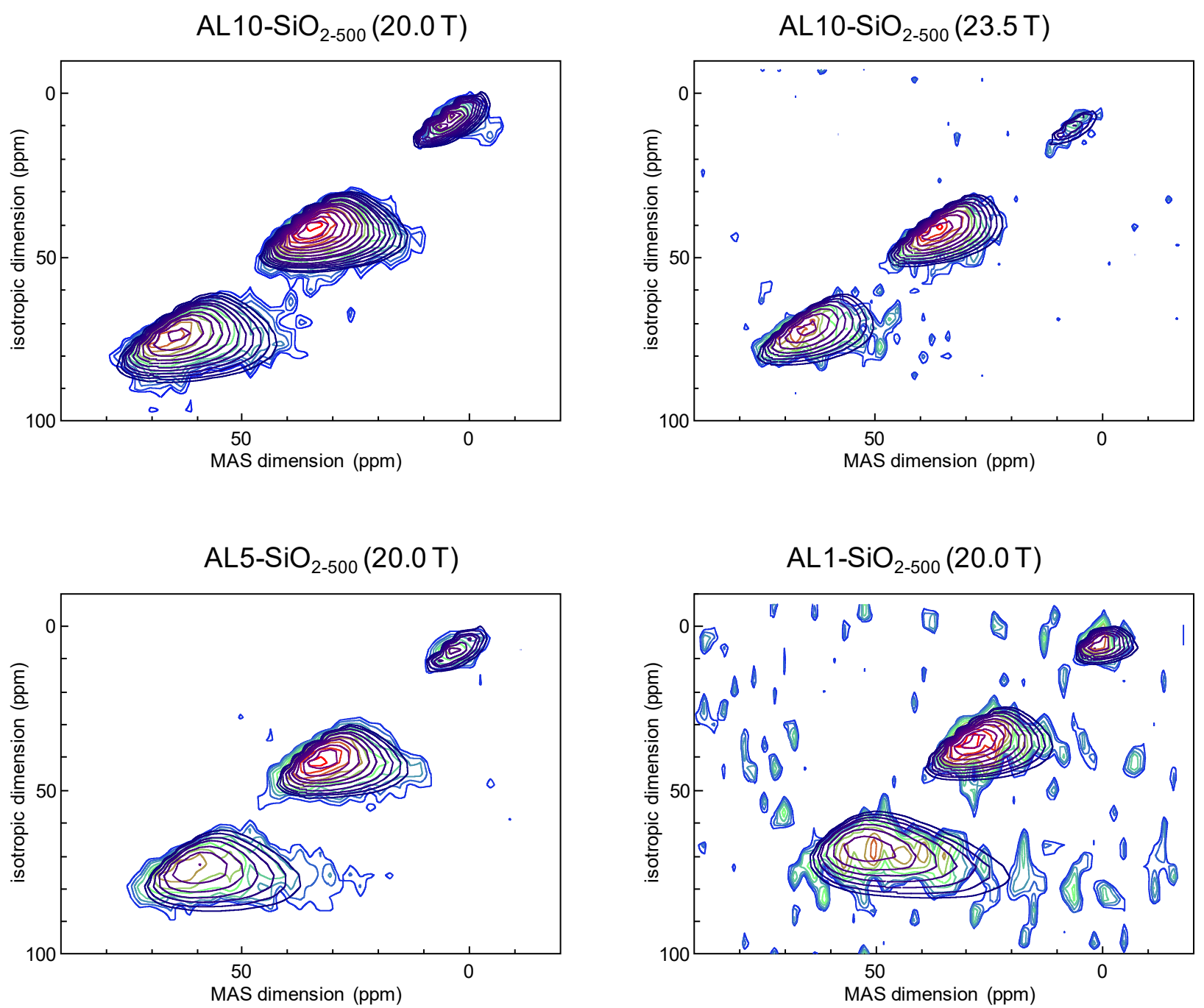

Figure S8. 2D 27 $\mathrm{Al}$ 3QMAS experiments performed on $\mathrm{Al} 10-\mathrm{SiO}_{2-500}$ at 20.0 $\mathrm{T}$ (top left) and 23.5 $\mathrm{T}$ (top right), Al5-SiO $2-500$ (bottom left) and Al1-SiO $2-500$ (bottom right). Experiments are displayed in color and GIM model-based simulations are displayed in purple. 


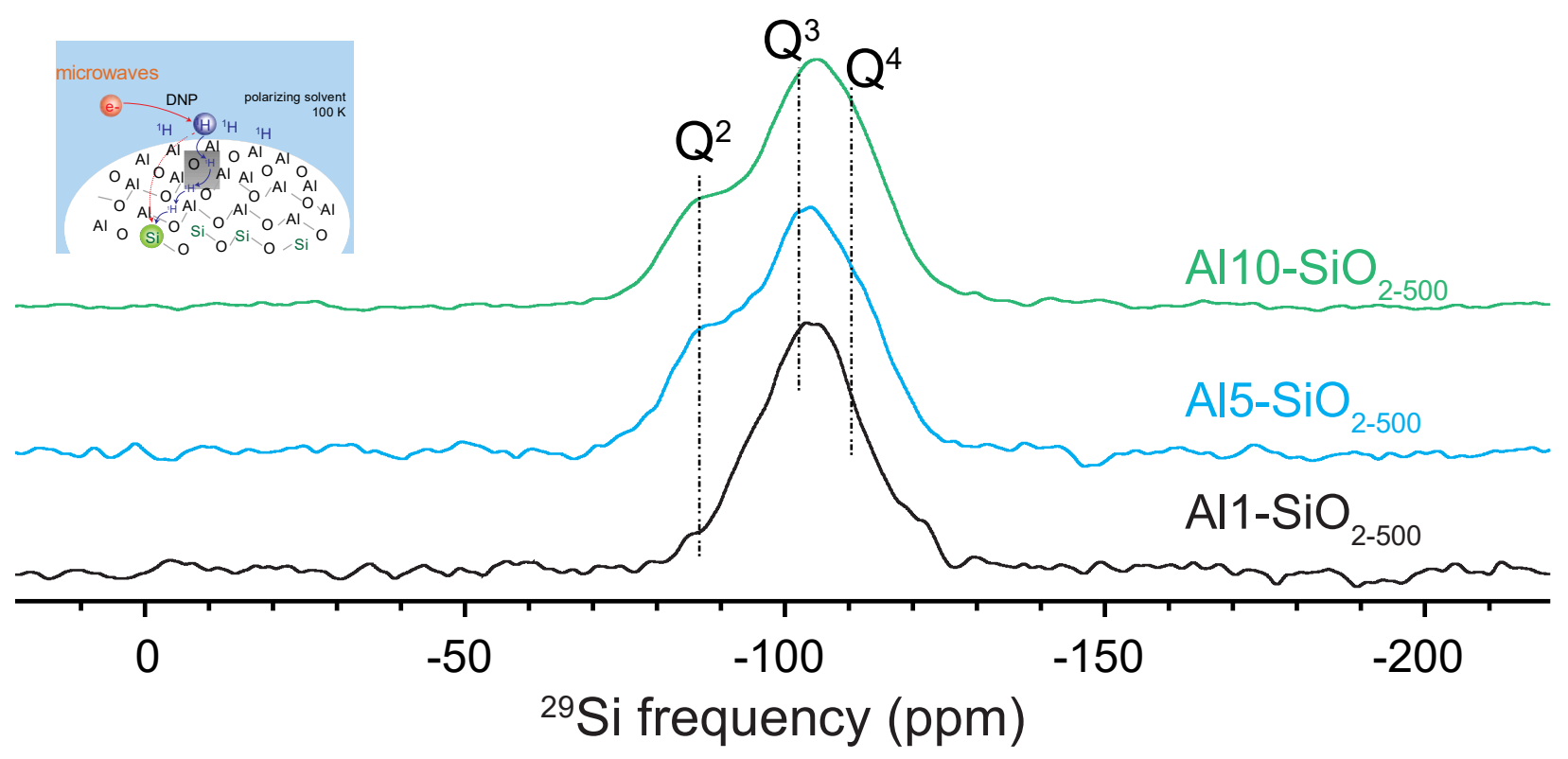

Figure S9. DNP enhanced ${ }^{29} \mathrm{Si}\left\{{ }^{1} \mathrm{H}\right\} \mathrm{CP}$ experiment on $\mathrm{Al} 1-\mathrm{SiO}_{2-500}$ (black), Al5-SiO $2-500$ (blue), and $\mathrm{Al} 10-\mathrm{SiO}_{2-500}$ (green) measured at $9.4 \mathrm{~T}$ with a $3.2 \mathrm{~mm}$ triple resonance probe. In the experiments, $10 \mathrm{kHz} \mathrm{MAS}$ and a sample temperature of $100 \mathrm{~K}$ were employed along with irradiating microwaves of power $40 \mathrm{~W}$. The expected chemical shifts of $Q^{2}, Q^{3}$, and $Q^{4}$ sites are represented by vertical, dotted lines. The schematic in the inset shows a simplified sketch of the DNP process.

Table S6. ${ }^{27} \mathrm{Al}$ and ${ }^{1} \mathrm{H}$ calculated errors of the NMR parameters derived from the simulation of the 2D ${ }^{27} \mathrm{Al}\left\{{ }^{1} \mathrm{H}\right\} \mathrm{D}-\mathrm{HMQC}$ experiment performed on $\mathrm{Al1}-\mathrm{SiO}_{2-500}$ and $\mathrm{Al} 10-\mathrm{SiO}_{2-500}$.

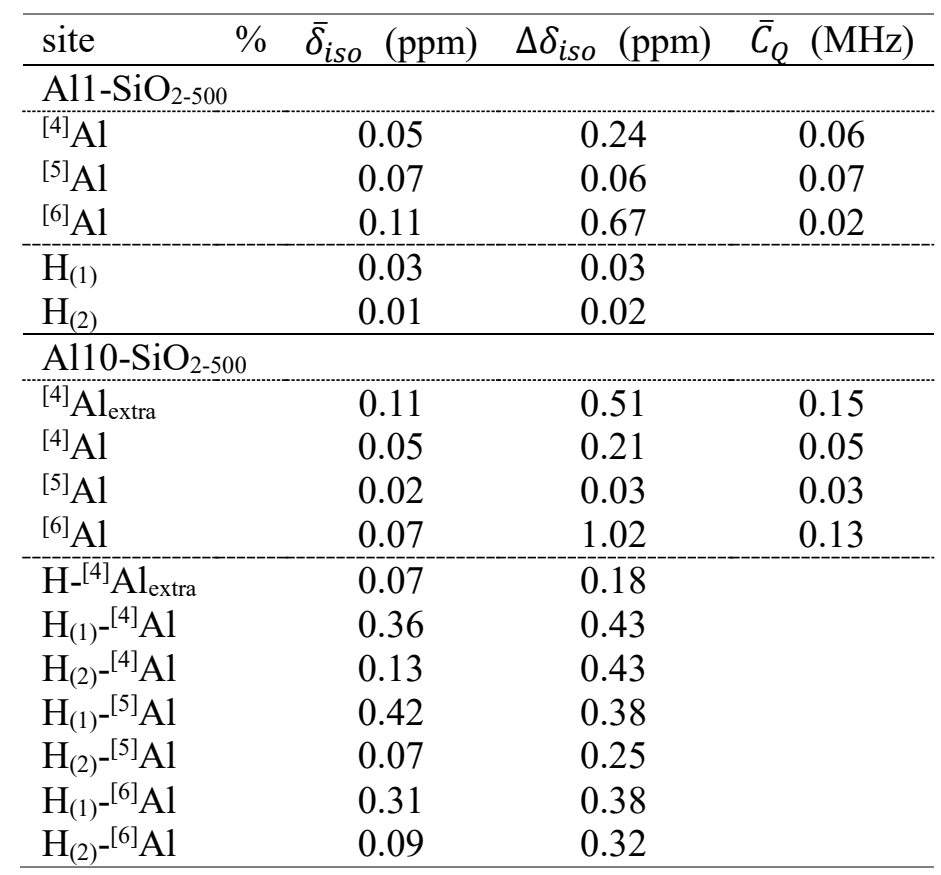


Table S7. ${ }^{27} \mathrm{Al}$ and ${ }^{29} \mathrm{Si}$ calculated errors of the NMR parameters derived from the simulation of the 2D D$\mathrm{HMQC}$ experiment performed on $\mathrm{Al} 1-\mathrm{SiO}_{2-500}$ and $\mathrm{Al} 10-\mathrm{SiO}_{2-500}$.

\begin{tabular}{|c|c|c|c|c|}
\hline site & $\%$ & $\bar{\delta}_{\text {iso }}(\mathrm{ppm})$ & $\Delta \delta_{\text {iso }}(\mathrm{ppm})$ & $\bar{C}_{Q}(\mathrm{MHz})$ \\
\hline \multicolumn{5}{|l|}{$\mathrm{Al1}-\mathrm{SiO}_{2-500}$} \\
\hline${ }^{[4]} \mathrm{Al}_{(1 \mathrm{Si})}$ & 2.7 & 0.7 & 1.41 & 0.46 \\
\hline${ }^{[4]} \mathrm{Al}_{(3 \mathrm{Si})}$ & 4.4 & 0.3 & 1.11 & 0.26 \\
\hline${ }^{[5]} \mathrm{Al}_{(1 \mathrm{Si})}$ & & 0.3 & 0.99 & 0.23 \\
\hline${ }^{[6]} \mathrm{Al}_{(1)}$ & 0.4 & 1.9 & 3.56 & 0.92 \\
\hline${ }^{[6]} \mathrm{Al}_{(2)}$ & 0.8 & 0.2 & 1.16 & 0.52 \\
\hline $\mathrm{Q}^{3}(1 \mathrm{Al})$ & & 1.1 & 1.14 & - \\
\hline${ }^{[} \mathrm{Q}^{4}(1 \mathrm{Al})$ & & 0.3 & 0.40 & - \\
\hline $\mathrm{All} 10-\mathrm{SiO}_{2-500}$ & & & & \\
\hline${ }^{[4]} \mathrm{Al}_{(1 \mathrm{Si})}$ & 1.3 & 0.2 & 0.19 & 0.24 \\
\hline${ }^{[4]} \mathrm{Al}_{(3 \mathrm{Si})}$ & 2.4 & 0.3 & 0.90 & 0.25 \\
\hline${ }^{[5]} \mathrm{Al}_{(1 \mathrm{Si})}$ & & 0.2 & 0.83 & 0.22 \\
\hline${ }^{[6]} \mathrm{Al}_{(1)}$ & 0.3 & 0.1 & 2.34 & 0.18 \\
\hline${ }^{[6]} \mathrm{Al}_{(2)}$ & 0.9 & 0.9 & 2.37 & 0.80 \\
\hline $\mathrm{Q}^{\mathrm{3}}(2 \mathrm{Al})$ & & 0.6 & 0.74 & 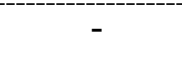 \\
\hline $\mathrm{Q}^{4}(1 \mathrm{Al})$ & & 0.3 & 0.38 & - \\
\hline
\end{tabular}
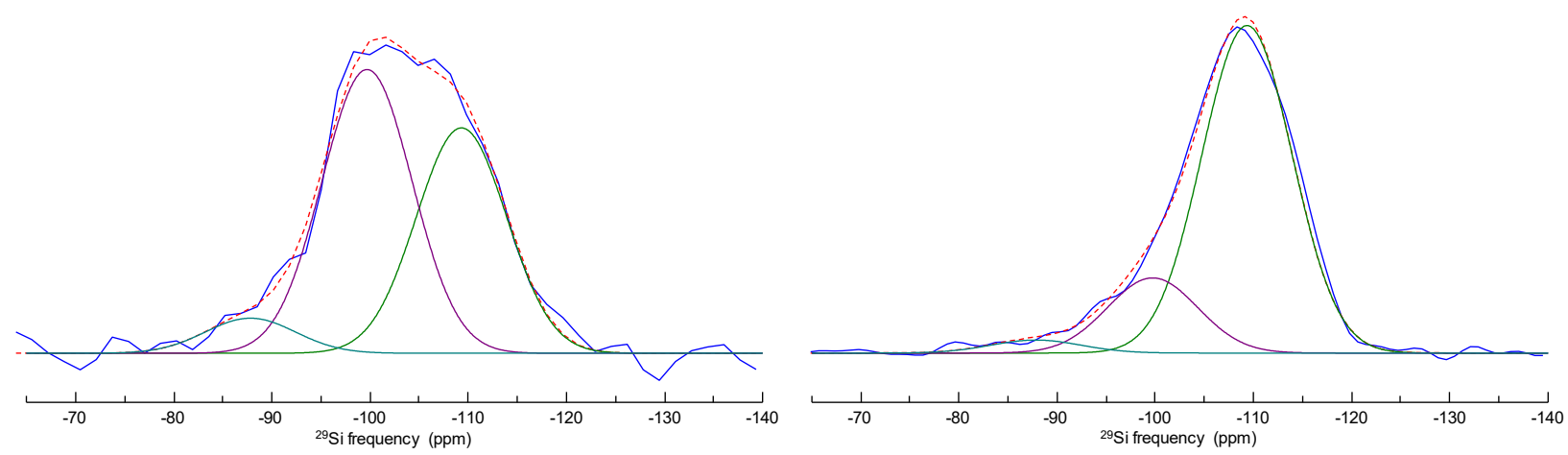

Figure S10. ${ }^{29} \mathrm{Si} \mathrm{CPMG-detected} \mathrm{MAS} \mathrm{experiments} \mathrm{performed} \mathrm{on} \mathrm{Al10-SiO} 2-500$ at $7.0 \mathrm{T:}{ }^{29} \mathrm{Si}\left\{{ }^{1} \mathrm{H}\right\} \mathrm{CPMAS}$ (left) and direct ${ }^{29} \mathrm{Si}$ (right) spectra. Experimental (blue), simulation (dashed red) and individual Gaussian components (colored).

Table S8. NMR parameters derived from the simulation of the ${ }^{29} \mathrm{Si}\left\{{ }^{1} \mathrm{H}\right\} \mathrm{CPMG}$ experiments on $\mathrm{Al} 10-\mathrm{SiO}{ }_{2-500}$ using Gaussian lines with identical widths.

\begin{tabular}{|c|c|c|c|c|}
\hline Site & \%direct & \%CPMAS & Position (ppm) & Width (ppm) \\
\hline $\mathrm{Q}^{[4]}$ & 78.6 & 41.5 & -109.3 & 10.8 \\
\hline $\mathrm{Q}^{[3]}$ & 18.2 & 52.1 & -99.7 & 10.8 \\
\hline $\mathrm{Q}^{[2]}$ & 3.2 & 6.4 & -87.8 & 10.8 \\
\hline
\end{tabular}


Table S9. Correlation map of the $2 \mathrm{D}^{27} \mathrm{Al}\left\{{ }^{29} \mathrm{Si}\right\}$ D-HMQC experiments performed on $\mathrm{Al} 1-\mathrm{SiO}_{2-500}$ and $\mathrm{Al} 10$ $\mathrm{SiO}_{2-500}$. Values are percentages of each individual 2D component with related errors given in parenthesis.

\begin{tabular}{|c|c|c|c|c|c|c|c|c|c|c|c|}
\hline \multicolumn{6}{|c|}{ Al1-SiO $2-500$} & \multicolumn{6}{|c|}{ Al10-SiO $2-500$} \\
\hline & ${ }^{[4]} \mathrm{Al}_{(3 \mathrm{Si})}$ & ${ }^{[4]} \mathrm{Al}_{(4 \mathrm{Si})}$ & ${ }^{[5]} \mathrm{Al}_{(2 \mathrm{Si})}$ & ${ }^{[6]} \mathrm{Al}_{(1)}$ & ${ }^{[6]} \mathrm{Al}_{(2)}$ & & ${ }^{[4]} \mathrm{Al}_{(2 \mathrm{Si})}$ & ${ }^{[4]} \mathrm{Al}_{(3 \mathrm{Si})}$ & ${ }^{[5]} \mathrm{Al}_{(2 \mathrm{Si})}$ & ${ }^{[6]} \mathrm{Al}_{(1)}$ & ${ }^{[6]} \mathrm{Al}_{(2)}$ \\
\hline $\mathrm{Q}_{(1 \mathrm{~A})}^{4}$ & & $\begin{array}{l}32.1 \\
(4.4)\end{array}$ & $\begin{array}{l}27.4 \\
(4.1)\end{array}$ & & $\begin{array}{c}2.6 \\
(0.8)\end{array}$ & $\mathrm{Q}_{(1 \mathrm{Al})}^{4}$ & & $\begin{array}{l}33.3 \\
(2.4)\end{array}$ & $\begin{array}{l}19.1 \\
(1.3)\end{array}$ & & $\begin{array}{c}3.4 \\
(0.9)\end{array}$ \\
\hline$Q^{3}(1 A l)$ & $\begin{array}{l}18.6 \\
(2.7)\end{array}$ & & $\begin{array}{l}17.5 \\
(2.3)\end{array}$ & $\begin{array}{c}1.8 \\
(0.4)\end{array}$ & & $Q^{3}(2 A l)$ & $\begin{array}{l}22.7 \\
(1.3)\end{array}$ & & $\begin{array}{l}20.3 \\
(1.5)\end{array}$ & $\begin{array}{c}1.3 \\
(0.3)\end{array}$ & \\
\hline
\end{tabular}
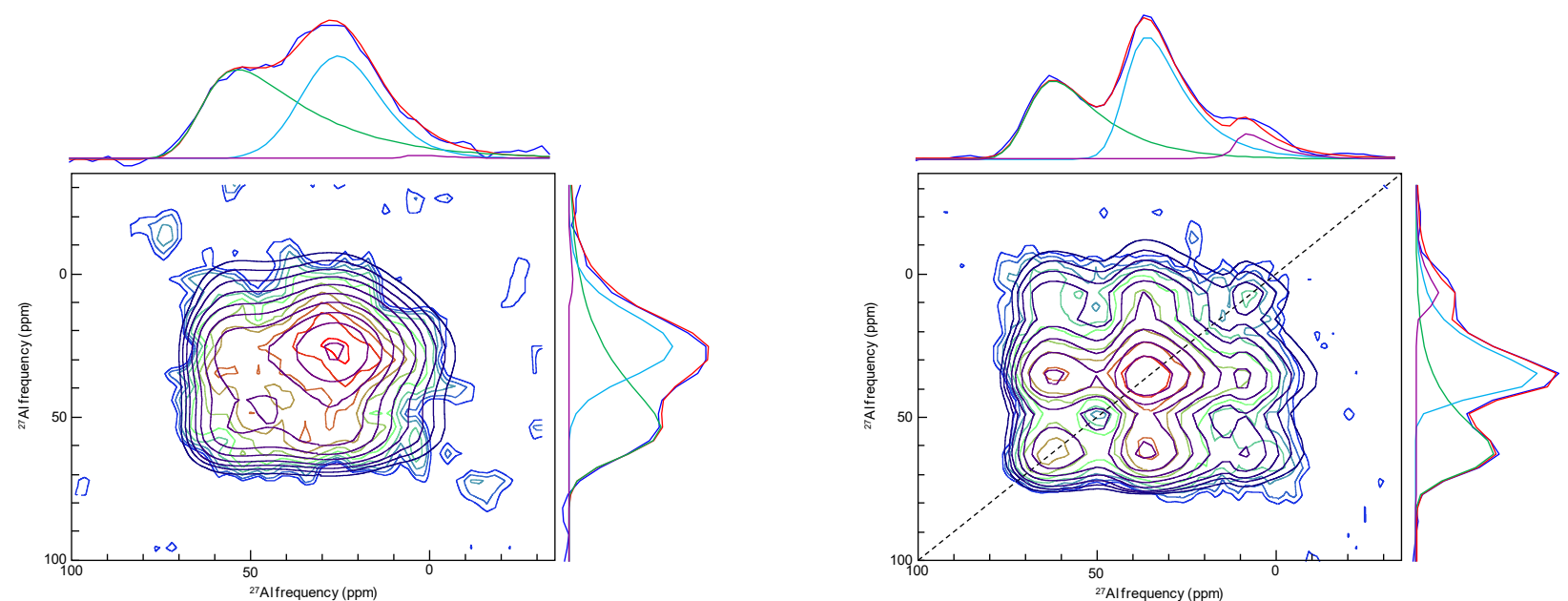

Figure S11. ${ }^{27} \mathrm{Al}$ 2Q/SQ R221 MAS NMR correlation 2D experiments for Al1-SiO 2-500 (left) and Al10-SiO $2-500$ (right) with projections along each dimension. Simulation of the 2D data are given in grey and individual components are given in the projections in color with their sum in red.

Table S10 ${ }^{27} \mathrm{Al}$ NMR parameters derived from the simulation of the ${ }^{27} \mathrm{Al} /{ }^{27} \mathrm{Al} 2 \mathrm{Q} / \mathrm{SQ}$ dipolar-based correlation experiment. $\left({ }^{*}\right)$ Lorentzian broadening. Correlation map of the $2 \mathrm{D}{ }^{27} \mathrm{Al}\left\{{ }^{29} \mathrm{Si}\right\} \mathrm{D}-\mathrm{HMQC}$ experiment performed on $\mathrm{Al} 1-\mathrm{SiO}_{2-500}$ and $\mathrm{Al} 10-\mathrm{SiO}_{2-500}$. Values are percentages of each individual 2D component. All related errors are given in parenthesis.

\begin{tabular}{c|ccc|ccc}
\hline site & $\begin{array}{c}\bar{\delta}_{\text {iso }} \\
(\mathrm{ppm})\end{array}$ & $\begin{array}{c}\Delta \delta_{\text {iso }} \\
(\mathrm{ppm})\end{array}$ & $\begin{array}{c}\bar{C}_{Q} \\
(\mathrm{MHz})\end{array}$ & $\begin{array}{c}\bar{\delta}_{\text {iso }} \\
(\mathrm{ppm})\end{array}$ & $\begin{array}{c}\Delta \delta_{\text {iso }} \\
(\mathrm{ppm})\end{array}$ & $\begin{array}{c}\bar{C}_{Q} \\
(\mathrm{MHz})\end{array}$ \\
\hline${ }^{[4]} \mathrm{Al}$ & $65.7(0.3)$ & $13.2(0.8)$ & $13.5(0.5)$ & $70.6(0.2)$ & $10.6(0.4)$ & $10.8(0.3)$ \\
${ }^{[5]} \mathrm{Al}$ & $32.9(0.7)$ & $21.4(0.9)$ & $7.93(0.5)$ & $42.8(0.1)$ & $9.63(0.28)$ & $9.30(0.10)$ \\
${ }^{\left[{ }^{6]} \mathrm{Al}\right.}$ & $7.8(9.5)$ & $2.3 *(18.0)$ & $8.40(11.4)$ & $11.8(0.4)$ & $3.16 *(1.40)$ & $7.48(0.43)$ \\
\hline \hline & ${ }^{[4]} \mathrm{Al}$ & ${ }^{[5]} \mathrm{Al}$ & ${ }^{[6]} \mathrm{Al}$ & ${ }^{[4]} \mathrm{Al}$ & ${ }^{[5]} \mathrm{Al}$ & ${ }^{[6]} \mathrm{Al}$ \\
\hline${ }^{\left[{ }^{[4]} \mathrm{Al}\right.}$ & & & & & & $4.0(0.8)$ \\
${ }^{[5]} \mathrm{Al}$ & & $67.3(5.3)$ & & & $43.2(1.5)$ & $6.7(0.6)$ \\
${ }^{\left[{ }^{6}\right] \mathrm{Al}}$ & $12.6(1.4)$ & $19.2(0.6)$ & $1.0(1.1)$ & $16.1(0.9)$ & $24.0(0.4)$ & $6.0(0.5)$ \\
\hline
\end{tabular}



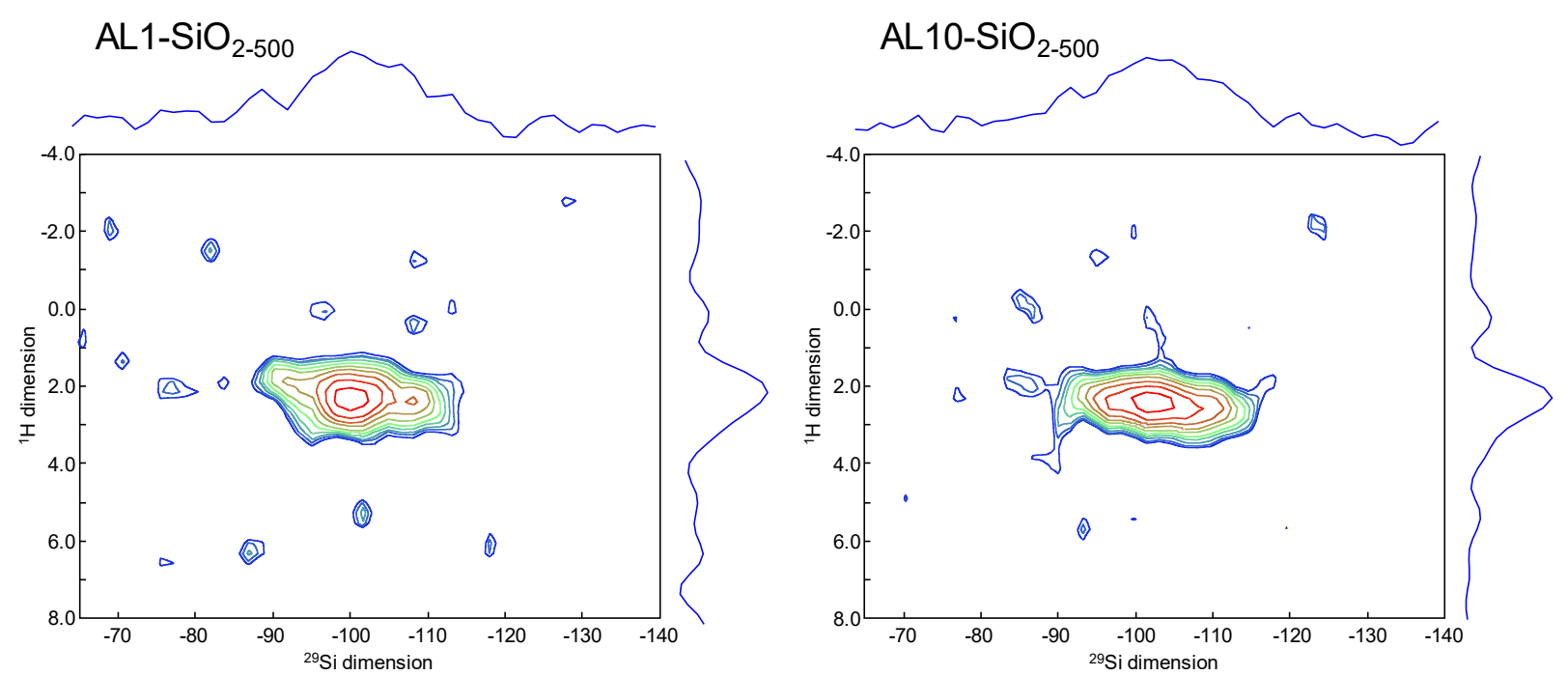

Figure S12. ${ }^{29} \mathrm{Si}\left\{{ }^{1} \mathrm{H}\right\}$ VACP CPMG-detected MAS experiments performed on Al1-SiO $2-500$ (left) and Al10$\mathrm{SiO}_{2-500}$ (right) at 7.0 T using a contact time of $0.5 \mathrm{~ms}$ and acquiring 512 echos with an inter-pulse delay of $8 \mathrm{~ms}$.
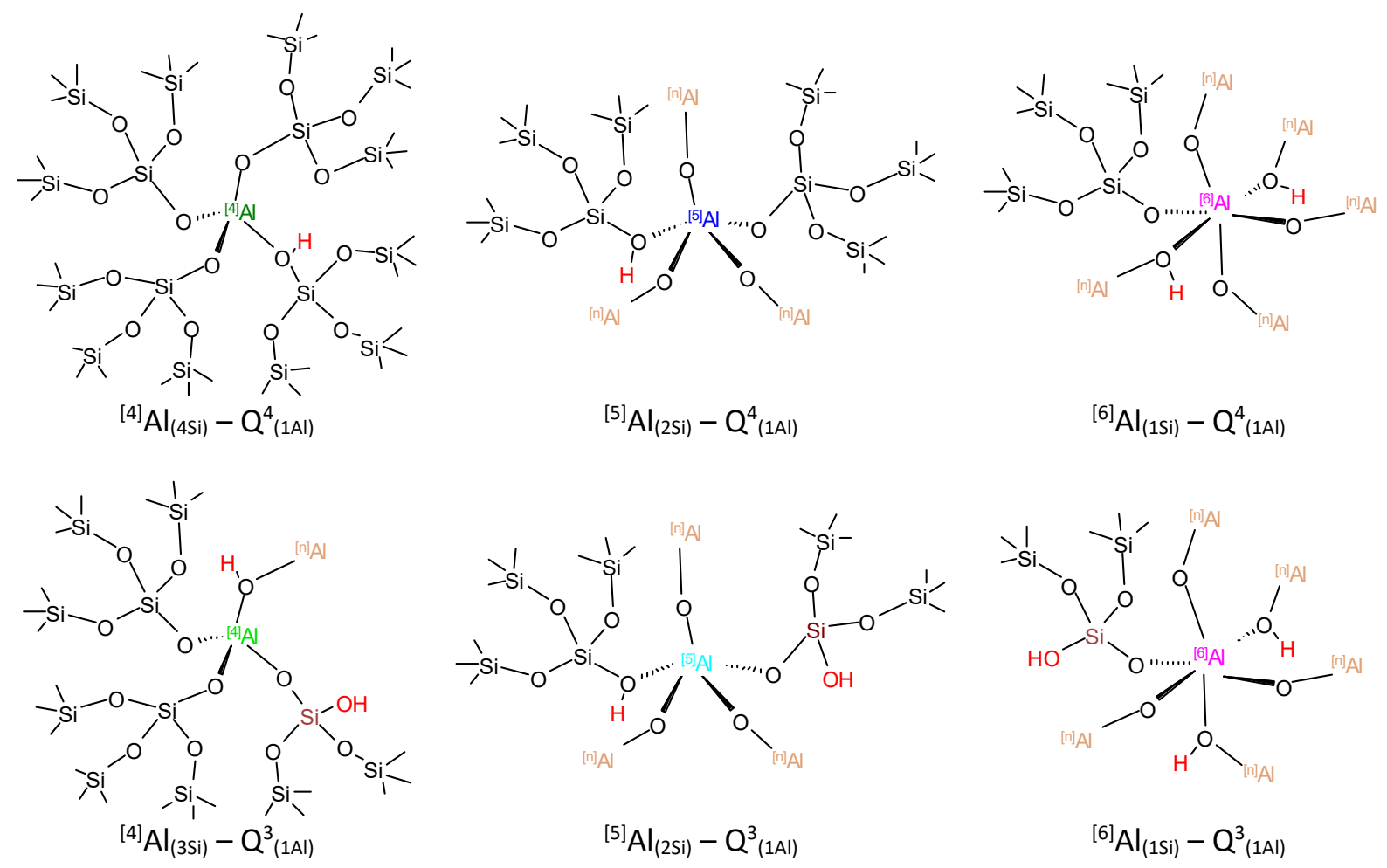

Figure $\mathrm{S} 13$. Sketch of the most probable aluminum environments in the $\mathrm{Al1}-\mathrm{SiO}_{2-500}$ material evidenced in this study. 


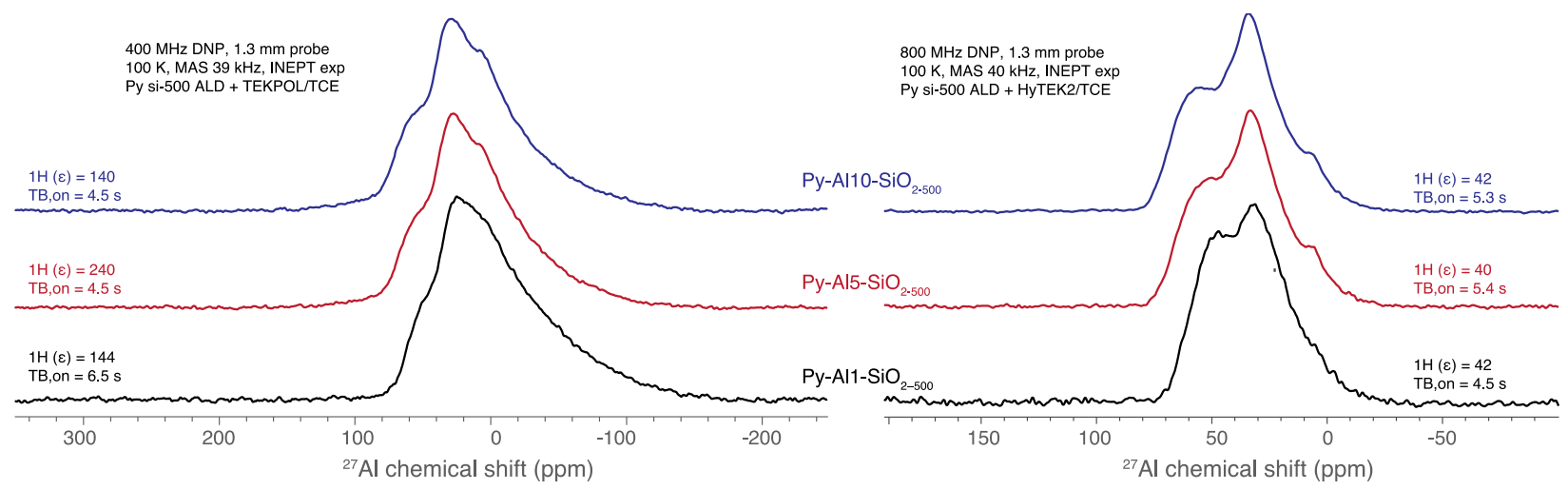

Figure S14. ${ }^{27} \mathrm{Al}\left\{{ }^{1} \mathrm{H}\right\}$ D-R-INEPT DNP NMR spectra of Py-Al1-SiO $2-500$ (black), Py-Al5-SiO $2-500$ (red), and PyAl10- $\mathrm{SiO}_{2-500}$ (blue) recorded at 9.4 and $18.8 \mathrm{~T}$ using a $1.3 \mathrm{~mm}$ probe, operated at $100 \mathrm{~K}$, and irradiation of suitable microwave powers for the respective biradical used. Corresponding ${ }^{1} \mathrm{H}$ DNP enhancements and DNP build-up times $\left(T_{B, o n}\right)$ are reported.

Table S11 ${ }^{15} \mathrm{~N}$ NMR parameters derived from the simulation of the ${ }^{15} \mathrm{~N}$ DNP enhanced NMR spectra of Py-Al1-SiO 2-500, Py-Al5-SiO $2-500$, and Py-Al10-SiO $2-500$. Values are percentages of each individual 2D component. All related errors are given in parenthesis.

\begin{tabular}{|c|c|c|c|c|c|c|}
\hline & \multicolumn{2}{|c|}{ Py-Al1-SiO ${ }_{2-500}$} & \multicolumn{2}{|c|}{ Py-Al5-SiO $2-500$} & \multicolumn{2}{|c|}{ Py-Al10-SiO $2-500$} \\
\hline site & $\begin{array}{c}\bar{\delta}_{i s o} \\
(\mathrm{ppm})\end{array}$ & $\begin{array}{l}\Delta \delta_{\text {iso }} \\
(\mathrm{ppm})\end{array}$ & $\begin{array}{c}\bar{\delta}_{\text {iso }} \\
(\mathrm{ppm})\end{array}$ & $\begin{array}{l}\Delta \delta_{\text {iso }} \\
(\mathrm{ppm})\end{array}$ & $\begin{array}{c}\bar{\delta}_{i s o} \\
(\mathrm{ppm})\end{array}$ & $\begin{array}{l}\Delta \delta_{\text {iso }} \\
(\mathrm{ppm})\end{array}$ \\
\hline$P y-L_{(1)}$ & $260.2(0.29)$ & $20.3(0.62)$ & $260.4(0.03)$ & $15.0(0.05)$ & $262.1(0.05)$ & $14.5(0.09)$ \\
\hline$P y-L_{(2)}$ & $239.1(0.13)$ & $15.3(0.34)$ & $239.8(0.03)$ & 21.3 & $242.6(0.08)$ & $24.3(0.19)$ \\
\hline $\mathrm{Py}-\mathrm{H}^{+}(1)$ & $208.1(0.40)$ & $20.3(0.46)$ & $209.2(0.12)$ & $19.3(0.12)$ & $216.2(0.30)$ & $9.5(0.58)$ \\
\hline $\mathrm{Py}-\mathrm{H}^{+}{ }_{(2)}$ & $203.8(0.10)$ & $11.8(0.33)$ & $203.7(0.04)$ & $10.5(0.13)$ & $204.5(0.15)$ & $13.3(0.28)$ \\
\hline
\end{tabular}




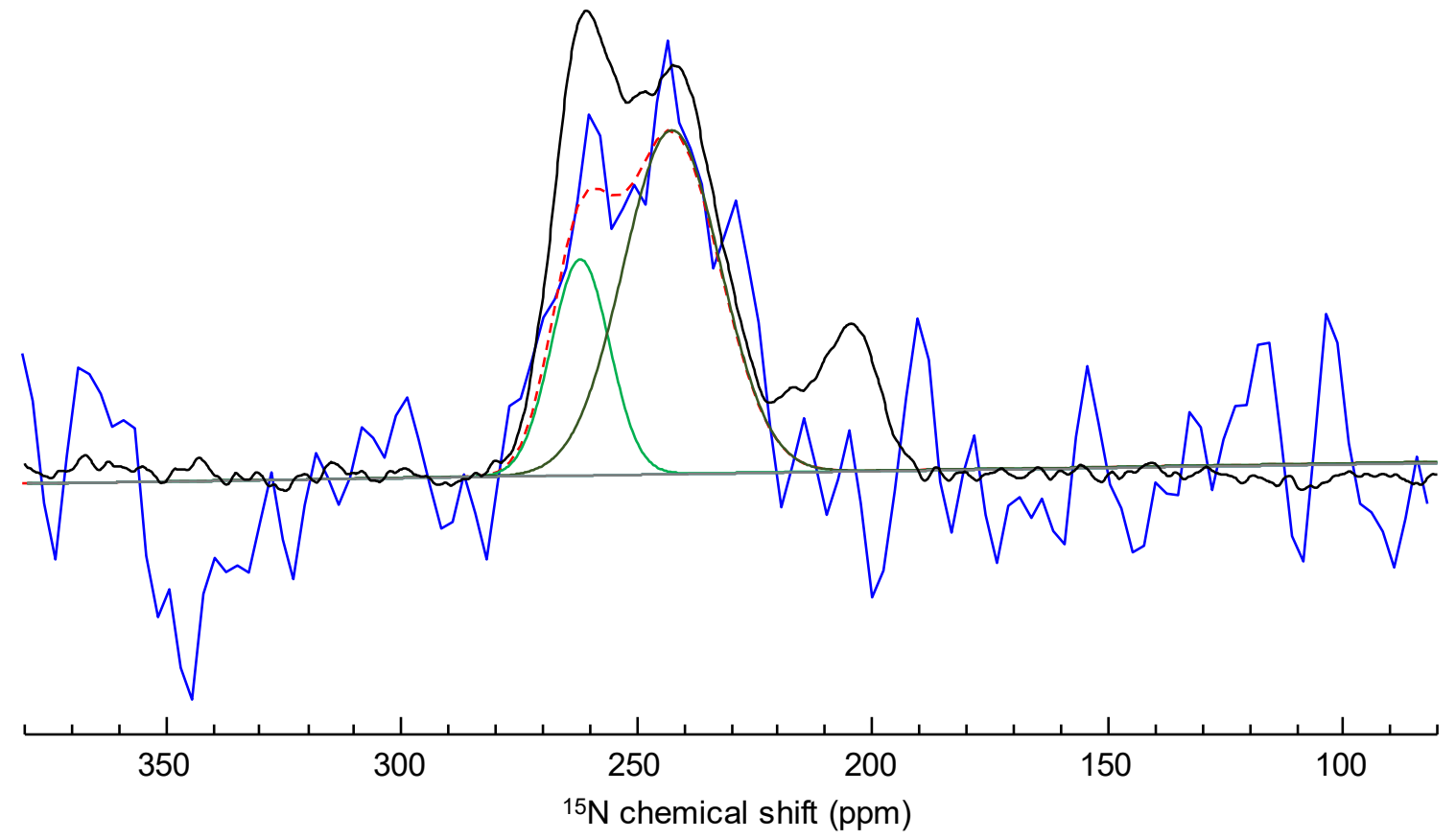

Figure S15. One-dimensional ${ }^{15} \mathrm{~N}$ DNP SENS spectra of Py-Al10-SiO $2-500$ recorded via ${ }^{15} \mathrm{~N}\left\{{ }^{27} \mathrm{Al}\right\}$ J-HMQC (blue) and ${ }^{1} \mathrm{H}_{-}{ }^{15} \mathrm{~N} \mathrm{CP}$ (black). Under $10 \mathrm{KHz}$ MAS using Bruker DNP spectrometer at 9.4 T equiped with a $1.3 \mathrm{~mm}$ probe, operated at $100 \mathrm{~K}$, and irradiation of suitable microwave powers for the respective biradical used. Deconvolution uses positions and width of components listed in Table S11 for Py-Al10-SiO2-500.

\section{References}

(1) Brunauer, S.; Emmett, P. H.; Teller, E. Journal of the American Chemical Society 1938, 60, 309.

(2) Miikkulainen, V.; Leskelä, M.; Ritala, M.; Puurunen, R. L. J. Appl. Phys. 2013, 113, 021301.

(3) Giovine, R.; Trébosc, J.; Pourpoint, F.; Lafon, O.; Amoureux, J.-P. J. Magn. Reson. 2019, 299, 109. 